Portland State University

PDXScholar

Summer 1-1-2012

\title{
Assessing the Relationship Between Intercultural Competence and Leadership Styles: An Empirical Study of International Fulbright Students in the U.S.
}

Chris Taylor Cartwright

Portland State University

Follow this and additional works at: https://pdxscholar.library.pdx.edu/open_access_etds

Part of the Bilingual, Multilingual, and Multicultural Education Commons, International and Comparative Education Commons, and the Leadership Studies Commons Let us know how access to this document benefits you.

\section{Recommended Citation}

Cartwright, Chris Taylor, "Assessing the Relationship Between Intercultural Competence and Leadership Styles: An Empirical Study of International Fulbright Students in the U.S." (2012). Dissertations and Theses. Paper 759.

https://doi.org/10.15760/etd.759

This Dissertation is brought to you for free and open access. It has been accepted for inclusion in Dissertations and Theses by an authorized administrator of PDXScholar. Please contact us if we can make this document more accessible: pdxscholar@pdx.edu. 
Assessing the Relationship Between Intercultural Competence and Leadership Styles:

An Empirical Study of International Fulbright Students in the U.S.

by

Chris Taylor Cartwright

A dissertation submitted in partial fullment of the requirements for the degree of

\title{
Doctor of Education
}

in

Educational Leadership: Postsecondary Education

\author{
Dissertation Committee: \\ Christine M. Cress, Chair \\ Janine M. Allen \\ Becky A. Boesch \\ Kimberley A. Brown
}

Portland State University

(C)2012 


\begin{abstract}
As U.S. higher education institutions strive to educate students to meet the needs of an increasingly complex world, there is great importance in studying the interplay between leadership and culture to enhance preparation of global-ready graduates. This inquiry examines the relationship between intercultural competence and leadership styles. The construct of intercultural competence focuses on effectiveness in engaging people across cultural differences, while the construct of leadership style or "connective leadership" focuses on the achieving styles employed to engage diverse followers. The Fulbright International Student Program offers an unparalleled opportunity to examine the dynamic interplay of intercultural and leadership development. More than 100 participants were surveyed using the Intercultural Effectiveness Scale and Achieving Styles Inventory psychometric instruments. Statistically significant correlations emerged between intercultural competence and connective leadership across four critical themes: individual development, the Fulbright Program, international education, and higher education. Overall, multiple leadership styles can be achieved through curiosity and continuous learning about cultural differences. Implications for individual learning and organizational development are discussed.
\end{abstract}




\section{DEDICATION}

I dedicate this dissertation to the many teachers in my life that have guided, mentored, and often gently prodded me to continue to learn and grow. There are many people who have played this role over the years, some for decades, some for minutes ... all have been generous and wise. I owe thanks to all of you. 
INTERCULTURAL COMPETENCE AND LEADERSHIP STYLES

\section{ACKNOWLEDGEMENTS}

I would like to thank the many people who have supported me in completing my doctorate. A few have played a major role in this sojourn of doctoral study and deserve a special thanks.

My dissertation committee have all been staunch supporters of me and my work for over a decade. Dr. Christine M. Cress, as my adviser has been particularly patient, firm, and entrusting. Dr. Janine M. Allen, has been generous with her feedback and direction. Dr. Becky A. Boesch has been a classmate, a colleague, and now a committee member; cheering me on at each step toward completion. Dr. Kimberley A. Brown has been a friend, colleague, and mentor in many ways.

I have had a shadow committee of faculty who have offered invaluable insights and support. The faculty from Portland State University includes Dr. Jacqueline Temple, Dr. Swapna Mukhopadhyay, Dr. Mary Kinnick, Dr. Cheryl Livneh, Dr. Karen Noordhoff, Dr. Gary Nave, Dr. Joan Strouse, Dr. Carolyn Carr, Dr. Daniel Johnson, Tom Tyler, Dr. Leslie Munson, Dr. Dalton Miller-Jones, Dr. Martha Balshem, Dr. Devorah Lieberman, Dr. Henry (Budd ) Kass, Dr. Doug Morgan, and Dr. Peter Collier. Earlier in my studies I received support and encouragement from Dr. Thomas DeCoster of Indiana University Purdue University at Indianapolis, Dr. Glen Knudsvig of the University of Michigan, and Dr. Antonia Gransden of the University of Nottingham and Cherry Merritt-Darrieau of Deer Path Park in Bloomington, IN. 
My classmates have listened, read, and stood beside me. These classmates are Dr. Nancy Cicirello, Jennifer Grove, Dr. Peter Boghosian, Deborah Miller-Allen, Lisa Dion, Dr. Deborah Peterson, Dr. Serap Emil, Dr. Zafreen Jaffrey, Dr. Tanya Ostrogorsky, Dr. Helen Young, Dr. Julie Esparza, Dr. Rita Moreno, Dr. Miki Yamashita, and Dr. Susan Rustvold.

My colleagues have been graceful in allowing me the time and space to complete my studies while giving me encouragement mixed with humor to keep my spirits up. These colleagues include Greta Krahn, Cathie Anderson, Leah Hershey, Toni Plato, Linnea Gunderson, AJ Arriola, Sandy Garrison, Dr. Kent Warren, Torey Browne, Dr. Lee Knefelkamp, Dr. Daryl Smith, Dr. Barbara Schaetti, Dr. Gordon Watanabe, Margaret Pusch, Dr. Martha Merrill, Dr. Allan Bird, Dr. Michael Stevens, Dr. Gary Oddou, Dr. Mark Mendenhall, Dr. Joyce Osland, and Dr. Jennifer Hall.

Being a person with dyslexia and color-blindness, completing a quantitative dissertation with statistics, color graphics, and in compliance with APA 6 has been a challenge. I have had a team of people who have helped me pull this together and I am deeply appreciative of their expertise and efforts. These people include Wayne St. John, Karen Jones, Siarra Voller, Tobi Kibel Piatek, Connie Dyer, David Schwager and Dave (The Grammar Geek) Nelson.

I have had two mentors throughout my doctoral studies who have tirelessly fielded my naïve questioning and generously responded to my every idea. Dr. Janet 
INTERCULTURAL COMPETENCE AND LEADERSHIP STYLES

Bennett of the Intercultural Communication Institute has opened her institute, her library, her network of colleagues, and herself to me without reserve and I am eternally grateful to her for this ocean of possibility and learning. Dr. Jean-Lipman-Blumen of the Connective Leadership Institute has been welcomed me in her home, her office, her Institute and shared her intellect with keen interest and kind (vicarious) support and I am forever in her debt.

I owe particular thanks to my spiritual teacher Swami Chetananda of The Movement Center. For me, it is not possible to stretch myself in the ways I seem to be called to do without a the depth and strength of my yoga practice.

I owe thanks to my parents Eleanor Louise (Taylor) Cartwright and Robert Dee Cartwright. My mother taught me that the world would change and that it was my job to adapt and to serve others in the process of growing. My father taught me that the path to growth was found through commitment and perseverance.

Finally, I owe thanks to my beloved wife Dr. Lisa Hoberg. She teaches me daily what real compassion, grace and humility mean.

This quote has sustained me over this journey and I am sure for many more:

There is wisdom in turning as often as possible from the familiar to the unfamiliar: it keeps the mind nimble, it kills prejudice, and it fosters humor. -George Santayana, philosopher, (1863-1952) 


\section{Table of Contents}

Abstract

Dedication

ii

Acknowledgements

iii

List of Tables

vii

List of Figures

Chapter 1: Introduction

Chapter 2: Review of the Literature

Chapter 3: Methodology

Chapter 4: Results

Chapter 5: Conclusions

Figures

Tables

References

Appendix A: The Intercultural Effectiveness Scale (IES)

Appendix B: The Achiebving Styles Inventory (ASI)

182

Appendix C: Intercultural Effectiveness Scale (IES) Group Scores for Groups $\mathrm{A}$ and $\mathrm{B}$

Appendix D: Leadership: Achiveing Styles Intentory (ASI) Results Composit for Groups A and B

Appendix E: Pearson's Rho $\rho$ Results 


\section{List of Tables}

$1 \quad$ Fulbright Participant Demographics

128

$2 \quad$ Fulbright Participant Inventories Completed

129

3 Academic Fields of Study Pursued by the Fulbright Students

130

$4 \quad$ World Regions by the Fulbright Students

131

5 Data Set, Research Questions, and Items on Survey

132

$6 \quad$ Intercultural Effectiveness Scale (IES) Results Summary

133

$7 \quad$ Achieving Styles Inventory (ASI) Results Summary

134

$8 \quad$ IES/ASI - Pearson's Rho $(\rho)$

135

$9 \quad$ IES Continuous Learning/ ASI Direct Pearson's Rho $(\rho)$

136

10 IES Continuous Learning/ ASI Instrumental - Pearson's Rho $(\rho)$

137

11 IES Continuous Learning/ ASI Relational - Pearson's Rho $(\rho)$

138

12 IES Continuous Learning/ ASI Total - Pearson's Rho $(\rho)$

IES Interpersonal Engagement and Relationship Interest/ ASI Power

$13-$ Kendall's Tau $(\tau)$

138

140

14 IES Total/ ASI Relational - Kendall's Tau $(\tau)$

141

ASI Power and Total / IES Exploration and Continuous Learning -

$15 \quad$ Kendall's Tau $(\tau)$ 


\section{List of Figures}

$1 \quad$ Model for International Adjustment 118

$\begin{array}{lll}2 & \text { Intercultural Competency } & 119\end{array}$

$\begin{array}{ll}3 \text { Developing Intercultural Competence } & 120\end{array}$

$\begin{array}{lll}4 \quad \text { Intercultural Effectiveness } & 121\end{array}$

\begin{tabular}{ll}
5 & IES Model Factors and Competencies \\
\hline
\end{tabular}

$\begin{array}{lll}6 & \text { Connective Leadership Model (Achieving Styles) } & 123\end{array}$

$\begin{array}{lll}7 & \text { Intercultural Leadership Research Conceptual Framework } & 124\end{array}$

$8 \quad$ Connective Leadership Ideal: Access and Success $\quad 125$

$\begin{array}{lll}9 & \text { Results of Study in Venn Diagram Format } & 126\end{array}$

Recommended Intercultural and Leadership Professional

$10 \quad$ Development Processes $\quad 127$ 


\section{Chapter 1: Introduction}

\section{Background}

This study examines the relationship between intercultural competence and leadership styles in international Fulbright students in the U.S. The construct of intercultural competence focuses on effectiveness in engaging people across cultural differences, while the construct of leadership style focuses on the achieving styles a leader employs to engage diverse followers. By studying intercultural competence and leadership styles together, it was possible to learn how they relate. U.S. higher education institutions are striving to create global-ready graduates to meet the needs of an increasingly complex world; the results of this dissertation offer new perspectives on the work of educating students for global engagement through a unique combination of assessments. The following quotation serves as the fulcrum and starting point of this study:

Around the globe, two antithetical forces - interdependence and diversity - are generating tension that will fundamentally change the conditions under which leaders must lead. To succeed in this dramatically altered environment, where inclusion is critical and connection is inevitable - that is, in the Connective Erawe need a new kind of leadership. (Lipman-Blumen, 1996, p. xiii)

As an epoch, the connective era (Lipman-Blumen, 1996) is defined more by the changing dynamics of the world than by a specific time frame. Whether a leader is rebuilding a nation after a war or natural disaster, reinvigorating a corporation in economic crisis, mobilizing an agency to fight the outbreak of a deadly disease, or guiding students to incorporate community service to diverse populations into their 
coursework, the leadership skills needed are complex and require multiple competencies. This new connective era, defined by Lipman-Blumen (1996), requires agile leaders whose competencies enable them to:

- be sensitive to diverse perspectives and peoples,

- build strong coalitions among diverse followers, and

- motivate diverse followers to meet their shared challenges.

These connective leadership competencies are recognized in studies conducted by the American Management Association (AMA, 2011), which names "managing change, exhibiting agility, and developing global strategies" (p. 2) as essential global leadership competencies. The AMA also names the following competencies to be developed for future global leaders:

- "collaborating with peers from multiple cultures,

- managing innovation in a multicultural setting,

- cross-cultural employee engagement, and

- applying ethical standards in multiple cultures" (p.16).

Research conducted by The Economist Intelligence Unit (2010) supports the AMA's findings and concludes that "cultural sensitivity" (p. 12) is the most important popular trait of an expatriate (global) leader. To develop these global competencies, we need to understand their underpinnings.

Intercultural sensitivity is defined as the ability to engage effectively with people who are culturally different from one's self (Bennett, M. J., 1993). But as Milton Bennett points out, "intercultural sensitivity is not normal" (p. 21), and history is full of instances in which people interacting with cultures different from their own has produced disastrous results. Frequently this contact has been followed by "bloodshed, oppression, 
and genocide" (p. 21). The human relations movement and intergroup contact theory (Allport \& Kramer, 1946; Allport, 1954) and subsequent studies (Pettigrew \& Tropp, 2006; Pettigrew, 2008; Pettigrew, Tropp, Wagner, \& Christ, 2011) are rooted in the need to ameliorate the disastrous effects of prejudice and prevent mistreatment arising from lack of intercultural sensitivity. Learning to withhold initial negative judgments until a more informed and reciprocal perspective can be gained is essential to corporate, governmental, and nonprofit leaders as well as the social justice movement in general. Many call this cross-cultural capacity "intercultural competence" (Deardorff, 2004a, 2009), which is defined as "a set of cognitive, affective, and behavioral skills and characteristics that support effective and appropriate interaction in a variety of cultural contexts" (Bennett, M. J., 2008b, p. 95). In the connective era, "where inclusion is critical and connection is inevitable" (Lipman-Blumen, 1996, p. xiii), leaders need to develop the ability to learn to accomplish tasks across differences, the ability to engage across differences, and, finally, the ability to manage themselves and others in a positive manner when difference is encountered. These characteristics and the ability to use them are the genesis of intercultural leadership.

Many governments, corporations, nongovernmental organizations, and higher education institutions seek to improve relations across cultural differences, typically through education and training programs on intercultural competence and leadership skills (Altbach \& Knight, 2007; Bennett, M. J., 2008a; Bird \& Osland, 2004; Cornwall \& Stoddard, 1999; Cornwall \& Stoddard, 2006; Fischer, 2007; Hovland, 2006; Meacham \& 
Gaff, 2007; Preece, Olssen, Codd, \& O’Niell, 2004; Stoddard \& Cornwell, 2003).

McTighe-Musil (2006) states:

The Association of American Colleges and Universities Greater Expectations Project on Accreditation and Assessment reported that global knowledge and engagement, along with intercultural knowledge and competence, have been identified as essential learning outcomes for all fields of concentration and for all majors. (p. 1)

So research conducted by higher education, business, and industry is linking intercultural competence and leadership as knowledge sets and behaviors to be developed. This study looks at how the constructs are related, so U.S. higher education can better understand how to respond to this need.

U.S. higher education has recognized that our world community has become increasingly interdependent and diverse, including whom we serve and how, and has stated this in numerous reports (Chickering, 2010; Cornwall \& Stoddard, 2006; General Motors Corporation, 2001; National Center for Postsecondary Improvement [NCPI], 2002; Tanaka, 2003). To meet these more pluralistic needs, higher education institutions have launched initiatives in diversity (The American Association of Colleges and Universities [AAC\&U], 1995, 2008; Green, 2008; Hayward, 2000; McTighe, Garcia, Hudgins, Nettles, Sedlacek, \& Smith, 1999; Milem, Chang, \& Antonio, 2005; Williams, Berger, \& McClendon, 2005; Zuniga, Williams, \& Berger, 2005), and/or internationalization (Braskamp, 2009a; Cornwall \& Stoddard, 1999;

Green, 2002; Green, 2008; Hayward, 2000; Noronha, 2003; Rubin, 2003; Tanaka, 2003). Janet Benett and Milton Bennett urged U.U. campuses to consider domestic 
diversity and internationalization as two perspectives on learning to deal with difference (Bennett, J.M, \& Bennett, M.J., 1994). The American Council on Education [ACE] has also released a white paper on the need for and possible synergies between campus diversity and internationalization initiatives (Olson, Evans, \& Shoenberg, 2007) as well as hosted two events specifically on this topic in 2008 and 2009.

These initiatives often include efforts to influence recruitment and retention of diverse students (ACE, 2002; Tinto, 2006), recruitment and retention of diverse faculty and administrators (ACE, 2002; Astin, Antonio, Cress, \& Astin, 1998; Marcy, 2002; Moreno, Smith, Clayton-Pedersen, Parker, \& Hiroyuki-Teraguchi, 2006), teaching and learning (Bleszynska, 2008; Deardorff, 2004a, 2009; DeJaeghere \& Zhang, 2008;

Gurin, Dey, Hurtado, \& Gurin, 2002; Gurin, 2003; Haigh, 2002; McClure, 2007; Noddings, 2005; Paige, 2006; Schuerholz-Lehr, 2007; Ukpokodu, 2011), cocurricular student development (Braskamp, Trautvetter, \& Ward, 2006; King \& Baxter Magolda, 2005), and organizational culture (Kezar and Eckel, 2000; Lucena, 2006; Schoorman, 2000). Also, there have been studies of the effectiveness of both internationalization and diversity initiatives on campuses (Garcia, 2001; McTighe-Musil, et al., 1999; Milem, et al., 2005; Moreno, et al., 2006; National Center for Postsecondary Improvement, 2003; Williams, et al., 2005).

Higher education institutions in the U.S. have been working to both realize and rise to the challenge of creating global-ready graduates in a number of ways. The AAC\&U has conducted several studies on global learning (Fischer, 2007) and student 
learning outcomes (AAC\&U, 2008). In focus groups with business leaders (Hart, 2008), participants considered attention to global issues underemphasized. In the assessment of student learning outcomes study (Hart, 2008), more than 300 employers were interviewed to determine which areas graduates were prepared for or needed improvement in. Ethical judgment, intercultural skills, self-knowledge, and adaptability all were rated as adequately learned. However, the study found higher education institutions needed improvement in global knowledge. It is impossible for any program of study to name all global knowledge as a viable learning outcome. But the ability to learn about global cultures is possible and can be cultivated with appropriate exploration skills, and these skills are supported by the students' empathic, intercultural self-knowledge and their adaptability skills. Hovland (2009) points out that in AAC\&U's Liberal Education and America's Promise initiative, "Global integration is now our shared context. The potential benefits of global interdependence are extraordinary, but so too are the challenges" (Hovland, 2009, p. 4).

Higher education leaders establish the focus or direction of their campuses through their vision and mission statements. Meacham and Graff (2006) looked at the mission statements as promulgated by higher education boards of trustees and leadership teams to find whether cultivation of global leadership is in evidence as well as being a learning outcome. Of the colleges listed in the 2001 edition of The Princeton Review's Best 331 Colleges in the U.S. (Franek, 2000), 312 had mission statements, but only 117 had discernible student learning goals. Leadership skills were included in 101 of the 312 
mission statements. Of the learning goals, appreciation of diversity is in 67 , building communities that acknowledge and respect difference is in 59, and international and global understanding is in 50 (p. 7). So despite the clear need for global engagement, this study found no evidence of a clear written mandate from the top leadership in U.S. higher education to grow global-ready graduates.

In looking for a clear vision for global engagement, finding evidence that it is present and assessed as an outcome of education is a natural progression. Assessment of student learning outcomes has become a driving force in higher education reform, and addressing intercultural competence and/or leadership has become an essential element of these endeavors (Association to Advance Collegiate Schools of Business [AACSB], 2011; Black \& Duhon, 2006; Braskamp, 2009a; Durrant \& Dorius, 2007; Karp, 2011; Rhodes, 2010; Tyler, Wade, \& Walton, 2006; Witte, Sequeira, Fonteyne, 2003). However, assessing intercultural competence is complex; it frequently requires multiple samples over time (Deardorff, 2004a; Paige, 2006). AAC\&U has created a specific rubric expressly for assessing intercultural knowledge and competence (Rhodes, 2010) in an undergraduate degree program, but no published studies of programs using this rubric exist yet.

International education offers a window into one of the most common ways U.S. higher education works to educate for intercultural competence. Student and faculty exchanges around the world are both popular and valued (Boyacigiller, Beechler, Taylor, \& Levy, 2004; Mendenhall, Kulhmann, \& Stahl, 2001; NAFSA, 2009; J. Osland, Bird, 
Mendenhall, \& A. Osland, 2006; Paige, Lange, \& Yershova, 1999; Paige, 2006;

Trooboff, VandeBerg, \& Rayman, 2007). The Institute for International Education (IIE) reports that in the year 2008-2009, 260,327 students left the U.S. to study abroad and 671,616 came to study in the U.S. from other places in the world (IIE, 2010). Business management and possibly leadership studies are an increasingly popular plan of study for incoming international students (IIE, 2010). In a 2011 C-SPAN/Washington Journal interview, journalist Greta Wodele-Brawner spoke with Ann Stock, education and cultural affairs assistant secretary for the U.S. State Department, and Allan Goodman, president and CEO of the IIE, about the value of international education. Stock listed the many contributions of incoming international students in particular, especially the value of their engagement with their U.S. classmates. She stated: “They're our future global leaders in everything we do: business, education, politics, arts, and culture. That's who they'll be doing business and working with forty, fifty, sixty years out." (C-SPAN \& Washington Journal, 2011).

One of the many programs that bring international students to U.S. colleges and universities is the Fulbright Scholar Program. This program offers an opportunity to observe one type of international student who may be on the road to develop both intercultural competence and leadership skills. The aim of the Fulbright Program is to cultivate and nurture the type of leadership advocated by Lipman-Blumen (1996). When it was established in 1946, Senator J. William Fulbright of Arkansas had envisioned that the program would grow new leadership: 
Fostering these-leadership, learning, and empathy between cultures - was and remains the purpose of the international scholarship program . . . it is a modest program with an immodest aim - the achievement in international affairs of a regime more civilized, rational and humane than the empty system of power of the past. (Fulbright Program, 2011a)

Since 1946, 225,000 scholars have been sent around the world to research and study, and 1,800 non-U.S. students have received grants to study in the U.S. each year (Fulbright Program, 2011a). The results have been impressive: 40 Fulbright alumni are identified as Nobel Prize recipients, three of whom were Peace Prize recipients (Fulbright Program, 2011c). Many more have gone on to undertake leadership roles in many contexts, with more than 330 alumni serving as current or former heads of government or chiefs of state (Fulbright Program, 2011b). The leadership development potential seems to be evident in this pool of students, whom the Fulbright Program chose for their leadership capacity (Fulbright Program, 2011a). While the Fulbright Scholar Program does not require participants to study leadership, it does include an introduction to leadership during onsite orientation and emphasizes civic engagement in annual conferences for the international students studying in the U.S. This study examines the intercultural competencies and leadership styles of young Fulbright scholars who attended one of these orientations.

\section{Theoretical Perspective}

Two primary theoretical models are engaged in this study:

1. intercultural competence as found in expatriate acculturation (Mendenhall \& Oddou, 1985) and 
2. connective leadership as found in achieving styles (Lipman-Blumen, Handley-Isaksen, \& Leavitt, 1983).

Both models are built on the identification and measurement of characteristics or behaviors found effective in either adjusting to cultural differences (Mendenhall \& Oddou, 1985) or in leading followers through complex situations (Lipman-Blumen et al., 1983).

There is no unifying theory of intercultural competence (Van de Vijver \& Leung, 2009). However, roots can often be found in the human relations movement and intergroup contact theory (Allport \& Kramer, 1946), which assert that engagement with culturally different people reduces prejudice. In a recent work building on contact theory, Pettigrew (2008) concludes that the cultivation of empathy and perspective-taking are more essential to the reduction of prejudice than building knowledge of culturally different people is (p. 133). One avenue for assessing intercultural competence is studies of expatriate adjustment (Black, Mendenhall, \& Oddou, 1991; Mendenhall \& Oddou, 1985; Thomas, 1998; Tuleja, 2008). These studies look at the myriad competencies expatriates learn to employ in order to adjust and be effective in new cultural surroundings. From these studies, psychometric instruments have been developed to measure intercultural competence (Mendenhall, Stevens, Bird, \& Oddou, 2008, 2010). However, these measurements address intercultural and/or leadership competencies but not leadership behaviors.

Many theories have been developed to study the types and development of leadership (Antonakis, Cianciolo, \& Sternberg, 2004). Transformative leadership models 
(Bass, 1985, 1997) are most interested in the development of leadership for a greater good - for example, improved global relations. Emerging issues percolating in leadership research focus attention on contexts and even culture, as in the dimensions of cultural values found in the works of Geert Hofstede (1980) and Robert Meade (1967), according to Den Hartog and Dickson (Antonlis et al, 2004, p. 9). Here researchers are looking for ways to identify unique characteristics of the leader who engages interculturally and also to understand how the leader might be most effective by flexing his or her style to better relate to diverse followers and match followers' expectations. By seeking to be effective in multicultural contexts, the global leadership school also supports leadership for a greater good. Assessment of leadership competencies is equally complex and frequently requires multiple measures (AACSB, 2011; Edwards, Crosling, Petrovic-Lazarovic, 2003). The connective leadership model (Lipman-Blumen, 1996) is one such model that seeks to uncover and explain inclusive leadership styles, ideally suited for engagement of diverse followers. This model and its accompanying assessment tool address leadership styles, or the ways leaders lead alone and not intercultural competence, nor the possible linkage to intercultural competence. Having the capacity to do something is different from the actual doing of it. This study looks at both capacity (competency or skill) of effective intercultural engagement and the way (action or behavior) leaders lead.

To summarize this first portion of the proposal, there is need for new leadership, one that takes intercultural competence into account. Government, nongovernment, 
business, and higher education institutions have recognized this need and are making efforts to address it through policies, initiatives, education, and training. There are wellgrounded theoretical models of intercultural competence and leadership as well as means to assess them. This study with the Fulbright students sheds some light on the correlation of intercultural competence and leadership styles, and the findings have implications for higher education faculty and staff who are charged with preparing global ready graduates.

\section{Statement of the Problem}

Purpose statement. This study finds that there is a measurable relationship between intercultural competence and leadership styles. It analyzed data from two assessments, one of intercultural competence and one of leadership styles, to discover the significance and closeness of the relationship.

Research questions. The primary research question is stated as follows: Is there a relationship between intercultural competence and leadership style? The secondary questions dig deeper into the specifics of the relationship and whether the perspective on the relationship is impacted by certain aspects of intercultural competence or leadership styles and/or key demographic variables. These details will be discussed more thoroughly in Chapter 3.

\section{Purpose of the Study}

The purpose of this correlational study is to examine the relationship between intercultural competence and leadership styles as measured in 108 international (nonU.S.) Fulbright students who participated in the Fulbright Gateway Orientation Program 
in August 2010. The construct of intercultural competence focuses on effectiveness in engaging people across cultural differences, while the construct of leadership style focuses on the achieving or behavioral styles a leader uses to engage followers. Intercultural competence helps a person be effective in a variety of cultural contexts. Connective leaders (Lipman-Blumen, 1996) are inclusive and agile in engaging diverse coalitions to solve complex problems. Studying the intercultural competence and leadership constructs together may provide insight into the ability to lead across cultures and contexts in the connective era (Lipman-Blumen, 1996). This study seeks insights from an empirical analysis of the results of two psychometric assessments that measure intercultural competence and achieving (leadership) styles to find a statistical correlation of the results of the two assessments taken on this pool of international Fulbright students.

\section{Significance of the Study}

The primary significance of this study is the addition of an intercultural lens to the connective leadership model (Lipman-Blumen, 1996), possibly adding a new perspective to the role of intercultural competence on leadership styles. It is also possible that adding the connective leadership model's achieving styles to the global/intercultural leadership and competency literature can be of mutual benefit. For both models some co-relational validity may be added to their inventories. Finally, the international education literature may benefit from a new perspective on inbound student orientation and assessment practices. 
For the practitioner - coaches and teachers - the findings of this study may help them with their students and clients to move toward more effective leadership practices across cultural differences. Practitioners who employ psychometric assessments as a part of their teaching and training may see value in adding either or both the Achieving Styles Inventory (ASI) or the Intercultural Effectiveness Scale (IES) to their assessment portfolios. International educators and the Fulbright Program in particular may also see value in more explicitly addressing leadership and intercultural competence together in their education programs. In terms of policy, the Fulbright Program and possibly the U.S. State Department might find value in more explicitly addressing intercultural leadership development through the use of psychometric assessments in their work.

\section{Definition of Terms}

Defining culture, diversity, and intercultural competenceleffectiveness, as well as the models of intercultural effectiveness and connective leadership is necessary so the reader can fully understand this research proposal and the literature review to follow.

Culture and diversity. Culture can be defined in several ways. Milton Bennett (2001) composed the following definition: "Culture is a set of norms and values that are the foundation of the roles and rules for operating in a social system, and is learned in socially constructed situations through affiliation and observation" (p. 10). Diversity can be defined broadly as differences including, but not limited to, "national, regional, 
ethnic, gender, class, race, religion, age, sexual orientation, and physical ability"

(Bennett, J. M., \& Bennett, M. J., 1994, p. 146).

Intercultural competence. Competency in general is defined as an "underlying characteristic of an individual or team that can be shown to predict effective superior performance in a job or situation.” (McClelland, 1975). Intercultural (or cultural) competence and intercultural effectiveness often are used interchangeably and are derived from studies of international or global exposure to differences as well as differences that can be experienced domestically. Janet Bennett defines intercultural competence as "a set of cognitive, affective, and behavioral skills and characteristics that support effective and appropriate interaction in a variety of cultural contexts" (2008b, p. 95). A more general definition is the ability to function effectively in another country (Dinges \& Baldwin, 1983; Gersten, 1990). These definitions illustrate the complexity of defining the term intercultural competence. Deardorff (2004a) adds that the list of characteristics that are presented as intercultural competence is often diffuse. Intercultural competence is the independent variable in this study. The primary goal is to ascertain whether there is a correlational relationship between intercultural competence and connective leadership, to see whether intercultural adaptability is related to leadership adaptability.

Intercultural Effectiveness Scale. The IES (Mendenhall et al., 2008) serves as the assessment tool for intercultural competence in this study. It is a psychometric inventory designed to assess how the participant gets along with people whose cultural background differs from his or her own. A full description of the instrument, including 
reliability and validity, is given in Chapter 3. The IES is split into three primary categories or factors, each having two subcategories or competencies. The first factor, Continuous Learning, looks at how participants learn about another culture and the accuracy of that learning. The second factor, Interpersonal Engagement, looks at how participants develop and manage relationships with people from other cultures. The third factor, Hardiness, looks at how participants manage the challenges and stress involved in interacting with cultural differences.

Leadership and connective leadership. Leadership in general is defined as "the process of persuasion or example by which an individual (or leadership team) induces a group to pursue objectives held by the leader or shared by the leader and his or her followers" (Gardner, 1990, p. 1). The connective leadership model (Lipman-Blumen, 1996) was derived from Lipman-Blumen's studies first of women's leadership styles (1972) and later to a full model of leadership needed for the connective era (1996). Lipman-Blumen (1996) identified leadership profiles that are balanced in multiple styles as connective or "third order," because, she said, leaders with this profile were more inclusive than those who used traditional models of leadership and therefore had the potential to be effective in the connective era. She defines this as the 21 st century era, a time when traditional models of leadership are inadequate to meet the dual demands of interdependence and diversity.

Achieving Styles Inventory. The Connective Leadership Institute's L-BL ASI serves as the assessment tool for leadership styles for this study because the primary 
purpose of the study is to examine the relationship between intercultural competence and leadership style through correlational statistical analysis. A full description of the instrument, including reliability and validity, is offered in Chapter 3. The ASI has three primary categories or leadership sets, each set having three subcategories or achieving (leadership) styles. The primary sets are: direct leadership styles, employed by participants who want to master their own tasks when presented with a challenge; instrumental leadership styles, employed by people who reach out and include others when presented with a task or challenge; and relational leadership styles, employed by those who prefer to work through or with others on tasks and challenges.

\section{Summary of Introduction}

This chapter has discussed the case for assessing intercultural competence and leadership style. It has addressed the need for new leadership and the response of U.S. higher education to meet this need. Then it laid out the purpose and research questions for seeking a correlation between the assessment of intercultural competence and leadership styles. It spelled out key definitions that the reader will need to understand the rest of the dissertation, with a brief overview of the models and assessment tools used in this study. Christine Lagarde, managing director of the International Monetary Fund, explained the current perspective on global connections to the graduates of the Kennedy School of Public Management at Harvard University this way:

We stand at the entrance of a new world, a whole new way of living, of communicating, of crossing borders. It is the great paradox of our age: The world gets bigger, with so many more people and places sharing the fruits of knowledge 
and prosperity; and the world gets smaller, with so many more people and places crossing paths and sharing destinies.

For today, the world is more closely knit than ever before. An infinity of little interconnections dances across the fabric of global society, transforming millions of fragmented images into one dazzling mosaic. As George Bernard Shaw put it, "We are all dependent on one another, every soul of us on earth." (Lagarde, 2012) 


\section{Chapter 2: Review of the Literature}

This dissertation is built upon the literature of the intercultural and leadership studies in general and the applied fields of intercultural competence, connective leadership (Lipman-Blumen, 1996), and international education in U.S. higher education settings. It is possible to view this research base as a series of intersecting conversations like the circles in a Venn diagram. This study finds areas in which the theoretical bodies of research underpinning intercultural and leadership studies engage, but only partially and with a focus to aspire to the combination of skill and aptitude. However, when the more applied research of intercultural competence and connective leadership (LipmanBlumen, 1996) are brought into the conversation, more possibilities for dialogue exist. In the applied arenas it is possible to witness the theoretical aspirations shift to the pragmatic abilities to lead effectively across cultures and context, whereas LipmanBlumen explains "interdependence and diversity" (1996, p. xiii) are driving forces.

On a conceptual level, the relationship that this study focuses on is between the "ability to interact appropriately in a variety of cultural contexts" (Bennett, J. M., 2008b, p. 95) and the adaptability to effectively engage diverse followers toward a shared goal (Lipman-Blumen, 1996). The former concept is a competency; the latter is a behavior. The differences between competencies and behaviors may seem to be a matter of semantics, but they are important to this study. Competency is broadly defined as "underlying characteristics of an individual that can be shown to predict effective superior performance in a job or situation" (McClelland, 1975). A behavior is "the 
aggregate of the responses or reactions or movement made by an organism in any situation," or, more simply put, the "way a person behaves toward other people" (http://www.visualthesaurus.com). Chomsky (1984) gives an example of this when he discusses the creative use of language and the "distinction that must be made between what the speaker of a language knows implicitly (what we may call his competence) and what he does (his performance)" (p. 431). An iceberg is a metaphor interculturalists commonly use to describe these same distinctions. Cultural values and beliefs lie beneath the surface of the water; they are things we know implicitly, such as a language competency. Conversely, the expressions of culture, such as music, graphic art, and language, appear above the surface of the water and are more explicit and take the form of performance in Chomsky's terms. It is the goal of this study to expand the understanding of intercultural leadership, and this is derived by relating the perspectives of both competency and behavior or performance.

For the purposes of this study, a connective leader needs to be competent or prepared to engage diverse followers and will demonstrate this by leading (behaving) in an adaptable way. As an example, a prospective intercultural leader may have the capacity to learn that his or her new followers prefer to work on tasks collaboratively with shared goals and rewards, but he or she may not be able to motivate followers in this way. In this case, the leadership behavior is not adapted to the cultural context. I believe that intercultural competency and connective leadership (Lipman-Blumen, 1996) are the two separate but related pillars of effective intercultural leadership in the 21 st century. 
By studying both constructs empirically, the results offer some correlational data to add to the literature of these two schools of research. To make this case clear to the reader, I need to discuss the literature of intercultural competence as it relates to leadership and can be found in international education.

\section{Intercultural Competence}

Boyatzis (1982) defines competency as "a capacity that exists in a person that leads to behaviors that meet the job demands within the parameters of the organizational environment." Again, there is no unifying theory of intercultural competence (Van de Vijver \& Leung, 2009, p. 406). However, intercultural competence is often defined as "a set of cognitive, affective, and behavioral skills and characteristics that support effective and appropriate interaction in a variety of cultural contexts" (Bennett, J. M., 2008b, p. 95). The human relations movement and intergroup contact theory (Allport \& Kramer, 1946) offer the antecedents to finding intercultural competence in prejudice reduction, and these have been propagated and expanded upon through numerous studies (Pettigrew \& Tropp, 2011). After an extensive meta-analysis of 50 years of quantitative and qualitative research on the topic, Pettigrew and Troop (2008) concluded that $95 \%$ of the 516 studies reported a negative relationship between contact and prejudice. They further found that careful mediation of shared goals and equal status brings about anxiety reduction and cognitive complexity, which supports the work of prejudice reduction (Bennett as cited in Deardorff, 2009 p. 132). In addition, Pettigrew (as cited by Bennett in Deardorff, 2009, p. 133) concludes that the cultivation of empathy and perspective 
taking are essential to the reduction of prejudice, even more so than the building of knowledge of culturally different people.

Building capacities such as empathy and perspective-taking as essential components to prejudice reduction are the foundation of intercultural competency studies. These capacities represent the types of cultural general knowledge or ways of knowing about cultural differences that set the intercultural field apart from other fields of study (Hall, 1959, 1966, 1976; Hofstede, 1991; Kluckhohn \& Kluckhohn, 1947). Deardorff (2004a, 2009) points out that the identification of intercultural competencies is complex and often fraught with long unmatched lists. It is an essential perspective of this dissertation to recognize this emphasis on intercultural competencies (cultural general aptitudes such as empathy and perspective-taking) and that they have greater value than culture-specific knowledge for effective work across cultural differences. This study focuses on characteristics and behaviors that can be found and applied in any cultural context. They will need to be adapted to the cultural group and employed at different levels of salience to be most effective, but the ability to adapt is the key objective.

As an example, a new leader in a new cultural context may need to inquire about his or her followers (gain perspective and develop empathy) through high-context and indirect methods if these are the cultural norms of that region. This refers to communication styles that are often cited as a common way of understanding cultural norms. Edward T. Hall (1959) conducted ethnographic studies of the Hopi and Navaho Indians in the 1930s and 1940s and published his finding in his book The Silent 
Language. Hall was able to identify high- versus low-context communication styles. In high-context communication, people prefer to find meaning in the context (time, people present, and symbols such as body language). In low-context communication, people prefer to find meaning primarily in the words. Hall also was able to find cultural preferences for communication that were verbally direct, indirect, circular, comprehensive, or linear, as well as preferences for certain paces (speed) and turn-taking systems in communication. Finally, he was able to identify nonverbal communication preferences, such as preferred space between participants, body language, volume, and tone. For the intercultural leader, learning to recognize these communication style preferences and adapt accordingly is the goal of intercultural competence.

\section{International Adjustment Model}

The study of the acculturation and adjustment process of the sojourner, the culturally different "other" in a new context, has opened a huge body of work on understanding intercultural competence and ultimately even measuring it. The genesis of the intercultural effectiveness model is the study of expatriate adjustment (Mendenhall \& Oddou, 1984). It delineates the competencies that support successful expatriates and was refined through an empirical literature review on expatriation (Mendenhall \& Oddou, 1985). The general model has three dimensions that conceptually align with the intercultural competencies used in this proposed study: others-oriented dimension $=$ cross-cultural relationship competencies, perceptual dimension $=$ cognitive orientation 
competencies, and self-oriented dimension $=$ traits and values (Mendenhall, Stevens, Bird, \& Oddou, 2008).

The adjustment model above was frequently employed in subsequent literature (Thomas, 1998) and became the basis for the international adjustment (IA) model, which Black, Mendenhall, and Oddou developed in 1991. In the IA model two of the categories above were relabeled: self-oriented became self-efficacy, and others-oriented became relational. Perceptual remained perceptual (Mendenhall, Stevens, Bird, \& Oddou, 2010). These three categories made up the individual dimension of the IA model; the other three dimensions were job, organizational, and network. This model has been the subject of several empirical literature reviews, (Bhaskar-Shrinivas, Harrison, Shaffer, \& Luk, 2005; Shaffer, Harrison, \& Gilley, 1999; Hechanova, Beehr, \& Christiansen, 2003; and Mendenhall, Kuhlmann, Stahl, \& Osland, 2002. In 2005 Bhaskar-Shrinivas et al. conducted a comprehensive meta-analysis of more than 50 expatriate adjustment determinants using data from 8,474 expatriates in 66 studies. Their findings were that the IA model and, in particular, the self-efficacy and relational skills from the individual dimension of the IA model were important in predicting successful adjustment. The general IA model is depicted in Figure 1.

In 2004 Allan Bird, Mark E. Mendenhall, Gary Oddou, and Michael J. Stevens synthesized this research into the psychometric assessment tool called the Global Competencies Inventory (GCI) (Kozai Group, 2004). The IA categories were renamed in the GCI for clarity and pedagogical reasons to perception management, relationship 
management, and self-management, with 16 different competencies divided among these three categories. The GCI was further refined to meet the needs of a more academic setting and renamed the Intercultural Effectiveness Scale (IES) in 2009 (Mendenhall et al., 2008), which is employed in this study. The categories were again renamed as three factors - Continuous Learning, Interpersonal Engagement, and Hardiness - comprising six competencies of the GCI's original 16 competencies divided evenly among the three factors. These factors and competencies are described in the Methods section of this paper under Instrumentation. Figure 2 focuses on the personal competencies, as those competencies most important to the success of expatriate adjustment.

Both the GCI and the IES are new tools and have only recently been made available to those besides the researchers who created them and their close associates. There are no published studies employing either of these tools to date. There is one study in progress (as of July 2012) that will on the assessment of student learning outcomes of an undergraduate business program with 900 participants that demonstrates the value of the IES in academic settings. Another study will be presented in fall 2012 studies sojourners learning a new language and the correlation between intercultural competence and language acquisition and found a positive correlation between the two constructs (Keeley, 2012).

\section{Intercultural Relations}

To better understand the theoretical foundation of the IA model (Black et al., 1991) it is essential to look to the field of intercultural relations. The ancient philosopher 
Aristotle coined the term civitas, meaning "learning to live in the city." He explained that very young children feel a natural kinship and comfort with blood relatives; as children grow up they learn to interact with immediate neighbors and schoolmates, and their kinship definitions are broadened to include friends. When people are fully mature and need to assume adult responsibilities in the public square of the city, they need to learn to extend that feeling of kinship to all of humanity. So they are to extend their sense of kinship to the stranger (Mouw \& Tippett, 2011). Historically, this leap of kinship from family to friend to stranger is a cause of tension and trouble, frequently leading to "bloodshed, oppression, and genocide" (Bennett, M. J., 1993, p. 21). But in the connective era, leaders and followers are expected to engage people from all segments of society and regions of the world. So, in the connective leadership model (Lipman-Blumen, 1996), leadership behaviors may be related to the intercultural competency.

Richard Mouw (2011) is a theologian seeking to understand effective civic engagement in the instance of culturally based ideological differences. Milton Bennett (1993) is a communication researcher seeking to explain effective intercultural communication in instances of cultural differences. Both are seeking ways to understand behavioral responses to cultural differences. Again, "culture is a set of norms and values that are the foundation of the roles and rules for operating in a social system, and is learned in socially constructed situations through affiliation and observation" (Bennett, M. J., 2001, p. 10). Cultural anthropologist Margaret Mead (1970) stated that "cultures 
are man-made, they are built of human materials; they are diverse but comparable structures within which human beings can attain full human stature" (p. 39). Mead's ethnographic studies observed and catalogued the acculturation processes employed by different societies to determine key cultural markers such as gender roles, rituals, accepted forms of communication (verbal and nonverbal), ways to negotiate and conduct conflict, hierarchical and work responsibilities, etc. This societal acculturation process engenders a sense of belonging, which psychologist Abraham Maslow (1968; Maslow \& Frager, 1970) explained is an unconscious basic need. He called this need cultural specificity and notes that humans seek this form of commonness on a very deep level (1970, p. 28).

An important distinction to highlight at this juncture is the difference between cultural general concepts versus cultural specific concepts. Cultural general concepts refer to aspects of culture that lie beneath the surface of the water-using the iceberg metaphor again — such as values, mores, beliefs, and, in the case of this study, competencies. Cultural specific concepts are those expressions or behaviors that are above the waterline and specific to a cultural group, such as a preference for folk dancing over ballet, or greeting rituals and language deemed appropriate in the Japan. Understanding cultural general concepts is deemed essential to interculturalists, because without knowing the values that underlie a greeting ritual, it is possible to perform or mimic the greeting in such a way as to offend the party being greeted. So interculturalists have researched cultural general concepts so that practitioners can analyze observed 
behaviors of a new or different cultural group and learn to adapt their behaviors effectively.

At the turn of the 20th century, sociologist William Graham Sumner wrote Folkways: A study of the sociological importance of usage, manners, customs, mores, and morals (1907), in which he outlines the concepts of ethnocentrism, in-groups, and out-groups. He defines ethnocentrism as positive sentiment toward the in-group: pride, loyalty, and perceived superiority. Sumner further postulates that there is a direct correlation called a negative reciprocity toward the out-group, with contempt, hatred, and hostility as the attitudes and resulting behaviors being found. Psychologist Gordon Allport refuted Sumner in his studies on prejudice (Allport \& Kramer, 1946; Allport, 1954). Allport and Kramer started by surveying 437 undergraduates about their experiences with prejudice (1946), and Allport expanded his studies with further surveys of a broader audience to seek a more comprehensive understanding of prejudice (1954). He discovered that the range of attitudes and behavioral responses to out-groups was quite large. In more contemporary studies researchers have built on Allport's finding to determine that the formation of in-group love is more pervasive than the shaping of outgroup hate (Brewer, 1999; Pettigrew \& Troop, 2011).

Learning about difference. Building on contact theory, the developmental model of intercultural sensitivity (DMIS) (Bennett, M. J., 1993) defines intercultural sensitivity as the set of knowledge, skills, and behaviors needed to become competent in cross-cultural contexts (note that intercultural sensitivity can be used interchangeably 
with intercultural competence). The intercultural effectiveness model (Mendenhall \& Oddou, 1985) measures levels of effectiveness (competency) in engaging difference, which parallels the levels of sophistication identified in the DMIS. Milton Bennett (1993) describes the DMIS as follows:

Intercultural sensitivity will be defined in terms of stages of personal growth. This developmental model posits a continuum of increasing sophistication in dealing with cultural difference, moving from ethnocentrism through stages of greater recognition and acceptance of difference, here termed "ethnorelativism." (p. 22)

The intercultural effectiveness model and DMIS closely align with the theories of Developmental Learning (Mezirow, 2000; Piaget, 1950), Experiential Learning (Kolb, 1984), and Transformational Learning (Mezirow, 2000). Learning to move toward more effective or ethno-relative levels of thinking and behaving occurs in stages that are affected by a person's experience in interacting with cultural differences. In short, the experience of difference directly impacts the response to differences and can (ideally, but not always) increase the level of sophistication in responding to differences. Typically the transformation of consciousness possible from an intercultural learning experience comes when the person experiences cultural difference, giving rise to a dilemma he or she finds culturally disorienting. In this study the disorientation that occurs around cultural norms can cause participants to reflect deeply about their own assumptions, to reevaluate their responses, and eventually reintegrate their thinking based on a new perspective (Mezirow, 2000, p. 22). 
Deardorff's intercultural competence model (Deardorff, 2004b), shown in Figure 3 , is often cited as the most comprehensive model of its kind. Note this model closely resembles the motivational framework for culturally responsive teaching (Wlodkowski \& Ginsberg, 1995), which is adapted from the Kolb's learning cycle (1984). Deardorff explains that an essential element of intercultural competence is curiosity, the interest in learning about differences. This process of learning about differences impacts intercultural competence and may also impact the level of participants' flexibility in enacting leadership styles as measured in this study. So the model above traces the likely paths of learning about difference that are experienced and explains the ideal for developing intercultural competence. Deardorff points out that by guiding learners to cultivate the appropriate attitudes about difference, they can gain access to the appropriate knowledge and skills about cultural difference. Having this new knowledge and skills moves the learner to a new level of confidence and produces an internal shift, which is then expressed in an external outcome of interculturally competent behavior. Although there is yet no empirical evidence that this same process can be employed when developing connective leaders, this type of process is the ascribed goal of the Connective Leadership Institute (www.connectiveleadership.com) and could be replicated when learning to lead diverse populations.

Relationships across difference. Understanding the shaping of cultural markers and in-groups (Sumner, 1907; Allport, 1954; Allport \& Kramer, 1946; Brewer, 1999; Pettigrew \& Troop, 2011) will be essential for understanding intercultural competence 
and the behavioral challenges of connective leadership (Lipman-Blumen, 1996). As an example, Lipman-Blumen highlights the intercultural construct of individualism versus collectivism in The Connective Edge (1996). She explains that leaders with a strong preference for direct leadership styles are more individualistic in their behaviors than those who prefer the relational leadership styles, who are more collectivistic. Those leaders who prefer the instrumental set of leadership styles are the bridge builders between the individualistic and collectivistic schools. Many social scientists identified this concept of individualism versus collectivism as a common way to analyze culture. Collectivist cultures prefer behaviors that emphasize a sense of in-group belonging, whereas individualistic cultures prefer behaviors that emphasize the achievement of the individual. Mead (1970) found clear cultural markers for a preference toward cooperation, competition, or individualism. Kluckhohn and Strodtbeck (1961) found similar patterns and labeled the construct collateraterality versus individualism.

Triandis, Leung, Villareal, and Clark (1985) employed three rounds of questionnaire refinement studies to find reliable ways to measure the construct of allocentrism (collectivism) versus idiocentrism (individualism). Allocentrism was found to be positively correlated with social support and low levels of alienation. Idiocentrism (individualism) was found to be positively correlated with achievement and perceived loneliness. Individualism and collectivism were further measured by organizational development researcher Hofstede $(1980,1991,2001)$, who conducted a 20,000-person 
quantitative survey study of IBM employees around the world to measure the countryspecific cultural preference of several cultural general constructs.

For the connective leader, the ability to grasp the construct of individualism versus collectivism and reach out to maintain a positive relationship with followers whose cultural orientation is different from their own is an essential skill set to master.

Maintaining self amid difference. Intercultural competence is informed by the theories of identity development (Perry, 1970). Perry describes nine developmental positions, which include an early dualistic thought process, a mid-level position of seeking multiple perspectives, and a final position of comfort with a more "relative" cognitive process. Throughout these developmental positions, the individual maintains his or her own sense of identity. This comfort with "relativity" in making judgments closely parallels the DMIS in upper "ethno-relative" stages of intercultural sensitivity and the higher intercultural competency as measured by the IES. It calls on the learner to maintain an attitude of positive regard when his or her sense of belonging (Maslow, 1968; Maslow \& Frager, 1970) is interrupted as well as the capacity to be resilient when his or her sense of self seems disrupted. An intercultural leader needs to respond well to meeting new cultural norms and possibly even learn to integrate some new cultural ways of being; in this way intercultural competence supports connective leadership.

Summary of intercultural competence. In summary, the intercultural dimensions and competencies highlighted in this literature review provide a perspective of the broad base of research that demonstrates that cultural differences can be witnessed 
and studied, that there are cultural orientations that can be measured and explained, and that there are competencies - especially intercultural competencies — that can be cultivated. The next section of this chapter will focus on connective leadership and its relation to intercultural competence.

\section{Connective Leadership}

The connective leadership model (Lipman-Blumen, 1996) began in 1972 with research on achieving styles conducted by Harold Leavitt of Stanford University and Jean Lipman-Blumen of the University of Maryland. They were looking into the different behaviors used to achieve goals between men and women. They were intrigued by the work of Matina Horner (1968) and her studies of women's fear of success as well as the perspectives on motivation for achievement and performance researched by David McCelland and J.W. Atkinson. The data from the achievement and performance experiments (McClelland, Atkinson, Clark, \& Lowell, 1953) unearthed different patterns of achievement for women than for men, particularly around the value of competition as an achieving style, which Leavitt and Lipman-Blumen wanted to explore. They were further intrigued by the work of organizational behaviorist Franklin Rubenstein (1971), whose situational case study on industrial pollution found that men tended to set about tasks directly, individualistically, and competitively, whereas women approached goals more indirectly, collaboratively, and vicariously.

In 1973 Leavitt and Lipman-Blumen developed their first iteration of the L-BL (for Lipman-Blumen and Leavitt) Achieving Styles Inventory (ASI), a psychometric 
inventory that measures the achieving (leadership) styles (behaviors) that make up the connective leadership model (Lipman-Blumen, 1996). Leavitt moved on to other pursuits in 1979, and Lipman-Blumen continued to fine-tune the ASI to the present. Lipman-Blumen continued to refine and broaden the model and the instrument to be inclusive of leadership styles beyond the initial gender perspectives to include national origin, educational levels, roles and responsibilities, and other variables (LipmanBlumen, 1996). The ASI has gone through numerous iterations and statistical studies (Lipman-Blumen \& Leavitt, 1976; Leavitt \& Lipman-Blumen, 1980; Lipman-Blumen, Handley-Isaksen, \& Leavitt, 1983; Lipman-Blumen, 1992; Lipman-Blumen, 2006). The ASI's dimensions are described in detail along with the validity and reliability statistics in the Methods/Instrumentation section of this paper.

The connective leadership model (Lipman-Blumen, 1996) is built on the premise that leaders need to be holistic in their practice, working to make the world a better place. To do this effectively they need to adapt their leadership styles to suit the context. Growing access and success with multiple leadership styles is the ideal for this model. In "What Business Needs To Learn from Academe" (1998), Lipman-Blumen asserts that the ability to adapt leadership styles is an important set of skills for any organization that desires to be effective in the connective era (1996). She adds that access to and success with multiple leadership styles is particularly valued in higher education settings. This is also true for the Fulbright students in this study, who will assume leadership roles on their campuses in teaching, research, and project management. 
Connective leadership: research. The following studies are examples of how the connective leadership model (Lipman-Blumen,1996) in general and the ASI in particular have been employed in ways that are germane to this study.

Access and success with multiple leadership styles. There have been studies conducted using the ASI, dominantly in master's degree and doctoral theses. There have been several studies involving kindergarten to high school leadership roles (Charest, 1996; Hernandez, 2004) demonstrating how achieving styles can impact the school learning environment. Also, there have been studies on differing aspects of leadership or achieving styles in higher education settings, such as studies of student affairs professionals (Beardsley, Stewart, \& Wilmes, 1987; Komvies, 1992; Stewart, 1983), faculty, (Brown, 2007; Reibling, 1989; Stokely, 1986; Surbeck, 1997) and college presidents (Fobbs, 1988; Overland, 1996). These studies all point to the prevalence of multiple achieving styles in leaders in specific roles.

Recognizing and adapting to a cultural context. There are a few studies employing the ASI that fall into the culture-specific model, in which one cultural group's achieving styles is compared to another or explicated using the ASI. Lange (1993) studied the differences in achieving styles between managerial versus non-managerial employees in South Africa; Suckow (1988) studied achieving style differences between college students in India and U.S.; Thompkins (1989) studied the differences of achieving styles between people from Finland and America; VanderHorst (1994) studied the achieving styles of managers from Bulgaria. Finally, Munoz (1994) studied the preferred 
leadership styles of leaders from Mexican-American business and professional women. Like the higher education theses, these studies examined the multiple styles prevalent within their survey populations. For the intercultural leader, the value of these studies is to learn about the preferred leadership styles of a cultural group he or she is assigned to serve and to adapt accordingly.

Correlation to complex thinking. The research most germane to this proposal was conducted by Wangler (2009), who used the ASI and Quinn's Competing Values Managerial Leadership Instrument (Quinn \& Rohrbaugh, 1983; Cameron \& Quinn, 2011) to determine whether there is a relationship among connective leadership, managerial complexity, and managerial effectiveness. They surveyed 1,400 participants, and 181 were deemed appropriate for inclusion in the study. Multiple regression analysis was conducted on the variables, and the results support Lipman-Blumen's assertion that connective leaders need behavioral complexity in order to be effective managers. In addition, the managers' ability to form trust with their constituents was found to be a significant predictor of effectiveness. Wangler's work (2009) indicates that correlational factors can be found in relation to achieving styles. Intercultural competence is often characterized as the ability to take in complex ideas and behaviors and manage complex feelings that arise from these encounters, so this measure of complexity lends credence to the proposed measure of intercultural competence. The results of this study can add to this body of connective leadership literature by adding correlative data in terms of 
intercultural effectiveness and achieving styles and can link to the international education field, especially the research on the Fulbright Scholar Program.

Each of these examples offers a different perspective on how the connective leadership model (Lipman-Blumen, 1996) and the ASI have been used to explicate the complexity of leadership practices in general and inform this study. But the connective leadership model does not exist in a vacuum and needs to be situated in the larger context of leadership studies as a field.

\section{Leadership Theories}

Leadership research, like intercultural competence, is fraught with complexity and a lack of a central unifying theory on which to build a doctoral thesis. Bennis (1959) stated:

Of all the hazy and confounding areas of social psychology, leadership theory undoubtedly contends for the top nomination. And, ironically, probably more has been written and less is known about leadership than about any other topic in the behavioral sciences." (pp. 259-301)

Even defining leadership is difficult. Fielder (1971) points out that "there are as many definitions of leadership as there are leadership theories - and there are almost as many theories of leadership as there are psychologists working in the field" (p.1 ). The following definition is used in this study: "possession of qualities, (especially mental qualities) to do something or get something done" (http://www.visualthesaurus.com).

Most scholars of leadership would caution new students of the topic to differentiate leadership from management. Leadership is commonly believed to go beyond the basic objective-driven processes and coordination of management work 
(Bass, 1985, 1997) to include a more purpose-driven focus on changing values, ideals, vision, symbols, and emotional exchanges (Bryman, 1992). Many note that management is considered an aspect of successful leadership (Zaleznik, 1989). While there are many schools or theories of leadership, the few that are most germane to this proposal are described below.

The trait school of leadership. The trait school of leadership (Bass, 1990) seeks to define the "great man," and stable characteristics of leaders, including especially the need for intelligence. The connective leadership model (Lipman-Blumen, 1996) was initiated as a negative response to the lack of inclusivity found in this historically common school of leadership studies, which frequently focused on males as role models for great leaders. Within the connective leadership model the direct set of leadership styles is most closely aligned but is repositioned to be more inclusive. Early proponents of this theory identified intelligence and dominance as key traits of leadership (Mann, 1959; Stogdill, 1948), and intelligence was confirmed as correlated in the 1980s (Lord, de Vader, \& Alliger, 1986). Stogdill employed analysis of multiple surveys, while Mann and Lord et al. used meta-analysis of 15 separate studies (quantitative and qualitative) conducted over an approximately 60-year period. Barnlund (1962) conducted a multistage case study with observations in order to determine which leadership characteristics were stable, could be enacted in multiple situations, and could be perceived as effective; Kenny and Zaccaro (1983) conducted rotational case studies, in which participants' roles were rotated and observed, and found that the results were 
dependent on the situational environment factors. Zaccaro, Foti, and Kenny (1991)

conducted a task analysis of 108 students and correlated the different behaviors to determine which were most stable. This dissertation seeks to find the relationship between intercultural competencies and leadership style characteristics that may influence great (connective) leaders and to redefine it to include leadership traits that are effective across cultures and contexts.

Relational school of leadership. Relational school of leadership (Graen \& UhlBien, 1995) started as the vertical-dyads linkage theory and has been refined to become the leader-member exchange (LMX) theory. This school defines leadership in terms of the quality of the leader-follower relationship. "High-quality relations between a leader and his or her followers are based on trust and mutual respect (i.e., the in-group)" (Antonakis, Cianciolo, \& Sternberg, 2004, p. 8). The connective leadership model (Lipman-Blumen, 1996) is informed by this school in that it too seeks to authenticate the LMX, but through adaptation of behaviors or leadership styles. The common method of study for this school is tabulating and correlating the responses of leaders' directives and followers' responses and vice versa in order to determine the relative match of intent and response. Scandura and Lankau (1996) conducted a study using the LMX dyad method and determined that more attention to diversity, especially race and gender differentials, needed to be attended to in future research. This result of this study finds the relationship between leadership styles and intercultural competence that may affect cultivation of trust and respect in leadership work through intercultural competence. 
INTERCULTURAL COMPETENCE AND LEADERSHIP STYLES

Information-processing school of leadership. Information-processing school of leadership (Lord, Foti, \& De Vader, 1984) focuses on the perceived match between followers' expectations and the leader's characteristics. The connective leadership model (Lipman-Blumen, 1996) identifies leadership styles as characteristics that influence this match and in an inclusive manner. Psychometric inventories were employed to assess participants in three different studies to see whether factors could be manipulated to determine their effect on the desired match, and the results were positive. In seeking the possibility of leaders' ability to adapt leadership styles to fit a variety of cultural contexts and expectations, this study is also informed by this school.

Both the relational (Graen, 1995) and the information-processing (Lord, Foti, \& De Vader, 1984) schools of leadership could be seen as relating to the Instrumental set of the connective leadership model (Lipman-Blumen, 1996) in that they look at the ability to engage followers. However, none of the models presented here fully understands the relational set of leadership styles that is unique to Lipman-Blumen's model. By uncovering and articulating the relational set of leadership styles and carefully integrating this set within a model that includes the more traditional modes of leadership, she has created an inclusive model of leadership. The following leadership research moves into areas that will strengthen Lipman-Blumen's desire for connective leaders to serve the global community.

New leadership models. A closely matched and often cited school of leadership is the new leadership (neocharismatic/transformational/visionary) school (Bass, 1985). 
Here the researchers are defining leadership as having a purpose and mission that benefits a greater good. The connective leadership model (Lipman-Blumen, 1996) seeks to build a better world through leadership that recognizes and can finesse interdependence and diversity for the greater good. In fact, in a 2011 speech Lipman-Blumen stated that the purpose of leadership ought to be world peace and proceeded to outline a plan to employ connective leadership in this pursuit. Building on the work of House (1977) and Burns (1978), this model seeks to identify the behaviors that a leader can enact to induce followers to interests of the greater good. This is a reconfiguration of the trait school of leadership, which promotes visionary and charismatic leadership theories. Ensari and Murphy (2003) conducted a correlational study measuring perceptions of leaders' charisma in a collectivist culture (Turkey) and an individualist country (the USA) and found that the followers from the individualistic culture responded better to the attributions of a charismatic leadership style than those from the collectivistic culture, where they preferred to attribute leadership to the organization and its outcomes. The connective leadership model of Lipman-Blumen (1996) clearly seeks to move leadership toward a more egalitarian model, seeking leadership for the connective era (LipmanBlumen, 1996). This dissertation hopes to contribute a global and inclusive perspective to these new schools of leadership studies by adding intercultural competence to the lens.

Emerging issues in leadership. Emerging issues percolating in leadership research focus attention on contexts and even culture, as in the dimensions of cultural values found in the works of Geert Hofstede (1980) and Robert Meade (1967), according 
to Den Hartog and Dickson (2004, p. 9). Here researchers are looking for ways to identify unique characteristics of the leader who engages interculturally and also to understand how the leader might be most effective by flexing his or her style to better relate to diverse followers and match followers' expectations. The contextual school of leadership (Shamir \& Howell, 1999; Zaccaro \& Klimoski, 2001) looks at factors that may encourage or inhibit leadership behaviors. These contextual factors can include cultural orientations (Meade, 1967; Hofstede, 1980) such as hierarchy and national culture as well as gender, which was the factor that most influenced the initiation of the connective leadership model (Lipman-Blumen, 1996). Antonakis, Avolio, and Sivasubramaniam (2003) conducted a 3,000-person study using the Multifactor Leadership Questionnaire (MLQ), a psychometric instrument, to determine the influences of gender, hierarchy, and environmental influences on leadership effectiveness and found that all three factors have an influence. In this arena, the theory of international adaptation (Mendenhall \& Oddou, 1985 ) is taking root and can be applied directly to the assessment of both leadership styles and intercultural competence. Here researchers are looking for ways to identify unique competencies of the leader who engages interculturally. By adding the connective leadership model (Lipman-Blumen, 1996) to these more global theoretical models, this dissertation hopes to add a transformational perspective to their work.

The last emerging issue in leadership research is the call for researchers to “integrate overlapping and complementary conceptualizations of leadership" (Antonlis, Cianciolo, \& Sternberg, 2004, p. 11) and constructing hybrid theories that bring in 
diverse perspectives. This research hopes to contribute to this calling by studying intercultural competence and connective leadership (Lipman-Blumen, 1996) simultaneously.

Assessment of leadership competencies. Assessment of leadership competencies is equally complex and frequently requires multiple measures (AACSB, 2011). There are tools for assessing different aspects of leadership; the most commonly used tools are called the "Big Five" personality traits (De Hoogh, Den Hartog, \& Koopman, 2005). These personality factors comprise Extraversion, Agreeableness, Conscientiousness, Neuroticism (anxiousness), and Openness. The tools and assessment practices employed in assessment of leadership work are often used only in schools of business or corporate human resource and organizational development units, not in general or international education settings. The ASI, which is the tool for assessing connective leadership, (Lipman-Blumen, 1996) is one such tool. However, this model and its accompanying assessment tool address leadership styles alone and not intercultural competence nor the possible linkage to intercultural competence. This is why this dissertation is using both the ASI and the IES to get multiple perspectives on the intercultural potential of the Fulbright students in this study.

Summary of leadership research. In summary of the leadership theories and model discussed above, many perspectives are employed to identify and explain leadership in general. Many can be tied to the connective leadership model (LipmanBlumen, 1996) and even the IA model (Mendenhall \& Oddou, 1985). But none of them 
takes the unique perspective of looking for either or both intercultural competence and leadership styles (behaviors). This is the purpose of this dissertation: to seek a relationship between these two constructs and in turn contribute to the leadership research in general.

\section{International Education}

International education is the applied field of research in which this dissertation is situated. This field is the confluence of the intercultural and the higher education fields of study (Eland, A, Greenblatt, \& Smithee, 2009). For the purposes of this study, the experience of the inbound international (non-U.S.) student and the effects of that experience are the focus.

Gaining intercultural competence is often finessed by engaging culturally different others (Paige, \& University of Minnesota, 2006), and international education is the form most germane to this study of the Fulbright scholars. The most comprehensive studies of the effectiveness of international education have been conducted by Paige, Jacobs-Cassuto, Yershova, and DeJaeghere (2003). In these longitudinal studies, students who went abroad during college were tracked over a 40 -year period to see what impact their overseas experiences had on them later in life. In general they explained that the overseas study experience positively affected the students' curiosity about the world outside their home countries, the cultivation of empathy for those who are culturally different from themselves, and the ability to self-mange in situations when cultural norms are different from their own. These studies all demonstrate an increased intercultural 
competence as a result of study abroad. A 2009 study by Paige, Fry, Stallman, Josic, and Jon also points to the returnees' feelings of interconnectedness with the world demonstrated by an increased concern about environmental and social justice issues, a willingness to participate philanthropically by volunteering and donating money, and voluntary practicing of simplicity in their lifestyles. They also grew global leadership acumen demonstrated by giving formal talks and taking leadership roles in civic engagement work. These findings are supported by Sandell (2007). Together, the studies above point to the possibility of measuring intercultural competence and its relationship to connective leadership (Lipman-Blumen, 1996) in the Fulbright students.

The studies mentioned here are all focused on U.S. students who have traveled abroad. The following literature supports this study and focuses on the ability of incoming international students like the Fulbright to adjust to the U.S. academic environment. This was the purpose of the original training contract that gave birth to this study. The "cultural adjustment" portion of this training was implemented to inoculate the incoming students from culture shock. Culture shock is defined as a disease with a host of negative psychological and physiological symptoms and is "precipitated by the anxiety that results from losing all our family signs and symbols of social discourse" (Oberg, 1960). Many studies have been conducted on the prevalence and treatment of culture shock in the study abroad environment (Andrade, 2006; Arasaratnam, 2005, Brown \& Holloway, 2008; Yamashita, 2009). Most point to the need to mitigate the impact of culture shock by carefully constructed pre-departure, onsite, and port-return 
orientations (Bennett, J. M., 1985; Paige \& University of Minnesota, 2006; Lee, 2001; Zhou, Jindal-Snape, Topping, \& Todman, 2008). A student's cultural socialization impacts a student's preferences for different modes of teaching and learning (Hofstede, 1985), so support is also needed to help the international student understand the differences in teaching and learning in the new environment (McClure, 2007; Myburgh, Niehaus, \& Poggenpoel, 2002; Yamashita, 2009). These teaching and learning differences can result in what a recent Portland State University doctoral graduate articulated as a "chilly climate" for international students (Brown, 2007; Yamashita, 2009). In the case of the Fulbright students, they are expected to not only be students in their graduate programs, but to also serve in leadership roles as teaching assistants, research associates, and campus spokespersons for the Fulbright Program on international issues from their regions of the world (Fulbright Program, 2011a). These roles can cause difficulty for the international student (Smith, 1992; Thompson \& Thompson, 1996).

The Fulbright students also represent to their campuses, and eventually their home countries, a complex synthesis of new global knowledge, experience, and possibly even competency. Their host campuses may see the Fulbright students as a form of imported knowledge base and income for their academic units (De Vita, 2006; McNamara \& Harris, 1997). Their campuses hope to be able to finesse their presence to infuse new perspectives on academic disciplines and possibly teaching and learning practices (De Vita, 2007; Dolby \& Rahman, 2008; Whalley, Langely, Villarreal, \& Collage, 1997). The Fulbright student may impact research that spans country- and cultural-specific 
boundaries, participate in international conferences, and help create new global academic communities (Hayden, \& Thompson, 2008). Whether their campuses are employing an "import" or "infusion" model in their internationalization practices, they will also need to address the differences in teaching and learning practices across cultures and develop more inclusive practices (De Vita, 2007; Edwards, Crosling, Tetrovic-Lazarovic, \& O’Neill, 2003; Grayson, 2008; Ibrahim \& Penfield, 2007). International students in particular often require special language supports (Wu, 2006). Across the field of international education it is widely recognized that more attention is required to the management of entire curricular and cocurricular learning experience in order to ensure that the transformational development can be fully realized (Braskamp, 2010; Gray, Murdock, \& Stebbins, 2002; Belenky \& Nokes, 2008; Green, 2008; VandeBerg, 2007). This dissertation seeks to understand the relationship between cultural competency and leadership in such a way as to influence the research on the themes outlined above.

\section{The Fulbright Program}

Research conducted about the Fulbright Program, especially the international student program, is varied and often limited to the mention of being conducted while on a Fulbright-funded period abroad (there are thousands of studies to cite and few that are germane to this study). McWhirter \& McWhirter (2010) composed a comprehensive field guide for counseling psychologists to catalogue the types of placement and possible research when on a Fulbright Program in counseling psychology. They note that the alumni of the Fulbright experience report continued involvement in international issues. 
Tokorozawa (1996) surveyed 3,013 Japanese Fulbright students and scholars from 1949 to 1989 and interviewed a small number of the respondents. She sought to understand the role the Fulbright scholarship period had on participants' personal and professional lives and what impact theses Fulbright alumni have on post-World War II Japan. Strategic elite and leadership trait theory were used to analyze the data. The Fulbright alumni hold very elite positions in Japanese society, which was heavily influenced by gender (more men than women in the sample), and this is consistent with the traditional (elitist) Japanese form of creating international leaders who are male. The survey results did not indicate that the Fulbright year had a significant impact on the participants' personal or professional lives. However, the qualitative data indicated that the Fulbright experience was meaningful. These two studies lend promise to the possibility of finding a relationship between intercultural competence and leadership styles in the measurements of Fulbright students.

Taylor (1998) used a mixed method approach (survey followed by focus groups and/or interviews) of 438 U.S. Fulbright scholars from 1995 to 1996 who had returned from their period abroad. She sought to determine the ways the Fulbright alumni changed as a result of their cross-cultural experience and how these changes affected their roles as leaders. Using descriptive statistics for the quantitative survey results, the study determined that the Fulbright scholars were able to adapt to the cultural differences with appropriate supports. The qualitative data found that the participants gained confidence and competence in cross-cultural engagement. It also found that the 
participants changed their organizational leadership styles by shifting their situational decision-making processes (Gruning, 1971) to accommodate their contexts and as a result were more willing to take on complex leadership roles. This finding indicates a growing of flexibility in leadership style as a result of intercultural engagement and a possible embracing of complex leadership roles as a result. Taylor builds her findings on the IA model of Mendenhall and Oddou (1985). Her research could be considered a precursor this dissertation, linking both the IA model and connective leadership as an indicator that the psychometric assessment of leadership styles and intercultural effectiveness could provide more insight into this construct.

The most comprehensive study of the Fulbright International Student Program is by Snow (1992). In this mixed method study, 290 Fulbright international graduate students were surveyed, and several were interviewed to determine their ability to be cultural mediators between their home and host (U.S.) cultures and the variable that contributed to this competency. The survey instrument used was the precursor to the Intercultural Development Inventory, with Mitchell Hammer (Hammer \& Bennett, 2001a) serving as doctoral advisor. The data supported many of the study's hypotheses, namely that the ability to form intimate relationships (move beyond the impersonal role persona) and the forming of multicultural networks were most valuable in strengthening individuals' abilities as cultural mediators. Knowledge of the home and host culture was positively associated with the cultural mediator role. Finally, in some instances, the preacademic training plus earlier exposure to American culture was beneficial. The 
process and findings of this dissertation study indicate that employing an intercultural competency assessment tool can generate good results in this population. Note that the indicators for becoming a cultural mediator match well to the IA model (Mendenhall \& Oddou, 1985) used in this dissertation. Forming intimate relationships and multicultural networks aligns with the Interpersonal Engagement factors of the model. Learning about their home and host cultures aligns with the Continuous Learning factor of the model. Finally, participating in the preacademic training, like the Gateway Orientation Program that this current dissertation is situated within, supports the Hardiness dimensions of the model.

Summary of international education research. The research conducted on international education that has informed this study clearly demonstrates the value of international education as a means to develop intercultural competence and leadership acumen. However, none of the research specifically addresses the relationship between intercultural competence and leadership behavior or how to assess them. This confluence is the unique contribution to research on international education that this dissertation adds.

\section{Summary of Literature Review}

In summary of the literature review chapter, the theories of intercultural competence, although not unified, are frequently based in contact theory (Allport \& Kramer, 1946; Pettigrew, 2011) and the desire to decrease prejudice. The process used to 
grow intercultural competence is the DMIS (1993), which can be observed using the International Adjustment model (Mendenhall \& Oddou, 1985). Intercultural competence as seen in expatriate adjustment and the DMIS have many antecedents that point to the possibility of increasing levels of intercultural competence with increased exposure to cultural differences. There are tools and methods for assessing intercultural competence, and the IES (Kozai Group, 2009) is an assessment tool for intercultural competencies that is based on the IA model (Mendenhall \& Oddou, 1985) and provides a valid and reliable means to accomplish this task for this study. In the realm of leadership research, leadership has been widely studied and formed into many theoretical schools (Antonakis, et al, 2004), and the school of transformational leadership (Bass, 1985) is most closely related to the model used in this proposal. Emerging issues in global leadership are also highlighted. The connective leadership model (Lipman-Blumen, 1996) provides the overview of the leadership adaptability that this research is based on, and it is accompanied with a valid and reliable assessment tool, the ASI. Finally, the Fulbright International Student Program is representative of higher education's initiatives to grow global-ready graduates through international education to meet the need of increased intercultural competence and leadership skills. By studying intercultural competence and leadership styles simultaneously, this dissertation seeks to find a relationship between these two constructs that can contribute to the Fulbright Program in particular and to fields of international education, higher education, leadership, and intercultural competence more broadly. The research discussed above indicates that there is a 
possibility of finding a relationship between the constructs of intercultural competence and leadership styles and that no previous studies have been completed with these exact constructs or participants. 


\section{Chapter 3: Methodology}

\section{Purpose Statement}

I believe that there is a measurable relationship between intercultural competence and leadership styles. I will analyze data from two assessments, one of intercultural competence and one of leadership styles, to determine whether this relation exists and to what extent.

\section{Research Questions}

There was one primary research question, and there were three secondary research questions:

1. Primary research question: Is there a relationship between intercultural competence and leadership style?

2. Secondary research questions:

(a) What correlations, if any, exist between leadership styles and intercultural competence dimensions?

(b) What correlations, if any exist between leadership style domains and intercultural competence scores?

(c) Do patterns of relationship emerge from analysis of different demographic variables?

\section{Research Design}

This study examined the relationship between the assessment of intercultural competence and the assessment of leadership styles as measured in 108 international (non-U.S.) Fulbright students who participated in the August 2010 orientation program. This was a correlational research study (Wiersma, 2000; Cresswell, 1994; Babbie, 2002). The study sample population selection was intact and not random. All members of the research pool were participants in the 2010 Gateway Fulbright Orientation Program. 
There was no control group for comparing the results of the assessments employed. The data were secondary data or ex post facto data (Wiersma, 2000, p. 158) gathered in August 2010 for a training contract named the "Fulbright Gateway Orientation Program." The data gathering process was single-stage and cross-sectional attained via an online invitation to complete two different psychometric instruments over a two-week period. The assessment tools used to gather the data (the Intercultural Effectiveness Scale [IES] and the Achieving Styles Inventory [ASI]) were chosen because I believed they best matched the training needs of the international Fulbright students, namely the need to adjust to living and studying in the U.S. and the need for a general introduction to leadership. The data from the two psychometric assessments made up the primary correlational data for this study. The enrollment roster demographic data and contexting data gathered in the two psychometric inventories made up the final and secondary data set. The inventory data were analyzed seeking a statistical correlation between the two psychometric inventories, with additional insights from the demographic and contextual data. Because both psychometric instruments were interval parametric Likert-type scales, data analysis was run constructing correlation tables seeking a Pearson's rho $(\rho)$ and Kendall's tau $(\tau)$ correlation coefficients (Wiersma, 2000, p. 334). Regression analysis was used to analyze the relation of the demographic data.

\section{Study Sample and Demographics}

The participants in this study were students attending the Fulbright Gateway Orientation Program that was hosted in August 2010 by Portland State University (PSU). 
One hundred and eight Fulbright students participated in the orientation program; all participants were inbound international non-U.S. citizen students. Students' destination universities were scattered throughout the U.S., with the majority of students to be attending universities in New York and Massachusetts.

Source of demographic data. The demographic data set for this study comes from the registration roster provided by the Fulbright organization and the contexting information embedded in the two psychometric inventories. The registration roster fields are grantee identification number, name, gender, home country, program name, general field of study, objective program of study, Fulbright status, confirmed, student e-mail address, alternative e-mail address, and organization/host institution. The two psychometric inventories both asked for name, e-mail address, age, gender, country of citizenship, race and/or ethnicity, level of education, and field of study. The IES also asked for the number of sojourns outside the home country, lengths of stay outside the home country, age at the time of sojourn, and languages spoken fluently. The ASI asked about marital status, children, work history, fields of work, and mailing address. Many of these data cannot be shared in order to maintain the participants' confidentiality and was not necessary for this study.

Time frame for gathering the data. The Gateway Program was held over a two-week period in August 2010 with two different cohorts, each lasting five days. Cohort A was hosted August 16-20, 2010, and 52 (48\%) of the total participants attended. Cohort B was hosted August 23-27, 2010, and $56(52 \%)$ of the total 
participants attended. The IES and the ASI were offered to Cohort A on August 13, 2010, with an online reminder sent on August 15, 2010; they were offered to Cohort B on August 18, 2010, with an online reminder sent on August 23, 2010.

Gender and level of study statistics. Of the 93 final participants, 54 (58\%) were female and $39(41 \%)$ were male. The majority of the participants $(62$, or $66 \%)$ were getting master's degrees, 17 (18\%) were getting doctorate degrees, and 14 (15\%) were in the U.S. to pursue postgraduate nondegree research interests. Table 1 outlines the participants' general demographics.

Number of psychometric inventories collected. In terms of survey collected, 93 (86\%) of the Fulbright students completed the IES, and $106(98 \%)$ of the participants completed the ASI. Many of the participants were traveling to Portland, OR, at the time the surveys were issued, which accounts for those who did not complete them. The IES platform had technical difficulties, resulting in the lower completion rate compared to the other survey. The participants had another day after arrival in Portland to complete the ASI, and many did so at that time. Table 2 shows the complete breakdown of the surveys collected for this training.

The original population of 108 participants in the Fulbright Gateway Orientation Program was pared down to $93(N)$, or $86 \%$, because only 93 participants took both the IES and the ASI inventories. Eighty six percent is considered a good-to-very-good percentage of the population attending this training to carry out this research endeavor (Babbie, 1999, p. 240; Wiersma, 2000, p.176). Once the population size was established, 
it was decided that the four most appropriate demographic variables for further analysis were gender, level of study, academic area of study, and world region where the participants come from. These variables were chosen because the parameters of what they are and how to group the participants are relatively clear. Other demographic characteristics of the Fulbright population are intriguing, but the data on them were problematic, so they can only be discussed in general terms.

Academic pursuits of the population. The Fulbright students identified 36 different fields of study for the academic pursuits in the US. In order to run regression analysis on this variable these 36 fields were recategorized to the following set of six categories based on the work of the Rockefeller Foundation (Clark, 1987, pp. 39-40) as listed in Table 3 in order of size.

World regions. The participants included in this study came from 41 different countries, which were grouped into the following five world regions based on the work of the Institute for International Education (Bhandari \& Blumenthal, 2011) for statistical analysis. Table 4 lists these world regions in order of size.

Unused demographic data: family status and work experience. There were contextual questions in both psychometric inventories that are not reported and used directly in this study. These include elements on the participants' family status, work history, race and/or ethnicity, languages spoken, and experience outside their home countries. All but one of the Fulbright students in this study were unmarried and had no children. Most of the participants had not worked beyond campus support or entry-level 
service work, and their fields of employment (such as engineering, or education, and so on) were too diffuse to be adequately grouped for statistical analysis.

Race and ethnicity data. Race and/or ethnicity are frequently used as variables when doing diversity studies, as in the research conducted by the American Association for Colleges and University (e.g., Antonio, Chang, Hakuta, Kenny, Levin, \& Milem, 2004; Milem \& Chang, 2005). In this study the ASI questionnaire asked the students to classify themselves using the standard U.S. affirmative action categories (WhiteCaucasian, Hispanic/Latino, African-American, Asian-American, and Native-American). These categories had little meaning to most Fulbright participants from other parts of the world. The IES on the other hand, provided a blank line or window for the participants to write their own interpretation of their race and/or ethnicity. The answers to this question were very diverse, ranging from "none" or even "??" to tribal (Zulu), world region (Mediterranean), country (Korea), native-language (Urdu speaking Pashtu), religion (Catholic), race (Caucasian), and ethnicity (Hispanic). While the breadth of responses seem rich with possibilities for exploration, they were too diffuse to categorize and employ for data analysis.

Language ability. The IES asked the students to identify the languages they knew fluently beyond the conversational level. The breadth and number of languages that this expatiate student population knew fluently is worth noting: $35 \%$ fluency in only one language, $23 \%$ fluency in two languages, $21 \%$ fluency in three languages, $8 \%$ fluency in four languages, 3\% fluency in five languages, and 1\% each report fluency in 
seven and nine languages respectively, (curiously, English is listed by only a handful of them.) The breadth of languages known is also impressive, ranging from common and dominant languages such as English and Chinese (Mandarin) to far less dispersed languages such as Uzbek and Yoruba. However, because the participants were not asked to first identify their native language and then the other languages they knew fluently, the results are muddled; approximately $25 \%$ did not identify English as a language they knew, even though the survey instrument is in English and they had recently been admitted to a U.S. institution of higher education and had to submit passing level scores on the Test of English as a Foreign Language (TOEFL) exam in order to earn their admission. Because of the confusion over fluency in English and the sheer breadth of the languages that the Fulbright students were fluent in, no statistical analysis was conducted on language ability and intercultural competence or leadership styles. Conversely, this wealth of language ability will be valuable in interpreting the participants' overall intercultural competency and leadership style scores in general.

Experience outside the home country. Finally, the IES contexting questions included four questions on the participants' experience being out of their home countries. Nearly half (48\%) reported that they had been outside of their home country at least once before their Fulbright experience. Of these, 33\% reported that this experience came before their college years. Many (20\%) reported that they had been to one other country prior to 2010, while a handful (10\%) reported visiting three-to-five countries before 2010 . The length of time outside their home countries is also impressive: $10 \%$ reported being 
abroad for between one month and one year, with three-to-six months being the most common length of sojourn. Five participants reported being abroad for between two and four years, four report the sojourn was for a length of six-to-nine years, two were away for eighteen years and one was abroad for 26 years. The countries they visited, studied, or lived in was also quite diverse. It is not possible to analyze the breadth and depth of the expatriate sojourn data above because there were such large ranges of responses to each of the questions that the responses cannot be combined in a meaningful or statistically significant way. But these data can be generalized to point to the high level of international experience the Fulbright students could draw upon for intercultural engagement prior to their 2010 start in their programs of study.

\section{Confidentiality}

The participants' names and other identifying information are kept confidential. This research is based entirely on secondary data or ex post facto data (Wiersma, 2000, p. 158) that was collected for the purpose of conducting the Fulbright Orientation Training

program. A waiver from full human subjects review paperwork was filed for and granted by the PSU Office of Graduate Studies. The participants in the Fulbright Gateway Orientation Program have not been notified that their data are being used for further study, as the data had already been gathered to prepare their orientation training program. There was no clear means to track and notify the students two years after their initial orientation program to ask for consent or follow-up interviews or to report the research 
findings. A copy of the dissertation will be presented to the Fulbright International Student office upon completion.

\section{Instruments}

The two psychometric inventories (the IES and the ASI) employed in this study are interval and parametric Likert scale instruments (Wiesrma, 2000, p. 296).

Participants ranked their responses to statements in a hierarchical ordering, and the instruments calculate scores based on a mathematical algorithm that predicts the level of competency or behavior each participant possessed. In this type of instrument a score of four is twice as high as a score of two. Both instruments have gone through extensive statistical testing for reliability and validity, which will be discussed later in this chapter. It is important to note that because these are statistically normed psychometric instruments, the median score will be the middle score of the Likert scale on which they are based ( 2.5 on the 5 -point scale for example); this bell-curve statistic will prove important in interpreting the inventories' results in Chapter 4. This type of correlational inquiry is possible even when the instruments employed are not entirely identical (Van de Vijver \& Tanzer, 2004) through the use of item response theory (Hambleton \& Swaiminathon, 1985, Hambleton, Swaiminathon, \& Rogers, 1991). Both instruments also gathered contextual or demographic data, which was discussed earlier in this chapter.

Intercultural Effectiveness Scale. The IES (Mendenhall, Stevens, Bird, \& Oddou, 2008) serves as the assessment tool for intercultural competence in this study. It 
is a psychometric inventory designed to assess how the participants get along with people whose cultural backgrounds differs from their own. It is recommended for use in programs in which students are on a short-term sojourn. It is split into three primary factors, each having two intercultural competencies. The first dimension, Continuous Learning, looks at how participants learn about another culture and the accuracy of that learning. The second factor, Interpersonal Engagement, looks at how participants develop and manage relationships with people from other cultures. The third factor, Hardiness, looks at how participants manage the challenges and stress involved in interacting with cultural differences. Figure 4 illustrates how this model seeks to find effectiveness in intercultural engagement.

The IES is a 52 -item or statement self-report psychometric inventory that measures a participant's effectiveness in engaging people who are culturally different from themselves. Participants rank their responses to the statements on a five-point Likert-type scale: $1=$ strongly agree, $2=$ agree, $3=$ neither, $4=$ disagree, and $5=$ strongly disagree. The inventory can be taken on paper or online. The Fulbright students were traveling to the orientation at the time of the assessments, so the online version was used. The IES could be taken in English or Japanese, but only English was used, as the Fulbright participants are required to be fluent in English to pursue graduate studies in the U.S. See Appendix A for a copy of the IES questionnaire. The participants' responses are scored automatically, and the results are available in the form of an 18-page PDF report. The administrators of the IES, in this case the researcher and his training partner, 
can access both the participants' individual reports and a composite report of all of their scores.

The participants' answers are compared to the answers of the other respondents to the IES over the years of development and ranked by a relative normed standing or percentile on a six-point scale with levels of low (scores 1-2), moderate (scores 3-4), and high (scores 5-6). At the time of this assessment, there were approximately 5,000 past participants providing the norming responses in the pool. These previous respondents represent a wide range of ages, educational attainment, race and ethnicities, and countries of origin. They are split almost evenly between men and women. The IES has gone through rigorous reliability and validity testing over the four iterations. Statistical analysis has been conducted to determine content validity, criterion-related validity, convergent/divergent validity, differential validity, and face validity (Mendenhall, et al., 2008). The scores on these tests prove that the IES is reliable for predicting the effectiveness of the participants' experience in intercultural encounters. The reliability scores for each of the subcategories or competencies in the IES all fall in the .72-.85 range (Mendenhall, et al, 2008). As an interval parametric Likert scale instrument with a 5,000-case-study norming pool and extensive statistical testing behind it, it is normed for the middle score ( 3 for the IES) and that scores over 3 are considered above average. This will be an important point to consider when the results of the instrument are reported in Chapter 4. 
INTERCULTURAL COMPETENCE AND LEADERSHIP STYLES

Descriptions of the IES factors and competencies. Following are descriptions of the three IES factors and six competencies.

Continuous Learning. Continuous Learning is defined as the degree to which the participant engages the world around him or her by continually seeking to understand it. It influences participants' intercultural success by motivating them to learn about why people in other cultures behave and think the way they do. People who strive to learn new things are more successful at living and working with people from other cultures than those who are comfortable with only what they already know. Continuous Learning has two intercultural competencies: self-awareness and exploration. Self-awareness looks at how aware the participant is of his or her personal values, interpersonal style, personal strengths, and weaknesses. It also looks at the degree to which participants reflect on this knowledge while engaging in personal development and learning activities. Exploration is the participants' openness to understanding ideas, values, norms, situations, and behaviors that are different from their own. It examines their fundamental inquisitiveness, curiosity, and inner desire to learn new things, as well as their willingness to seek out new experiences that can provoke learning or a change in perspective. Finally, it focuses on their ability to learn from mistakes and make adjustments to their personal strategies to ensure success in what they do.

Interpersonal Engagement. The Interpersonal Engagement factor assesses participants' interest in other cultures and the importance of developing relationships with people from other cultures in general. The development of positive interpersonal 
relations is essential for effective performance in an intercultural environment. It is split into two intercultural competencies: global mindset and relationship interest. Global mindset is the degree to which participants are interested in - and actively seek to learn about - other cultures and the people in them. It also looks at the degree to which they seek out such learning by their own choice to expand their global knowledge about people and their cultures. Relationship interest is the extent to which the participant initiates and maintains relationships with people from other cultures. It looks at whether the participant finds engaging others as an energy-producing versus an energy-depleting activity. Finally, it looks at the participant's willingness to use a foreign language in developing new relationships.

Hardiness. The final factor, Hardiness, is the participant's ability to manage his or her thoughts and emotions in intercultural situations, along with the ability to be openminded and nonjudgmental about ideas and behaviors. It looks at the participant's tendency to remain calm when encountering situations, people, behavior, and ideas different from what he or she is used to. Finally, it looks at the participant's ability to manage emotions constructively and learn from failures and setbacks. Hardiness is split into two intercultural competencies: positive regard and emotional resilience. Positive regard is the participant's ability to assume the best about people and be more accepting of different behaviors as well as avoiding negative stereotypes about other cultures or people. Resilience is the participant's ability to manage emotional strength and cope with challenging emotional experiences and the capacity to recover quickly from 
psychologically and emotionally challenging situations. Figure 5 illustrates the dimensions and sub-dimensions in this model.

Leadership: L-BL Achieving Styles Inventory. The L-BL ASI serves as the assessment tool for leadership styles in this study because the primary purpose of the study is to uncover the effect of intercultural competence on leadership style through correlational statistical analysis. Like the IES model, the ASI has three primary categories, in this case of achieving styles, with a set of three subcategories of each of the primary categories. The primary categories are direct leadership styles, employed by participants who want to master their own tasks when presented with a challenge; instrumental leadership styles, employed by people who reach out and include others when presented with a task or challenge; and relational leadership styles, employed by those who prefer to work on group tasks and challenges. Figure 6 illustrates the ASI model.

The ASI is a 45-item self-report psychometric inventory that measures a participant's preferred use of nine leadership styles; the nine styles constitute the participant's connective leadership profile. Participants rank their responses to the statements on a seven-point Likert-type scale ranging from $1=$ never to $7=$ always. The inventory is administered online only and can be taken in English, Finnish, Bulgarian, or Japanese, but only English was used for this study. See Appendix B for a copy of the ASI questionnaire. The participants' responses are scored automatically, and the results are available in the form of an approximately four-to-six-page PDF report. The 
administrator of the ASI, in this case the researcher alone, can access both the participants' individual reports and a composite report of all of their scores. The participants can choose to have their individual reports withheld as private in the ASI system; nine (7\%) did so.

Like the IES, the ASI is an interval parametric inventory. The participants' answers are compared to those of other respondents to the ASI over the years of development and ranked by a relative normed percentile on a seven-point scale and then mapped onto a spider-web-type chart. At the time of this report, there were approximately 22,000 past participants providing the norming responses in the current pool, with more than 50,000 cases having been taken in total over the span of the ASI's development. Confirmatory factor analyses (both forced and discriminate) have been conducted on previous respondents, representing a wide range of ages, educational attainment, race and ethnicities, and country of origin. The database is split almost evenly between men and women. The ASI has undergone rigorous reliability, validity, and predictability testing over the four iterations. Statistical analysis was conducted to determine content validity, criterion-related validity, convergent/divergent validity, differential validity, and face validity on 22,940 of the recorded cases. The scores on these tests prove that the ASI is reliable for predicting the participants' preferred leadership styles. The Cronbach's alpha reliability scores for each of the subcategories or competencies in the ASI all fall in the .82-.92 range (Lipman-Blumen, 2006). 
INTERCULTURAL COMPETENCE AND LEADERSHIP STYLES

Description of the ASI sets and leadership styles. Following are descriptions of the ASI sets and leadership styles.

Direct set. With the direct set of behavioral styles, people prefer to master their tasks head-on and alone. They like to master a task, outperform others and take charge of situations. These are the individualists of the leadership pool. This set has three leadership styles: intrinsic, competitive, and power. Those who prefer intrinsic achievement like to set a standard and meet it. Doing their best work is often their source of satisfaction. If competitive is a person's preferred achieving style, he or she likes to win against an opponent or get a score that surpasses a benchmark. If there is no competition in a task, this person tends to invent one. People who prefer power like to organize everyone and everything. They frequently delegate tasks but maintain control of the end result.

Instrumental set. In the instrumental set is what Lipman-Blumen (1996) calls “denatured Machiavellianism” (p. 193), because these people engage others in accomplishing tasks, but for the greater good and not for some evil intent as Machiavelli did. These are the bridge-builders between the individualists and collectivists of the leadership pool. There are three styles to the instrumental set: personal, social, and entrusting. People who use the personal achieving style use their wit and charm to persuade others to follow their lead. They enjoy public speaking and have a flair for dramatic gestures. Those who prefer the social behavioral style like to know who they need to find to get every task accomplished. They are networkers and thrive in 
environments with the need for social contacts. For the entrusting style, these people like to empower others by delegating tasks to them and offering little supervision. They believe in their followers and work to support the followers in moving forward in their work.

Relational set. Finally, with the relational set, we have people who prefer to join with or even work through others to accomplish their tasks. These are the collectivists of the leadership pool. There are three styles in this set: collaborative, contributory, and vicarious. Those who prefer to achieve using collaboration prefer to pull together coalitions of people and groups and join the efforts together to achieve a task. For the contributory style, these people like to join other groups and support them in achieving their tasks, often with little need to have a direct stake in the outcome. Finally, those who prefer the vicarious achieving style are the mentors of the leadership pool. They like to help others in their work and careers and do not expect to be present or even know if the people they help achieve their goals.

\section{Bias}

Construct, method, and item bias (Van de Vijver \& Tanzer, 2004) are controlled by using two well-established psychometric inventories (IES, ASI) that have been put through rigorous statistical testing. The contexting data collected by the two psychometric inventories may have both construct and item biases in the items in terms of languages spoken. These items may be excluded from the final data analysis if they 
prove problematic; their exclusion would not dissipate the impact of the other questions on the inventories. In the case of this study, contexting questions on marriage, family, work, race/ethnicity, language ability, and out-of-country experience were all excluded due to being (a) unimportant to the study; (b) insignificant in terms of the numbers of respondents; or (c) unclearly worded, leading to muddled data.

\section{Conceptual Framework}

Figure 7 offers a graphic explanation of the conceptual model and relational data sets of this study.

\section{Data Sets}

The data sets of this study are outlined in Table 5 and are matched to the corresponding research questions.

\section{Data Analysis}

There were four steps to the data analysis phase of the study. Wiersma (2000), Babbie (1999), and Field (2009) recommended these steps as both thorough and adequate to analyze the data for this study.

Step 1. Gathered all data from the IES and ASI databases and combined it with the registration demographic data. This step matched all responses by individual participants and made note of those who had not completed either or both of the psychometric instruments. Lack of participation has already been noted, but completion rates are between $86 \%$ and $98 \%$. However, with the IES participation at 93 people, this 
was the final $\boldsymbol{N}$ of this study, so that all participants' data were evenly matched ASI-toIES.

Step 2. Used univariate analysis (Babbie, 2002, p. 349) to describe the general statistical patterns that were recorded from the participants' responses to the IES and the ASI. I split the data for each of the inventories into subgroups indicated by the demographic data and again looked for statistically significant patterns.

Step 3. Used bivariate analysis (Babbie, 2002, p. 358) to construct a correlation matrix of the data from the two inventories' data sets for the primary research question and Secondary Research Question 2(a). Then both Pearson's rho ( $\rho)$ and Kendall's tau $(\tau)$ correlation coefficients (Wiersma, 2000, p. 334) were run to seek a correlation between the IES data and the ASI data to find the clearest perspective on the possible relationships in this study. Pearson's rho is the common calculation to determine the prevalence of a statistical correlation (Field, 2009) and was used here, with the Greek symbol $\rho$ used before the statistical score and $p$ to depict the size or significance statistic. Kendall's tau, with the Greek $\tau$ symbol was also employed in this study and is likened to the use of corrective lenses and the use of a bifocal lens to see the details of the data. This use of two correlation coefficients is recommended for studies in which there are several elements with ranked scores that are similar, like the psychometric inventories used in this study (Field, 2009, p.181).

Step 4. Used multivariate analysis (Babbie, 2002, p. 363) to factor in the variables with any possible correlation data between ASI access and success score and 
the ASI/IES correlations. Then ran a regression analysis on the demographic data, ASI scores, and IES scores to answer the remaining questions. This is adding a third dimension variable $(Z)$ to an $\mathrm{X}-\mathrm{Y}$ axis, and asking a series of "what if" questions. In this case, the primary relationship mapped on the $\mathrm{X}-\mathrm{Y}$ axis is the correlation between the intercultural competence and leadership styles scores. The "what if" questions are generated by the demographic data mapped on the Z-axis. For example, we are asking the correlation data, "what if we considered differences in gender?" to see whether the relationship shifts in any significant way.

\section{Delimitations and Limitations of the Study}

This study is based on secondary data or ex post facto data (Wiersma, 2000, p. 158), and was confined to the data gathered in August 2010 for the Fulbright Gateway Orientation Program. There were no plans to add to the study through follow-up interviews or gathering additional corroborative data.

Limitations. The limitations of this study were significant and need to be viewed as clearly as possible. Whereas none of the limitations was considered significant enough to halt the progress of the study, many of them do limit the generalizability or replicability of the study.

Size. The size of this study limits the generalizability of findings. The final $N$ of the study sample in this dissertation was 93 inbound (non-U.S. citizen) Fulbright students. In 2010, the year these data were gathered, 1,100 incoming international students were brought to the U.S. by the Fulbright organization (2011). This means that 
only $8 \%$ of the inbound Fulbright population participated in the study, and this would not be considered an appropriate proportion of the overall population to make a broad generalization of other cohorts of Fulbright students (Babbie, 1999; Wiersma, 2000). From the perspective of all inbound international students to the U.S. in the year 2010, there were 680,923 (IIE, 2010) and the $N$ of 93 shrinks to an even less significant percentage.

Uniqueness. The study sample employed in this research was highly unique in many ways and makes generalizability to other populations problematic. The Fulbright students, as inbound international students coming to the U.S., are unique in that they competed for and won an elite scholarship (the Fulbright awards), they were all studying at the graduate or postgraduate levels, they came from so many different countries, and they were studying in so many different fields. There are no comprehensive statistics on scholarship awards for incoming international students. However, there are few scholarship programs with the longevity, reach, and prestige of the Fulbright Program. So the study sample on this study was unique due to the elite nature of the Fulbright Program.

If the population was coming from only one country, or clustered in only a few countries or world regions, the findings may have been generalizable to those particular countries or world regions. But this Fulbright cohort, and Fulbright cohorts in general, were made up of many countries and world regions, making it complex to gather enough data on any one region or country. This is also the case in terms of areas of study, as the 
Fulbright Program mixed the cohorts for breadth of fields and not commonality. Again, this made it difficult to gather enough data on any one grouping in order to generalize the findings across such characteristics.

Language of the psychometric inventories. The psychometric inventories employed in this study were administered in English only. At the time of the data gathering, there were very few additional languages that either of the instruments had been translated into, not enough to meet the diverse language needs of the Fulbright participants to take the assessments in their native languages. Research has shown that the language of assessments and even instruction have a deep and direct impact on the ability of the learner to fully cognitively participate and succeed in the learning (Pappamihiel \& Walser, 2009). However, as the data collection process began as a training contract, and the client (PSU, International Studies Dept.) acknowledged that $95 \%$ of the participants had taken and passed the TOEFL exam to be admitted to graduate school in the U.S. (two were native English speakers), it was determined that administering assessments in English was appropriate. PSU, as an example, requires international inbound graduate students to achieve TOEFL scores of 80 overall in the Internet version, 550 in the paper version, and 213 on the computer-based version. This pragmatic decision does not mitigate the possible difficulty that the Fulbright students may have experienced in completing the IES and ASI; it makes explicit only the assumption of English language fluency for the purpose of this work. 
Correlation versus predictive model. This study was conducted using a correlational statistical model rather than a predictive model. So it finds the prevalence of certain intercultural competencies present when certain types of leadership styles are enacted. For example, this type of mutual relationship exists between the practices of the Mediterranean diet correlated to a reduced prevalence of heart disease (Jenkins, 2009, p. 470). The diet does not predict or directly cause a healthier heart; it simply creates a complementary condition for a human heart to thrive. A very different form of study would have been required in order to state that the ability to employ one or more intercultural competencies might predict the enactment of one or more leadership styles. This was an intentional epistemological and methodological choice in that a predictive type of outcome would have required a much larger $N$ and a more broadly representational set of sample populations, plus the time and resources for repeat measures to ensure the findings are replicable.

Empirical versus mix-method methodology. For the findings of this study to be easily adaptable in the personal and professional development fields, some qualitative data would have needed to be employed to help the practitioner find evidence on why and how these correlations are present so others can benefit from the measures. Again, this was a conscious epistemological choice for this research, given that the data being considered were two years old at the time of the analysis and the participants were not easily tracked after they attended the orientation program in August 2010. The addition of a performance measurement could have enriched the findings greatly as well. An 
example of a performance measurement would have been a scoring of a participant work sample (case study or essay) using a rubric such as the Intercultural Knowledge and Competency Meta-Rubric from the Association of American Colleges and Universities, (Rhodes, 2010) so that there was something other than student self-report data to triangulate the findings. The lack of qualitative data will leave those with a preference for a more narrative form of results wanting a more contextual explanation of the findings (Cresswell, 1994; Onwuegbuzie, 2002).

Cultural frameworks and comparative studies. Lipman-Blumen asserts that the connective leadership model correlates to the collectivist/individualist cultural framework (Hofstede, 1984, 2001; Chhokar, et. al, 2007). This could not be fully explored with the data and methods from this study. A study clearly directed to unearthing this possible linkage could be conducted with different instrumentation and access to larger pools of international participants and would be intriguing.

IES versus the GCI. Using IES instead of the more sophisticated Global Competency Inventory (GCI) (Kozai Group, 2004) also is a limitation. The GCI is based on the same model but offers far more granularity of data (16 competencies) with which to compare and contrast the ASI. Moreover, it is specifically designed to assess people who will be living and working in leadership roles abroad, which would be more appropriate for the Fulbright students, because they are expatriates from their countries while studying in the U.S. and assuming leadership roles on their new campuses. However, the GCI requires an hour to complete online and usually more than one hour to 
INTERCULTURAL COMPETENCE AND LEADERSHIP STYLES

interpret, which was not possible during the Fulbright Gateway Orientation program. Also, the focus of the training in which the IES was employed was an adaptation to avoid culture shock. For this purpose, the IES is a good choice. There are enough data in the participant reports to make the learners aware of their strengths and challenges in adapting to new cultures to support their transition to graduate studies in the U.S. without overwhelming them with an in-depth personal and professions global leadership coaching framework.

\section{Summary of Methods}

In conclusion, in order to address the problem of not knowing the role of culture on leadership, I asserted that by assessing both intercultural competence and leadership styles for the international Fulbright students, it may be possible to find a correlative relationship between the two measures. With these data, it may be possible to note a correlation between intercultural competencies on connective leadership, and thus better inform potential leaders and leadership educators of the importance of considering intercultural competence when preparing leaders for the connective era, in which interdependence and diversity require leaders be inclusive and seek connection across cultures and contexts. 


\section{Chapter 4: Results}

This chapter presents the results and statistical analysis of the surveys completed by the Fulbright students. These results point to a new perspective on ways intercultural competence and leadership styles are related within the research sample. The chapter begins with a review of the purpose and research questions and a brief overview of the process by which this analysis was conducted, then moves to the full results of the Intercultural Effectiveness Scale (IES) and Achieving Styles Inventory (ASI) respectively, followed by correlational and regression results linked to the research questions. The chapter concludes with a brief summary.

\section{Statement of the Problem}

Purpose statement. I believe that there may be a measurable relationship between intercultural competence and leadership styles. I analyzed data from two assessments, one of intercultural competence and one of leadership styles, to determine whether this relationship exists.

\section{Research Questions}

1. Primary research question: Is there a relationship between intercultural competence and leadership style?

2. Secondary research questions:

(a) What correlations, if any, exist between leadership styles and intercultural competence dimensions?

(b) What correlations, if any exist between leadership style domains and intercultural competence scores?

(c) Do patterns of relationship emerge from analysis of different demographic variables? 


\section{Data Analysis Process}

All the data used in this study were analyzed using version 18 of IBM's SPSS

software package. The statistical results of this study were analyzed using correlational methods to determine whether there is a complementary or reciprocal relationship between the measures of Intercultural competence and leadership Styles. There were four steps to the data analysis phase of the study.

Step 1. All data from the IES and IES databases were gathered, combined with the registration and contexting data, and loaded into SPSS. A final $N$ of 93 participants with evenly matched ASI-to-IES.

Step 2. Univariate analysis (Babbie, 2002, p. 349) was used to describe the general statistical patterns that are recorded from the participants' responses to the IES and the ASI. The data were split for each of the inventories into subgroups indicated by the demographic and contexting data; these included gender, world region, area of study, and level of study. I again searched for statistically significant patterns within each of these demographic groupings.

Step 3. Bivariate analysis (Babbie, 2002, p. 358) was used to construct a correlation matrix of the data from the two inventories' data sets for the primary research question and secondary Research Question 2a above. Both Pearson's rho ( $\rho)$ and Kendall's tau $(\tau)$ correlation coefficients (Wiersma, 2000, p. 334) were run to seek a correlation between the IES data and the ASI data. Pearson's rho is the common statistical correlation coefficient (Field, 2009) with the Greek symbol $\rho$ used before the 
statistical score and $p$ to depict the size or significance statistic. A Pearson's $\rho$ score of .30 is considered a moderate correlation, .40 is considered moderately high, and a score of .50 and above is considered high (Field, 2009, p.173). With the significance score, $\mathrm{p} \leq$ .01 is considered a moderately significant score, and $\mathrm{p} \leq .001$ is considered a high level of significance (Field, 2009, p. 193). Kendall's tau, with the Greek $\tau$ symbol, was also employed in this study. With Kendall's $\tau$, a statistical score of .02 is considered moderately correlated, and a score of .03 is considered highly correlated (p. 182). The significance scores $(p)$ are the same as for the Pearson's $\rho$.

Step 4. Multivariate analysis (Babbie, 2002, p. 363) was used to factor in the variables with any possible correlation data between ASI access and success score and the ASI/IES correlations. Finally, a regression analysis was run on the demographic and contexting data, ASI scores, and IES scores to answer the Secondary Research Questions 2(b) and 2(c). Demographic and contextual factors (gender, level of study, field of study, and world region) were cross-referenced using simple linear regression analysis. Significance in a regression is determined by low $p$ figures - the closer to $.000(p<.05)$, the better (Field, 2009, p.209).

\section{IES Results}

The IES is an instrument that measures the participants' effectiveness or competency in engaging interculturally different people. A full table of IES is available in Appendix C. Table 6 is a composite of the total scores. 
Generally, the results of the IES demonstrate a relatively high level of intercultural competence: average score of 3.76 out of 5 , with the range of scores between 1 and 5 and a majority of the participants (55\%) scoring in the high level (total scores in the 4-5 range). Again, the IES, as a normed psychometric inventory of intercultural effectiveness, rates the competencies of the study's participants' against the competencies of the approximately 5,000 people in the norming pool at the time of this data-gathering. This means that because the 5,000 people in the database in August 2010 score on a normal bell curve distribution, that a score more than the median score of 2.5 out of 5 would be considered better than average. Because the IES is both a valid and reliable instrument for predicting these competencies (Mendenhall, Stevens, Bird, Oddou, 2011), the majority of the Fulbright students are unique and even better prepared for intercultural effectiveness than a typical group of individuals. These results can be explained in part by the results of the contexting data reported earlier, in which a significant proportion ( $48 \%$ ) have traveled, lived, or studied abroad previous to the start of their Fulbright Program. Another explanation could be their advanced mastery of multiple languages. Although their Test of English as a Foreign Language scores are not available for analysis, it is safe to assume that those who were required to take the language exam for English language proficiency had high scores. This level of mastery would be required to be admitted into graduate-level programs in the U.S. and to qualify for the U.S. inbound Fulbright Program, in which high levels of fluency are expected and screened for. Recent research by Keeley (2012) correlates higher levels of intercultural 
competence to higher levels of fluency in new languages. But there is clearly something unique about this population in terms of intercultural competence that continues with the analysis of their leadership style scores.

\section{Leadership: ASI Results}

The ASI measures the participants' preference and level of commitment for employing particular leadership styles when tasked to accomplish responsibilities. Of the Fulbright students included in this study, the average score on the ASI is 4.74 out of 7 , with the range of scores being from 0.87 to 7 . In this study sample of Fulbright students, $86 \%$ demonstrated access and success (scores $\geq 5$ ) to multiple leadership styles in general. Again, the ASI is a normed psychometric inventory, and so the average score is 3.5 out of 7. Like the IES, the ASI is a relative measure inventory, meaning the study's participants' scores are compared against the approximately 26,000 case studies in the database in August of 2010. Because the ASI norming population has a normal bellcurve of distribution, and because it is both valid and reliable in its measurements (Lipman-Blumen, 2006), it follows that having a majority of the study sample with high scores indicates an above-average access to and success with multiple leadership styles. The Complete ASI results are in Appendix D. Table 7 is a composite of the scores by dimension.

Access and success measure; the ideal connective leadership profile. One way to look at the ASI results is to consider the ideal in the connective leadership model 
(Lipman-Blumen, 1996). This model is built on the concept that having access to and success in each of the three leadership domains (direct, instrumental, and relational) can support a leader to be an effective leader in the 21 st century (Lipman-Blumen, 2006). A metaphor for this ideal might be a three-legged stool that is placed on the floor with concentric circles painted on it, with each leg placed on a different domain (direct, instrumental, and relational) and the circles representing the ASI scores within each domain. Figure 8 illustrates the concentric circles in this model.

If the legs are too close together, the stool will be unable to stand or will easily tip over (scores $4<$ ). However, the broader the base (meaning the farther apart the legs), the more stable the stool becomes (scores $\geq 4$ ). Similarly, if a potential leader does not have access to at least one leadership style in each domain (scores $\geq 4$ ), then the leader will have difficulty leading in complex situations with diverse followers and constituents. If the leader lacks in only one dimension, then the stool would have a short or weak leg in that one arena and would cause a lack of access or reach in dealing with diverse followers with needs supported within that domain. For example, if a potential leader is presented with a task that requires that he or she reach out and engage a diverse spectrum of new people and talents to achieve success with that task, but his or her scores in the instrumental domain, where social engagement is essential, are weak $(4 \leq)$, then that potential leader may fail in this task.

An assumption that contributed to the genesis of this dissertation is that access and success with multiple leadership styles might be correlated to intercultural 
competence. To test this assumption, a dummy variable was created and took into account all leadership inventory (ASI) respondents who had this set of access and success scores $(\geq 4)$ in at least one leadership style in the three ASI domains (direct, instrumental, and relational). First the dummy variable for access and success score was calculated by taking the average of leadership style scores in each leadership styles domain (direct, instrumental, and relational) and seeking candidates with an average score of at least 4 in each of the three domains. The IES total score was used as the dependent variable. The independent variable in the regressions were this ASI dummy variable for access and success score along with the demographic elements (gender, level of study, world region, and field of study), which were pulled in as the dummy variables. The comparator variables that the regressions were controlled for were: (a) male gender, (b) nondegree research level of study, (c) Sub-Saharan Africa world region, and (d) arts field of study. The results of the regressions found the access and success variable to be insignificant across the board ( $p=$ between .138 and .457$)$. However, this analysis did determine that a majority (57 participants or $61 \%$ of $N$ ) of the Fulbright participants in the study do have this access and success type of score. So although this measure did not prove significant in terms of the leadership/intercultural correlation, it does demonstrate the preponderance of leadership styles as measured by the dummy variable access and success within this set of Fulbright students. This means that a majority of the Fulbright students in this study match the ideal in the connective leadership model (Lipman-Blumen, 1996). The only plausible explanation for such a broad pool of participants with this level of ideal 
connective leadership scores is the vetting process employed by the worldwide Fulbright organization in searching and screening potential applicants. This vetting process was not the direct purview of this dissertation, as it is both qualitative in nature and widely dispersed among the country-specific Fulbright organizations, the main international offices in the U.S., and, finally, their host academic institutions. But the correlation of access and success score data and the results of the Fulbright vetting process may be an intriguing study in the future.

\section{Primary Research Question Results}

For the overall research question on whether there is a measurable relationship between intercultural competence and leadership style, this study finds a partial or moderate correlation between intercultural competence and leadership styles. Again, both Pearson's $\rho$ and Kendall's $t$ were computed to determine the level and significance of this correlation.

Correlation of all IES factors and all ASI dimensions. The overall IES/ASI total Pearson's $\rho$ of $.312, p=.003$ is a moderate correlation. The IES Continuous Learning factor coefficients when correlated with the ASI dimensions and ASI total scores can be seen in row 2 of Table 8 and are significant. When the IES Continuous Learning scores are correlated to the ASI instrumental and relational scores, the results are $\rho$ of $.306, p=.001$ and $\rho$ of $.339, p=.003$, respectively, which are moderate correlations. When IES Continuous Learning factor is correlated to ASI total score, the 
correlation coefficient $\rho=.433, p=.001$, which is moderately high. Table 8 is the results of Pearson's $\rho$ correlation computations.

\section{Correlation of IES Continuous Learning factor and competencies with ASI} direct dimension and leadership styles. To better understand the correlations in Table 8, the next step was to look at the IES competency level and the ASI dimensions and leadership Styles within each dimension. The IES Continuous Learning factor is made up of two competencies: self-awareness and exploration. When these competencies, with the Continuous Learning factor scores, are correlated to the ASI dimensions and leadership styles, a relatively strong pattern of correlation emerges. Tables 9-12 flip the axis used earlier to make more room for most of the ASI dimensions and leadership styles for a comprehensive perspective on this phenomenon.

The exploration competency correlation coefficients above demonstrate the moderate strength across these competencies in the direct set of leadership styles. The self-awareness competency also shows relative strength when correlated to the power leadership styles. An explanation of this finding is that the Fulbright students are very inquisitive; they are motivated to learn in general and especially about differences. The leadership styles in the direct set on the ASI are those used by people who take charge of their tasks and take pride in completing them well. The intrinsic style in this case has to do with having high standards for their own work and being motivated to match or exceed these standards. This would explain their academic achievements and drive to complete graduate degrees in the U.S. at dominantly elite universities with a prestigious 
scholarship award such as the Fulbright award. It also explains their ability to complete and manage the rigorous three-step screening process for earning a Fulbright scholarship. The self-awareness competency has to do with knowing their own values and cultural preferences at a deep level, so they have a firm foundation of self-knowledge on which to learn about the differences they encounter. This, combined with the power leadership style, is an example of being able to take charge of their learning about differences based on the strength of their own strong foundation of self-identity and self-efficacy. All the correlations above can also be explained by the students' drive to master multiple languages to achieve their goals and the complex linguistic and cultural learning that would be required in such an endeavor.

\section{Correlation of IES Continuous Learning factor and competencies with ASI}

instrumental dimension and leadership style. Table 10 examines the ASI instrumental set as a means of understanding the IES continuous learning corelationship.

Within the instrumental set of the ASI, only the social leadership style showed a moderate correlation coefficient and only with the self-awareness IES competency. In general, leadership styles in the instrumental domain are those that actively engage people in accomplishing tasks. The social leadership style in particular focuses on networking to bring people into the work at hand. In the case of the Fulbright students, they would have had to know themselves and their own capacity well enough to actively engage a diverse spectrum of people at each of the three levels of their screening process. They would have needed to solicit support from their countries' Fulbright nominating 
committee, then at the U.S.-based international organization level, and finally within the academic institutions where they planned to study. This amount of networking and social engagement is remarkable given that most of the people they engaged with would have come from culturally different backgrounds than themselves. So their high IES selfawareness skills were supported by their high social leadership style preferences to move them effectively through the complex screening process to a successful Fulbright scholarship award. Again, note that much of the networking to be accomplished would be through a non-native language and would require confidence in their new language abilities (self-awareness) for them to be successful.

\section{Correlation of IES Continuous Learning factor and competencies with ASI}

relational dimension and leadership styles. Table 11 displays the correlational strength between the Continuous Learning factor and competencies and the ASI relational leadership set. The evidence points to the exploration IES competency again being moderately correlated to the relational set of ASI leadership styles. One explanation for the findings represented in Table 11 is that within the relational leadership set of competency are ways of leading that value working with others and supporting others in accomplishing their tasks as a way of achieving. The Fulbright students are curious about cultural differences and need to work in teams to conduct research, teach courses, lead seminars, and even to support others who support their applications for the Fulbright award. Also, they are willing and able to learn by engaging culturally different others and to collaborate and contribute to others' goals to achieve their own. All of this is again 
accomplished in a non-native language for most of the participants, requiring a willingness to share in the learning across linguistic and cultural differences.

\section{Correlation of IES Continuous Learning factor and competencies with ASI}

total. Table 12 demonstrates the overall correlation between the Continuous Learning factor and competencies and the overall ASI total scores. In this set of results the highest Pearson's $\rho$ correlation $(\rho=.433)$ is found. The correlations for self-awareness and exploration are moderate to moderately high. These scores demonstrate the thoroughness of this relationship. One explanation is that being self-aware and inquisitive can lead to strong leadership capacity.

\section{Correlation of IES Interpersonal Engagement factor and competencies with}

ASI power leadership style. There are two other broad combinations in which the confluences of correlation coefficients are in the moderate range: (1) when the IES measures of the Interpersonal Engagement factor and its subcompetency relationship interest are correlated to the ASI power leadership style, and (2) when the IES total score is correlated to the ASI relational leadership dimension and the collaborative and contributory leadership styles. Tables 13 and 14 give these correlations and significance scores.

This set of correlations can be explained as follows. The power achieving style is typified by taking charge of tasks, and in this case creating and maintaining relationships across cultural differences, which is the definition of the IES relationship interest

competency. Again, the application process for achieving the Fulbright scholarship 
requires the ability to reach out and engage people and several levels of campus, national, and international organizations. The Fulbright students demonstrated their effectiveness in navigating these complex relationships effectively while using non-native languages.

\section{Correlation of IES total with ASI relational dimension and leadership styles.} Finally, Table 14 looks at the correlation between IES total scores correlated to the ASI relational dimension total, collaborative, and contributory leadership styles. The moderate correlation of the total IES scores with the relational achieving styles set demonstrates that intercultural effectiveness is related to the capacity to support others in accomplishing their tasks when working in a leadership role.

\section{Kendall's $\tau$ correlation coefficient; IES Continuous Learning factor and}

competencies with ASI power leadership style. As mentioned earlier, Kendall's tau $(\tau)$ was employed to magnify the correlational data. The pattern of coefficients and significance closely parallels that of the Pearson's $\rho$. However the $\tau$ correlation coefficients when continuous learning and exploration of the IES are correlated to the ASI power leadership style in particular, they become fully significant. Table 15 offers the Kendall's $\tau$ coefficients considered germane at this point in the study.

This final correlation table, completed in Kendall's $\tau$, demonstrates that the correlation between the IES Exploration Competency and the ASI power leadership style are quite strong. This correlation has been explained above and is reinforced by these statistics. (A full set of Kendall's $\tau$ coefficients for the IES/ASI summary scores can be found in Appendix E for Pearson's $\rho$ and Appendix F for Kendall's $\tau$.) 
INTERCULTURAL COMPETENCE AND LEADERSHIP STYLES

Summary of primary research question results. In summary, when answering the primary research question, this study finds that there is a strong correlation between the IES exploration competency and the ASI power leadership style. Although these two elements do not predict each other, it is very likely that where we find a strong desire to learn about differences, we will most likely also find people who take charge of their leadership tasks. Other relationships are prevalent as well at the moderate level, but exploration and power are the most prevalent at this juncture in the study. Figure 9 provides a graphic image of what this correlation looks like in the form of a Venn diagram.

\section{Secondary Research Questions Results}

The secondary research questions are as follows:

(a) What correlations, if any, exist between leadership styles and intercultural competence dimensions?

(b) What correlations, if any, exist between leadership style domains and intercultural competency scores?

(c) Do patterns of relationship emerge from analysis of different demographic variables?

Questions (a) and (b) above have been partially answered using the correlational analysis above. However, the answers came into greater focus when regression analysis was completed on question (c) to compute the effect (if any) that the demographic variables would have on the correlation. The IES total score was used as the dependent variable. The independent variable in the regressions were the ASI dummy variable for access and success score along with the demographic elements (gender, level of study, 
world region, and field of study), which were pulled in as the dummy variables. The comparator variables that the regressions were controlled for were: (a) male gender, (b) nondegree research level of study, (c) Sub-Saharan Africa world region, and (d) arts field of study. No significant influence was determined by most demographic differences. The one anomaly is that the participants from Central and South America world region indicate a preference for relational leadership styles within the ASI model, especially if the IES Continuous Learning factor along with self-aware and positive regard competencies are present.

Regression with world regions. For the world regions demographic variables an [between-subjects factor: world regions in general; covariate: relational leadership set of leadership styles] revealed a significant effect of the world regions, $F(4.88)=4.61, p=$ $.002, r 2=.14$. This covariance is explained when the IES competencies of selfawareness and positive regard are factored in with the Central and South American world region and onto the relational leadership styles set; there is a moderately significant correlation. A between-subject factor: Central and South America world region; covariate IES, self-awareness competency, $F(1,85)=7.38, p=.008, r 2=.241$ and with the same world region and positive regard, $F(1,85)=7.46, p=.008, r 2=.241$. Finally this same analysis of variance between world regions in general revealed a significant effect of the IES Continuous Learning factor, $F(1,85)=8.60, p=.004, r 2=.250$.

This anomaly of a relationship can be partially explained by past research on cultural norms and values around the world. Both Hofstede $(1980,2001)$ and Chhokar et 
al. (2007) looked at a variety of cultural value patterns shared within people of certain countries around the world. Both studies found the people from Central and South America prefer a more collectivistic organization to their societies, meaning they prefer to belong to their families and or clans and value participating in activities that benefit these same groups. This type of value and the behaviors that it engenders parallels the type of Leadership Styles preferred in the ASI relational dimension set and leadership styles. Lipman-Blumen (1996) discusses the relational set of leadership styles as the antidote to rampant individualism in current leadership models. The same studies can also support the explanation of the positive regard competency. In this region of the world there is a prevalence of face-saving or conflict avoidance and indirect communication in daily interactions, meaning that the people of this region would prefer to let difficult situations work themselves out - without direct communication or conflict.

Regression analysis. Regression analysis was conducted using either the ASI dimensions or the IES Factors as the dependent variables and tested against the various leadership styles or intercultural competencies as the independent variables to see whether the relationship was significant. The pattern of relationship that emerged from the correlation analysis was heightened through the regression analysis, demonstrating strong relationships between the ASI direct-power and the IES Continuous Learningexploration measures in particular. Additional relationships were found to be significant as well. The significant regressions are described in the following two paragraphs. 
INTERCULTURAL COMPETENCE AND LEADERSHIP STYLES

Regressions: ASI direct to IES Continuous Learning. Each of the following regressions can be viewed as a tightening of the focus on a microscope to bring deeper or more acute elements of the respective models into clearer focus. First the analysis of variance showed a significant effect of the total ASI leadership styles scores on a preference for the IES Continuous Learning factor, $F(1,90)=20.81, p<.001, r 2=.179$, a beta score of $\beta=.433$. When this regression is brought down to ASI domain level, analysis of variance displayed a main effect of the ASI direct set of leadership styles on a preference for the IES total scores, $F(4,87)=2.26, p=.040, r 2=.066$, with a beta score of $\beta=.301$. Taking the aperture down slightly to the ASI power leadership style level, analysis of variance showed a main effect on a preference for the IES total scores again, $F(1,90)=16.05, p<.001, r 2=.142$, with a beta score of $\beta=.389$. At the perspective of the ASI direct set of leadership styles, analysis of variance showed a positive effect on the preference for the IES Continuous Learning factors, $F(1,90)=15.24, p<.001, r 2=$ .135 , with a beta score of $\beta=.381$. Again at the ASI domain level, analysis of variance depicts a main effect of the ASI direct set scores on a preference for the IES exploration competency, $F(1,90)=14.22, p<.001, r 2=.127$, with a beta score of $\beta=.369$. At the ASI leadership style level, analysis of variance denotes a main effect of the ASI power leadership style on a preference for the Continuous Learning factors, $F(1,90)=18.90, p<$ $.001, r 2=.164$, with a beta score of $\beta=.417$. These regressions demonstrate the strength of the corelationship between the ASI direct set and power leadership style in particular and the IES Continuous Learning factor and exploration competency in 
particular. The results of this study suggest these styles and competencies have the most in common, and the possible explanations were offered earlier.

\section{Regressions: ASI power and relational to IES Continuous Learning and}

positive regard. There are a few additional corelationships that emerge through regression analysis. The ASI power leadership style also demonstrates a significant effect on the IES Interpersonal Engagement factor, $F(1,90)=9.66, p=.003, r 2=.087$, with a beta score of $\beta=.311$. The ASI instrumental leadership style set also shows a preference on the Continuous Learning factor with analysis of variance, $F(1,90)=9.33, p$ $=.003, r 2=.084$, with a beta score of $\beta=.306$. The ASI relational leadership set of leadership styles displayed an influence on a preference for IES factors and competencies on two different levels. A regression of the ASI relational leadership style set showed a preference of IES total scores, $F(4.87)=3.04, p=.022, r 2=.082$, with a beta score of .279. Similarly, the ASI relational leadership style set displayed a preference for the IES Continuous Learning factor, $F(1,90)=11.69, p<.001, r 2=.105$, with a beta score of $\beta=$ .339. Finally, the ASI relational leadership style sets shows a main effect of positive regard as an intercultural competence, $F(1,85)=7.43, p=.008, r 2=.250$, with a beta score of $\beta=.491$. So whereas the correlation between the ASI instrumental leadership style set shows only one effect on intercultural competence, the ASI relational set of leadership style shows a slightly more layered relationship to intercultural competence. Again, the pattern of correlation that can be observed by the regression analysis discussed above highlights the findings of the correlations from the Pearson's $\rho$ and Kendall's $\tau$ 
computations completed earlier. The regressions bring this analysis into sharper focus and were also explained earlier.

Summary of secondary research questions. The regression analysis conducted for Research Question 2 clearly indicates that most demographic variables have no effect on the overall correlation of the IES and ASI constructs. The only anomaly is the slight preferences for relational leadership styles and positive regard intercultural competency in Central and South America. Overall the regression analysis brings greater focus to the correlations found in the data analysis for the primary research question, namely that there is a significant measurable relationship between the IES exploration competency and the ASI power leadership style.

\section{Summary of Results}

The results of this chapter can be viewed through several lenses. This summary looks to a more pragmatic look at the statistical correlations discovered here. Overall, the results of this study have demonstrated that there is a significant correlation between the ASI leadership styles and the IES intercultural competencies, not across all styles and competencies, but in particular areas. The strongest of these correlations is between the ASI direct set of leadership styles, especially the power leadership style, and on the IES side, with the Continuous Learning factor and the exploration competency in particular. Other relationships exist and are significant, but the depth and multilevel complexity of the ASI direct domain and power leadership style and the IES Continuous Learning factor and exploration competency are the most significant as measured in this study. 
Although the demographic factors of gender, level of study, area of study, and world regions did not have a significant impact on the correlations in the study, the preference for relational leadership styles did seem evident in the Fulbright participants from Central and South America. Finally, the construct of "access and success" was explored to see whether a relationship between the types of engagement with diverse people that is required for intercultural competency could be related to the access and success in multiple leadership styles. This did not prove true, but a prevalence of access and success scores in leadership styles did become evident within the pool of Fulbright students participating in this study.

The results of these findings, focused on the key areas of direct/power leadership style and Continuous Learning/exploration intercultural competence, will be more fully discussed in Chapter 5, including potential implications in terms of broader implications for the Fulbright participants, the Fulbright Program, higher education institutions, and international education programs in particular. 


\section{Chapter 5: Conclusions}

The results of this dissertation indicate that intercultural competence is correlated to connective leadership (Lipman-Blumen, 1996). I conclude that intercultural competence also should be taken in account on the theoretical level in leadership studies, in theories on leadership traits (Bass, 1990), relational leadership (Graen \& Uhl-Bien, 1995), information-processing (Lord, et al., 1984), transformational leadership (Bass, 1985), and contextual leadership (Shamir \& Howell, 1999; Zaccaro \& Klimoski, 2001). I further conclude that leadership styles ought to be considered on the theoretical level for intercultural theories, specifically the expatriate adjustment model (Mendenhall \&

Oddou, 1985), and contact theory (Allport, 1954; Pettigrew, 2011). I will begin this chapter with a discussion of the theoretical implications of my findings and then progress to the more pragmatic implications for the Fulbright participants and the Fulbright Program. Next, implications are presented as they can be applied to the fields of international education and higher education in general. Finally, recommendations for further study are noted.

\section{Intercultural Competence and Leadership}

The data clearly demonstrate that there is a measurable correlation between intercultural competence and leadership styles in this population. Stated in another way, utilizing multiple cultural perspectives is related to multiple ways of leading. For the Fulbright participants, this relationship is strongest between the ability to be curious about cultural differences and leadership styles in general. Of course the population 
employed in this study is highly unique and makes generalizability problematic. The Fulbright students, as inbound international students to the U.S., have competed for and won an elite scholarship (the Fulbright awards). In addition, they are all studying at the graduate or postgraduate level, come from many different countries, and are studying in a wide variety of academic fields. It may be possible that this vetting process selects a certain type of leader to join the Fulbright Program and that this process favors connective-leadership-type (Lipman-Blumen, 1996) behavioral preferences. Still, the findings are provocative and have multiple implications at the individual and organizational levels, which will be discussed next.

\section{Leadership Theory}

There are many ways in which this research supports, expands, and contributes to the different leadership theories discussed in the literature review of this paper. The primary arena this contributes to is the connective leadership model (Lipman-Blumen, 1996). The data demonstrate the ability to identify ideal candidates for leadership development based on the connective leadership model. They also link the connective leadership model to the expatriate adaptation model (Mendenhall \& Oddou, 1985) at the intersections of power, social, collaborative, and contributory leadership styles, but most clearly at the power leadership style. So we now have evidence that for this small sample population, it is possible that intercultural competency is correlated to leadership style. This evidence supports the connective leadership model as a transformational leadership model and states as its purpose the need to grow leaders who are prepared to meet the 
conflicting and dual needs of interconnectedness and diversity. With further research on how these styles are enacted, it may be possible to steer professional development plans based on the ASI toward higher levels of connective and intercultural competency simultaneously.

From the perspective of the other leadership theories discussed in Chapter 2, it is possible to see that the evidence collected in this study links the transformational connective leadership model (Lipman-Blumen, 1996) to the global leadership expatriate adjustment model (Mendenhall \& Oddou, 1985). This also demonstrates that intercultural competence could be aligned or linked to the trait theory school (Bass, 1990). Trait theorists could look to intercultural competence as an essential characteristic, possibly starting with the capacity for continuous learning about differences. Culture could be seen as an influence on the quality of the leader-to-follower exchange that is essential to the relational leadership school (Graen \& Uhl-Bien, 1995), and the combination of power leadership style and exploration intercultural competence could positively influence the characteristic match required for quality leadership as discussed by the information-processing leadership school (Lord, et al., 1984). Both of these leadership schools look at ways that leaders and followers interact, just from a different perspective. The findings of this study indicate that the ability to continuously learn about differences and to take charge of learning/leading tasks can contribute to the impact of these leader/follower exchanges.

\section{Intercultural Competence Theory}


As with the leadership theory conclusions, this dissertation contributes the most to the expatriate adjustment theory (Mendenhall \& Oddou, 1985) upon which the IES is built. This correlational research opens the possibility for a new perspective on how intercultural leadership is enacted, at least within this finite and highly specialized population. It clearly links the power leadership style primarily and, to a lesser extent, extends the relational, collaborative and contributory leadership styles to the Continuous Learning factor and exploration intercultural competence most directly, with some support from the self-awareness and relationship interest intercultural competencies. As a theoretical model built to help practitioners identify and develop global leaders, this new evidence offers a new perspective on how this development might occur, especially if focused on the ASI leadership styles that most closely correlate to the Kozai model. Further, more qualitative research could explain the types of leadership enactments that could support the development of global leaders.

Much of the literature that this dissertation was based upon in terms of intercultural competence echoes back to the work of Allport (1954) and Pettigrew (2011) in prejudice reduction. By using both the IES and the ASI inventories in this study, it may be possible to see that the majority of the Fulbright participants overcame any prejudices that they might have had in terms of studying in the U.S. through active exploration of differences and taking charge of their learning tasks. Other social scientists could use these new insights to see whether these same skills and traits can be replicated in different contexts. 


\section{Implications for Individual Development}

Bennett and Castiglioni (2004) outline a process of learning that causes one to first understand his or her own cultural perspectives so he or she can better engage people from new cultures. This "self-to-other" format is a common instructional design format employed in intercultural education. Using this pedagogical process as a model, this chapter starts with the conclusions (theoretical and practical) as they might impact the immediate individuals (the Fulbright students) who participated in the study. This will be followed by the data-based insights as they might apply to the Fulbright Program at the organizational level.

In terms of the individual participants, the results of the research offer rich potential for personal and professional development. The scores of both inventories indicate an overall high level of self-knowledge or efficacy. Highlighted more than four decades ago, Perry's (1970) model of identity development asserts that advanced levels of more relative cognitive processes afford an individual access to potentially successful interactions. This same type of relative cognition is found in the developmental model of intercultural sensitivity (Bennett, M. J., 1993) and can be seen in the Fulbright students as they begin their sojourns. The identity development above parallels Chickering's (2010) model, in which higher levels of development afford the individual opportunities for developing purpose and integrity in broad community contexts. Chickering's model (1993) is reflected in the expatriate adaptation model (Mendenhall \& Oddou, 1985), in which a high level of adaptation allows people to be effective in diverse intercultural 
contexts. Again, the data indicate the Fulbright students' abilities to adapt at the start of their programs of study is firm. Similarly, this type of development is supported by research on the effects of international education experiences in general (Paige et al., 2003; Paige et al., 2009) and other researchers examining the relationship among student development, leadership, and intercultural competence (Braskamp, 2010; King \& Baxter Magolda, 2005).

To optimize these assets, the intercultural adaptability model (Mendenhall \& Oddou, 1985), supports the cultivation of continuous learning and exploration. Thus, to fully support the individual development, Osland (2011) would recommend the design of professional development plans. The participant's self-knowledge can be cultivated to bridge to additional intercultural and leadership competencies at higher levels of capacity and performance through goal setting and accountability feedback that increases in complexity and intensity until the participant and his or her mentor feel the participant is competent. Osland's developmental methodologies model assesses the individual for the level of experience in intercultural settings against his or her access to amounts of increasingly complex feedback and then maps out a process toward increased intercultural competence development. Figure 10 illustrates this recommended development process.

\section{Implications for the Fulbright Program}

The data of this study indicate that the Fulbright Program is doing admirable work in screening and selecting potential intercultural leaders in its current process. The 
Fulbright students demonstrate high levels of access and success scores, meaning they are able to adapt to many leadership styles. This leadership acumen is correlated most strongly with their drive to master their learning tasks. It seems particularly strong in recruiting people who are both curious about cultural differences and "take-charge" types of leaders. Indeed, the program appears to identify a majority of leaders who fit the ideal model of the connective leadership model (Lipman-Blumen, 1996), leaders who possess the skills, talents, and intelligence to effectively interact across cultural and global boundaries. Still, the Fulbright Program lacks a clear and cohesive process to build upon this foundation to maximize the leadership and intercultural competencies discovered in this study. After the orientation program neither intercultural competence nor leadership skills are explicitly addressed in the Fulbright Program. Pettigrew's (2008) analysis of prejudice reduction finds that people need to be guided toward engagement that causes them to find reciprocity across difference. Adult and higher education researchers (Huba \& Freed, 2000; Preskill \& Russ-Eft, 2005) recommend adopting evaluation practices that support performance improvement through learner-centered assessment that is aggregated and analyzed for programmatic improvements. As administrators of an international education program, the Fulbright staff could find ways to mentor the students over their plans of study as best practices would recommend (Berry \& Chisholm, 1999; Paige et al., 2003). This is supported and made more concrete by Osland's (2011) professional development model recommended above. To assume that the Fulbright Program will 
necessarily grow intercultural competence and leadership capacity across cultures without attention is not supported by the evidence found in this study.

\section{Implications for International Education}

The results of this dissertation can be utilized by international educators at four intervals in the overall design of programs: (a) instructional design, (b) preprogram (c) onsite participant mentoring, and (d) post program follow-up, especially reverse-culture shock. The assessments employed in this study were used to inform the instructional design and preprogram training for the Fulbright orientation. The full four levels of the overall of learner-centered instructional design are advocated by The Forum for Study Abroad (http://www.forumea.org/), NAFSA (http://www.nafsa.org/), and other international education researchers (Paige et al., 2009; Bennett, J. M., 1985; Bolen, 2007).

Instructional design. Faculty and program staff can use the competencies named in the inventories to write explicit and measurable learning objectives in their instructional design process to create or update programs of study. They can carefully consider both the curricular and cocurricular components of their programs to maximize the overall educational effectiveness. The combination of exploration as a competency and power as a leadership style may be unique to this population and clearly were not expected. This combination of skills and styles may be important to consider, especially as a starting place in the sequencing of learning modules. In addition, international educators can embed assessment and evaluation plans into their overall instructional 
designs by employing the IES and ASI tools or other instruments that are germane to their programs' learning outcomes, building in pre-post-test results with the psychometric inventories and/or a portfolio review (Rhodes, 2010) to ensure the programs' quality.

Pre-program. Faculty and program staff can use the preprogram or early program assessment data as recommended by Paige and Stallman (2007) to initiate the learners' self-knowledge, which gives rise to constructive engagement with difference (Bennett \& Castiglioni, 2004). This self-discovery process cultivates the curiosity that is strong in the Fulbright students and supports their intercultural learning. The data on leadership styles suggest that projects, case studies, service learning, or community-based learning across cultural differences as teaching methods would all lend themselves to activating the student's leadership capacities.

Onsite program mentoring. Ongoing onsite mentoring is considered a hallmark of best practice in international education programming (Savicki, 2008; Paige et al., 2003; Berry \& Chisholm, 1999) and would be supported in leadership development outcomes as well (Osland, 2011). Causing the learner to reflect on his or her development, reframe negative stereotyping judgments, and seek reciprocal relationships with culturally different others engenders relevance and competence building in the learning process (Berry \& Chisholm, 1999; Wlodkowski \& Ginsberg, 1995; Pettigrew, 2008). International education programs are often criticized for not doing enough onsite (in-program) mentoring or post program follow-up, especially for reverse culture shock (Steinberg, 2007; Lou \& Bosley, 2008; Pusch \& Merrill 2008; Berry \& Chisholm, 1999). 
So the lack of evidence of thorough individual, or even cohort, mentoring and follow-up for this program only serves to support the criticism. The models and assessments employed in this study give international educators common themes or objectives in both intercultural competence and leadership development to employ to channel learners to focus on their competencies.

Post program follow-up. One of the biggest challenges for international educators is post-program follow-up (The Forum for Study Abroad, http://www.forumea.org/; NAFSA http://www.nafsa.org/). Again, by using the data from the inventories and the ongoing feedback, the international educator can structure opportunities for learners to share their learning, initiate projects, and mentor new learners. These practices engender high levels of relevancy and competency on the part of the learners.

Finally, reverse culture shock is a recurring challenge in international education (Lou \& Bosley, 2008). Learners often return from their sojourns and are seemingly unable to readjust to their home environments, which leads to both physiological and psychological stress. The data from this study indicate that the Fulbright students are resilient in facing transitions. Reminding them of their strength and flexibility will help them take charge of the task of adjusting and being curious about the process.

\section{Implications for Higher Education}

The academic implications for preparing global-ready graduates (Hovland, 2009; Lewin, 2009) support the findings of this study. Given the participants' scores, these 
Fulbright awardees seem poised for success in contexts in which the complexity of cultural differences intrigues them and their capacity to take charge of situations is expected and appreciated. Moreover, Hofstede's $(1984,2001)$ and Chhokar et al.'s (2007) work seems to confirm that these participants' curiosity and leadership styles will serve them well, especially in U.S. postsecondary institutions, where hierarchical power is often the norm. Conversely, the Fulbright students' well-roundedness or flexibility in leadership styles can also serve as an example to learning leaders in higher education on the value of new and possibly less hierarchal ways to lead. In short, their mix of intercultural competence and leadership styles may offer both a globalizing perspective and change agency opportunity to U.S. colleges.

Faculty and administrators can consider these findings to (a) impact learning outcomes in intercultural competency and leadership skills within the disciplines and across degree programs, especially in their accreditation assessment processes. They can use them to (b) develop training and professional development opportunities to strengthen instruction skills in intercultural competency and leadership skills. They can use this evidence to (c) advocate for research and expansion of partnerships between higher education and governmental or corporate entities such as the Fulbright Program, where intercultural competency and leadership acumen are or could be an essential outcome. Finally, they can use this evidence to (d) launch or improve student services programming. 
INTERCULTURAL COMPETENCE AND LEADERSHIP STYLES

Intercultural and leadership competence outcomes across campus. As

discussed in the Implications for International Education section, the data from this research can be employed to construct a more focused instructional design that fosters intercultural and leadership competence. At a more campus-wide level, these data can be used to look for opportunities to embed and leverage intercultural and leadership learning opportunities both within the disciplines and across the curriculum. Exploration intercultural competency and power leadership style can be translated into curiosity about difference and self-directed or take-charge learning opportunities, which can easily be adapted to any discipline in academia. Group work in the form of case studies, service learning, cooperative or internship placements, and practicum all elicit access to difference and the need to engage one or more people to complete a task.

The evidence that international education can engender both intercultural and civic leadership competence in particular is very thorough (Paige et al., 2009), and this pedagogical tool is reframed to be more useful across disciplines. Traditionally, international education experiences have focused on language, social science, or liberal arts disciplines and dominantly at the undergraduate level. But this dissertation notes that intercultural and leadership competence can be found across myriad disciplines and at the graduate level. Campuses are increasingly seeking international education experiences in biological and applied sciences as well as in the professions. This evidence indicates that the potential for discovering and developing intercultural and leadership competence exists across disciplines and educational levels. 
Campuses can also consider opportunities for engaging difference that do not require international travel. More than $40 \%$ of the Fulbright students had not traveled, lived, or studied outside their home countries before coming to the U.S. Yet they displayed high levels of intercultural competence through continuous learning about difference and leadership acumen through self-directed and collaborative learning. These same competencies can be cultivated in interdisciplinary work (Rhodes, 2010), service learning (Stokamer, 2011; Cress, Collier, \& Reitenaur, 2005), and other pedagogical practices without leaving the immediate community or with shorter, more accessible travel.

Assessment of student learning outcomes, especially for accreditation purposes, has become a major influence on U.S. campuses over the past decade (Rhodes, 2009). The evidence from this study can be used to construct assessment plans using either or both of the psychometric inventories. These inventories can easily be aligned to the AAC\&U Valid Assessment of Learning in Undergraduate Education (VALUE) rubrics on intercultural knowledge and competence and the civic engagement for portfolio review. This combination of assessment practices (survey plus student work sample review) is considered the hallmark of best practices in the assessment literature (Huba \& Freed, 2000).

Faculty and staff training. A challenge for all educational institutions is keeping the faculty and staff adequately trained for the constant changes that occur in higher education. Faculty and staff development opportunities are frequently used to educate 
and train campus personnel about changing demographics, new pedagogies, and new educational resources. If the faculty and staff are going to be successful in embedding intercultural and leadership competence into their courses and projects, they too will need the same training and support that the individual participants would need to develop the skills. Most faculties are trained within their disciplines, and many disciplines do not look at intercultural competence and leadership as essential outcomes. So adopting these will take training. As an example, the model of multicultural course transformation constructed by Morey and Kitano (1997) outlines a complex and thorough process for looking at a curriculum and transforming it from a mono-cultural context to a multicultural context. Adopting this thorough and comprehensive model of inclusive instructional design would benefit from both practice and mentoring to master effectively. Faculty and staff development is also frequently employed in the adoption and refinement of assessment practices. The methods and data from this study could be employed to train them to measure intercultural competence of leadership acumen.

International education partnership programs. The Fulbright Program's success in finding intercultural competent and connective leaders would lend support to the types of government or corporate to higher education partnerships that foster and maintain such programs (Berry \& Chisholm, 1999; Fulbright, 2011a), partially due to their expanse of international alumni available for support and networking. The Humphrey Scholars program, as an example, brings public health and medical sciences scholars from around the world to the U.S. to study ways to combat AIDS. 
(http://www.humphreyfellowship.org). The newer Intel Scholars program brings engineering students from around the world to study engineering (http://www.intel.com/about/corporateresponsibility/education/highered/index.htm). The Marshall (http://www.marshallscholarship.org) and Rhodes (http://www.rhodesscholar.org) scholarships send U.S. students overseas for their programs of study. There are many programs that seek to advance world knowledge through international study that are funded by a combination of public, private, and higher education institutions. Campuses can use the data from this study to advocate for expanded opportunities to both send students abroad and receive international students at all levels and in myriad academic disciplines to cultivate global perspective and leadership acumen in their graduates. This advocacy would be supported by the solid research behind the expatriate adaption (Mendenhall \& Oddou, 1985) and the connective leadership (Lipman-Blumen, 1996) models, which can be an advantage in the political environment of campus policy making, where sound academic research is highly valued.

Student services programming. In the student services realm of higher education research, the push to develop intercultural competence and leadership skills in general through cocurricular work is increasingly evident (Braskamp, 2010; King \& Baxter Magolda, 2005; Berry \& Chisholm,1999). The findings of this study could be utilized to expand the focus on exploration of differences and combination of individualized and collaborative leadership tasks as a starting point for cocurricular offerings. Orientation programs, both for campus life in general and overseas study, are common student 
services responsibilities. The focus on intercultural and leadership competencies supports the students in their personal global-ready development and as aligns the student services programming to overall campus academic outcomes. By adopting the international adaptation model (Mendenhall \& Oddou, 1985) and/or the connective leadership (Lipman-Blumen, 1996) model for their development plans, the student services program manager ensures the sound underpinnings of his or her design and the capability to create and gather measurable outcomes.

\section{Recommendations for Further Research}

There are many paths for future research based on this dissertation. If this research were to be expanded to a longitudinal study complete with posttest data, this type of research could shed light on higher education's endeavors to develop these 21 st century leaders, ready for global engagement. There are many ways in which this research supports, expands, and contributes to the different leadership theories discussed in the literature review of this paper. The primary arena this contributes to is the connective leadership model (Lipman-Blumen, 1996). The data demonstrate the ability to identify ideal candidates for leadership development based on the connective leadership model. It also links the connective leadership model to the expatriate adaptation model (Mendenhall \& Oddou, 1985) at the intersections of power, social, collaborative, and contributory leadership styles, but most clearly at the power leadership style. Again, the connective leadership model is a transformational leadership model that states as its purpose the need to grow leaders who are prepared to meet the conflicting 
and dual needs of interconnectedness and diversity. With the results of this study we now have empirical evidence that for this small sample population, it is possible that intercultural competency is correlated to leadership style. With further research on how these styles are enacted, it may be possible to steer professional development plans based on the ASI toward higher levels of connective and global competency simultaneously.

One of the more obvious research routes would be to expand the participant pool with more incoming Fulbright students, add a sampling of the outgoing U.S. Fulbright students, and then track them during their plans of study, through to completion. The full complement of approximately 3,000 Fulbright participants annually would go a long way to solidifying the correlations discovered here. There could be a possibility of studying the screening process in depth to see what elements could be replicated in other arenas. There could be postprogram data to measure outcomes of leadership and intercultural competence that had developed over the plan of study. There could be a mixed-method approach with qualitative data to learn how leadership work is enacted in a culturally competent manner. There could even be research conducted on the current alumni of the program to ascertain how the Fulbright Program has impacted their intercultural competence and leadership skills. If the researcher would prefer a more representative pool, a mix of undergraduate and graduate students participating in either international or off-campus cross-cultural work could be recruited to see whether these measures could be replicated and made more generalizable. 
One of the movements in both higher education assessment and corporate settings is to look for performance measures. These types of measures in higher education settings are most frequently conducted with portfolios of student work (Rhodes, 2010). The VALUE rubrics of the AAC\&U are an example of a set of standards that can be employed to look for learning outcomes as embedded in student work. There is even a rubric on intercultural knowledge and competence that was cowritten by the author of this dissertation (Rhodes, 2010, pp. 44-45). It would be valuable to see whether there is evidence of the Fulbright students' growth and development of intercultural competence and leadership acumen based on samples of their work during their Fulbright award years. This type of evidence could help the Fulbright Program better understand its strengths and challenges, as well as help other higher education programs learn from the Fulbright experience. In the corporate realm, these types of performance measures are often conducted with a combination of psychometric assessments, as was done here, in combination with 360 assessments of the participants' performance by their superiors, peers, and subordinates of clients, in addition to case studies and review of work produced by the participants (Preskill \& Rust-Eft, 2005).

As mentioned earlier, further study of the Fulbright screening process could support similar efforts elsewhere in higher education. These data support the Fulbright Program in their initial selection process of attracting leaders who will be prepared for the 21 st century. Further study of just the current screening process could prove beneficial in explicating how this caliber of potential leaders is found. Such a study would be valuable 
to other programs in higher education or to organizational development, human resource, and training professionals in noneducational settings. These data could be greatly expanded with the addition of longitudinal data both during the participants' plans of study and afterward. Huba and Freed (2000) point out that quality program assessment is essential to understanding the value and impacts of academic programs of study. Because the Fulbright Program claims to prepare future leaders for world engagement (2011a) then this type of data would support the continued work of the Fulbright Program, but possibly even its expansion in key arenas. Longitudinal program assessment could also unearth aspects of the program that are less effective and support targeted improvement.

Lipman-Blumen (2006) asserts that the connective leadership model correlates to the collectivist/individualist cultural framework. This could not be fully explored with the data and methods from this study; however, it is possible to see that the minority of Central and South American Fulbright participants did prefer relational leadership styles. When compared to the work of Hofstede $(1984,2001)$ \& Chhokar et al. (2007), it is clear that people from these regions do prefer collectivist cultural frameworks. A study clearly directed to unearthing this possible linkage could be conducted with different instrumentation and access to larger pools of international participants and would be intriguing.

Overall, each of the limitations discussed in Chapter 4 points to new avenues for future research. Depending on the focus and desire of the researchers, any of these 
limitations (size, uniqueness, statistical method, and even overall research model) could be adapted, grown, combined, and expanded upon to add to the generalizability of the findings of this study.

\section{Dissertation Conclusion}

Overall, the thesis goal was to look for a measurable correlation between the fields of intercultural competence and connective leadership (Lipman-Blumen, 1996), and it was found for the select population of the study. This study finds that access and success in multiple leadership styles can be achieved through continuous learning about cultural differences. Frequent calls for cultural competency and global leadership come from many sectors of our economy (corporate, government, and nonprofit), and higher education has responded to these calls with numerous endeavors. I believe I have found empirical evidence that intercultural leadership acumen can be seen, measured, and ultimately learned. Creating the opportunities for learners to cultivate their curiosity about differences through a combination of individual and shared learning/leadership opportunities is essential to nurturing future intercultural leaders. Our students can learn to mitigate cultural differences and find shared meaning and purpose, combating forms of prejudice and increasing effectiveness across difference. This combination of curiosity and learning/leading acumen will support potential leaders in being prepared for the dual challenges of an ever-increasingly interdependent world and the vast array of cultural differences they engage. 
Figures

Figure 1. Model for International Adjustment

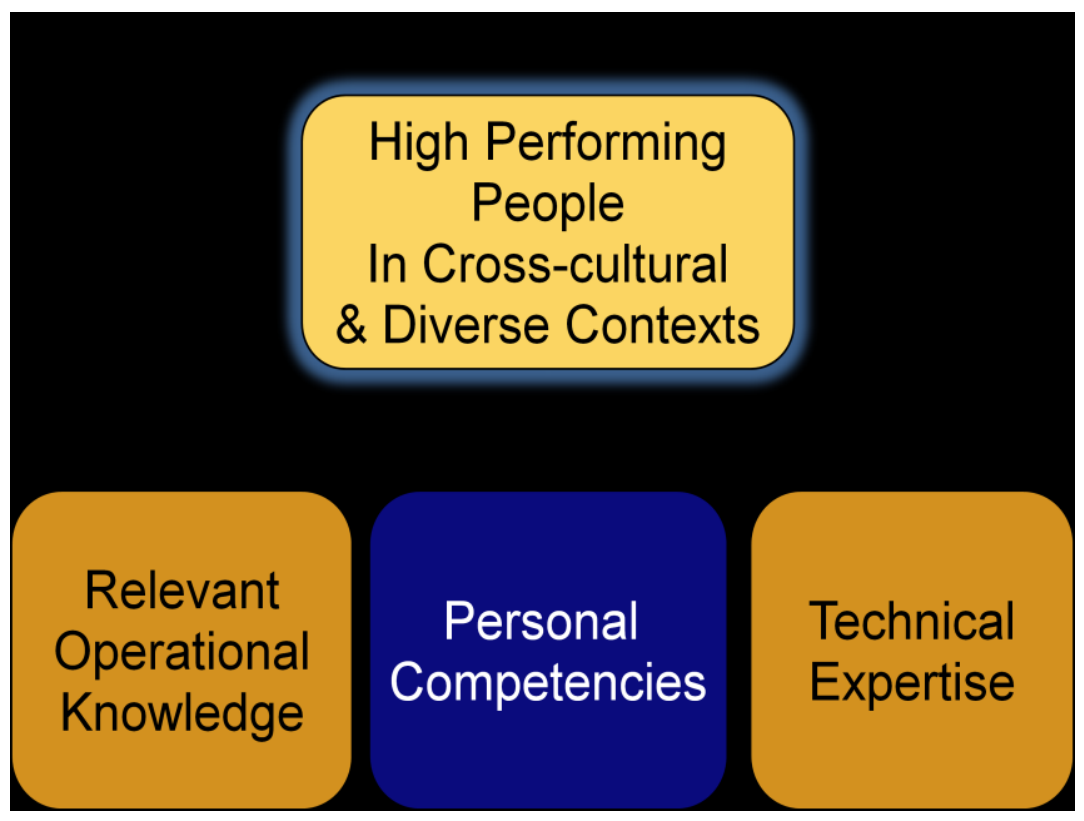

Mendenhall, Stevens, Bird, \& Oddou, 2010. Reproduced with permission of the authors. 
Figure 2. Intercultural Competency

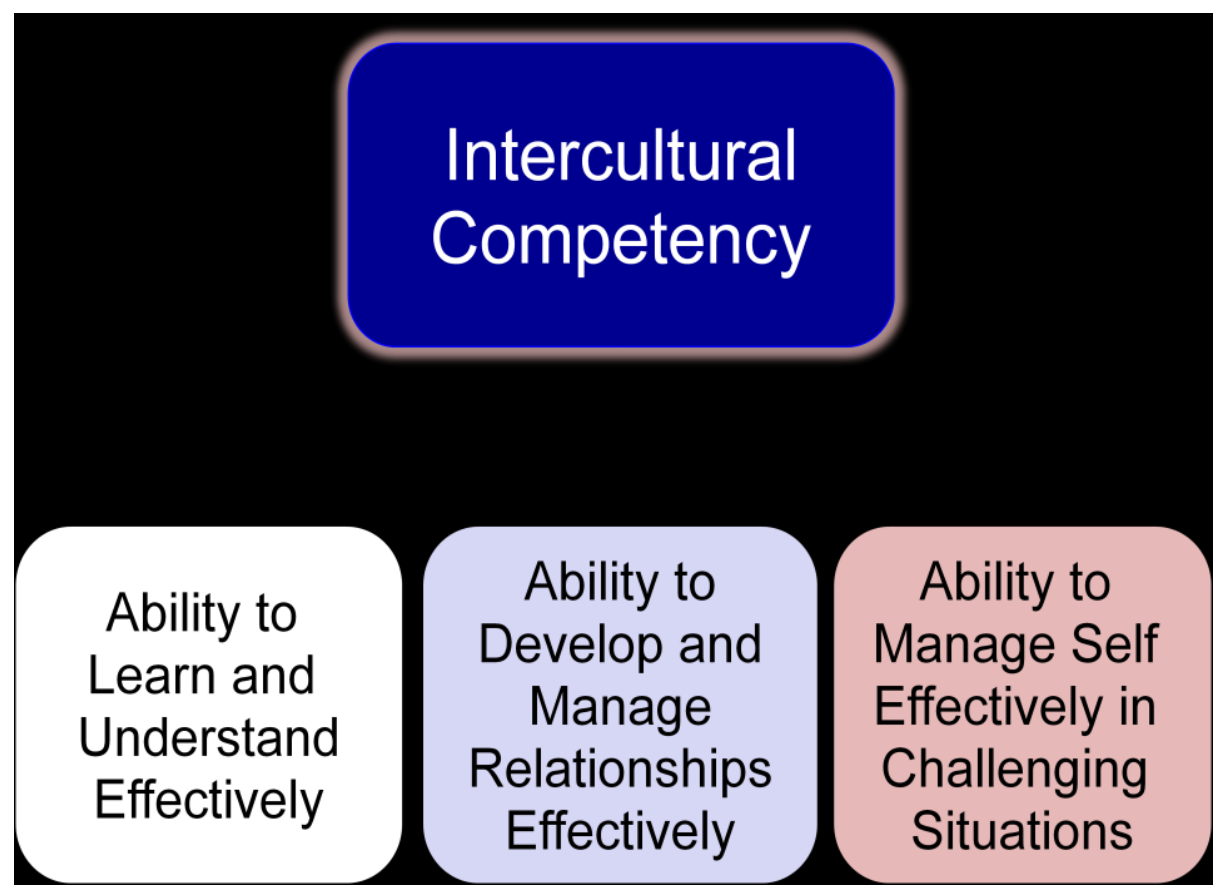

Mendenhall, Stevens, Bird, \& Oddou, 2008. Reproduced with permission of the authors. 
Figure 3. Developing Intercultural Competence

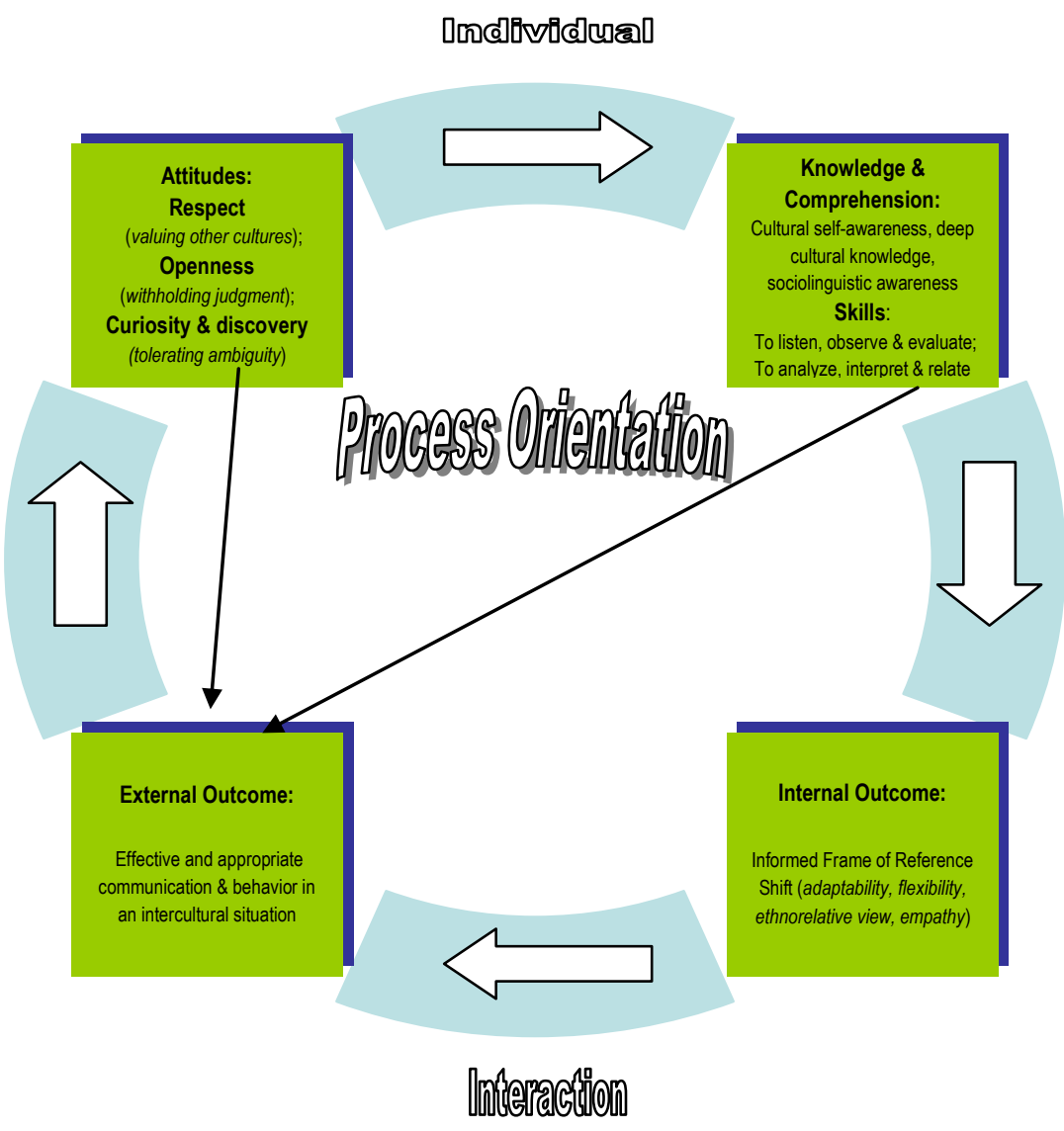

Deardorff, 2004b. Reprinted with permission of the author. 
Figure 4. Intercultural Effectiveness

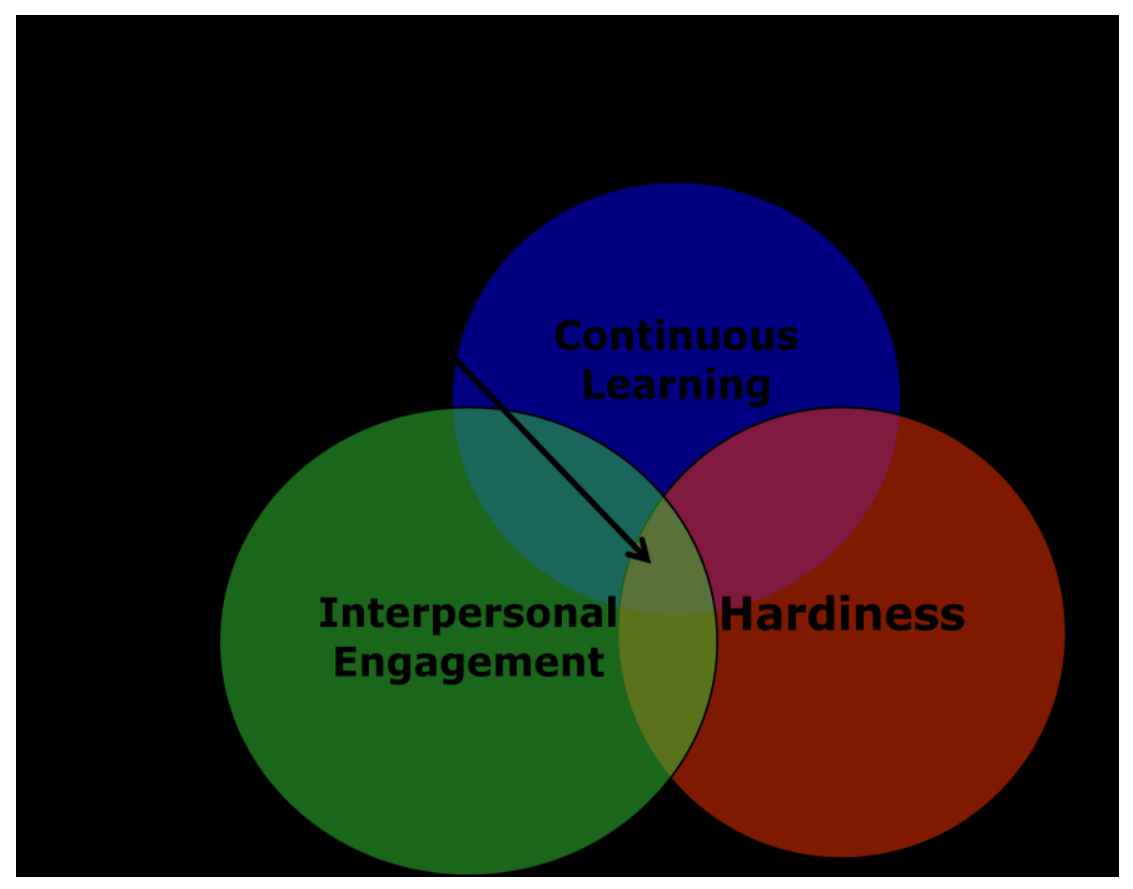

Stewart, 2010. Reprinted with permission of the author. 
Figure 5. IES Model Factors and Competencies

\begin{tabular}{|l|l|l|}
$\begin{array}{l}\text { Continuous } \\
\text { Learning }\end{array}$ & $\begin{array}{l}\text { Interpersonal } \\
\text { Engagement }\end{array}$ & Hardiness \\
\hline exploration & $\begin{array}{l}\text { global mindset } \\
\text { positive regard }\end{array}$ \\
\hline self-awareness & $\begin{array}{l}\text { relationship } \\
\text { interest }\end{array}$ & resilience \\
\hline
\end{tabular}

The Kozai Group, 2010. 
Figure 6. Connective Leadership Model (Achieving Styles)

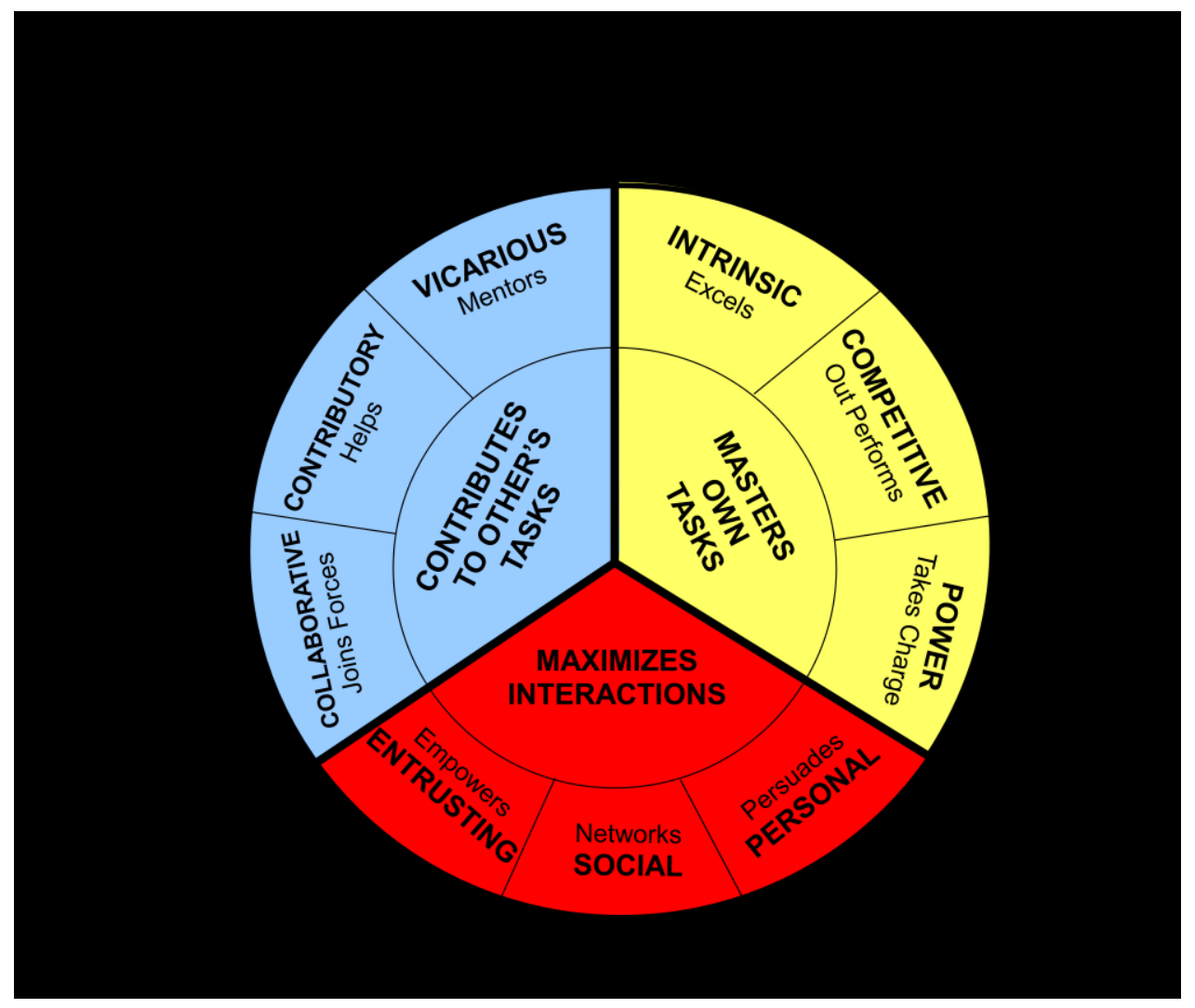

Lipman-Blumen, 1996, p. 112. Reprinted with permission. 
Figure 7. Intercultural Leadership Research Conceptual Framework

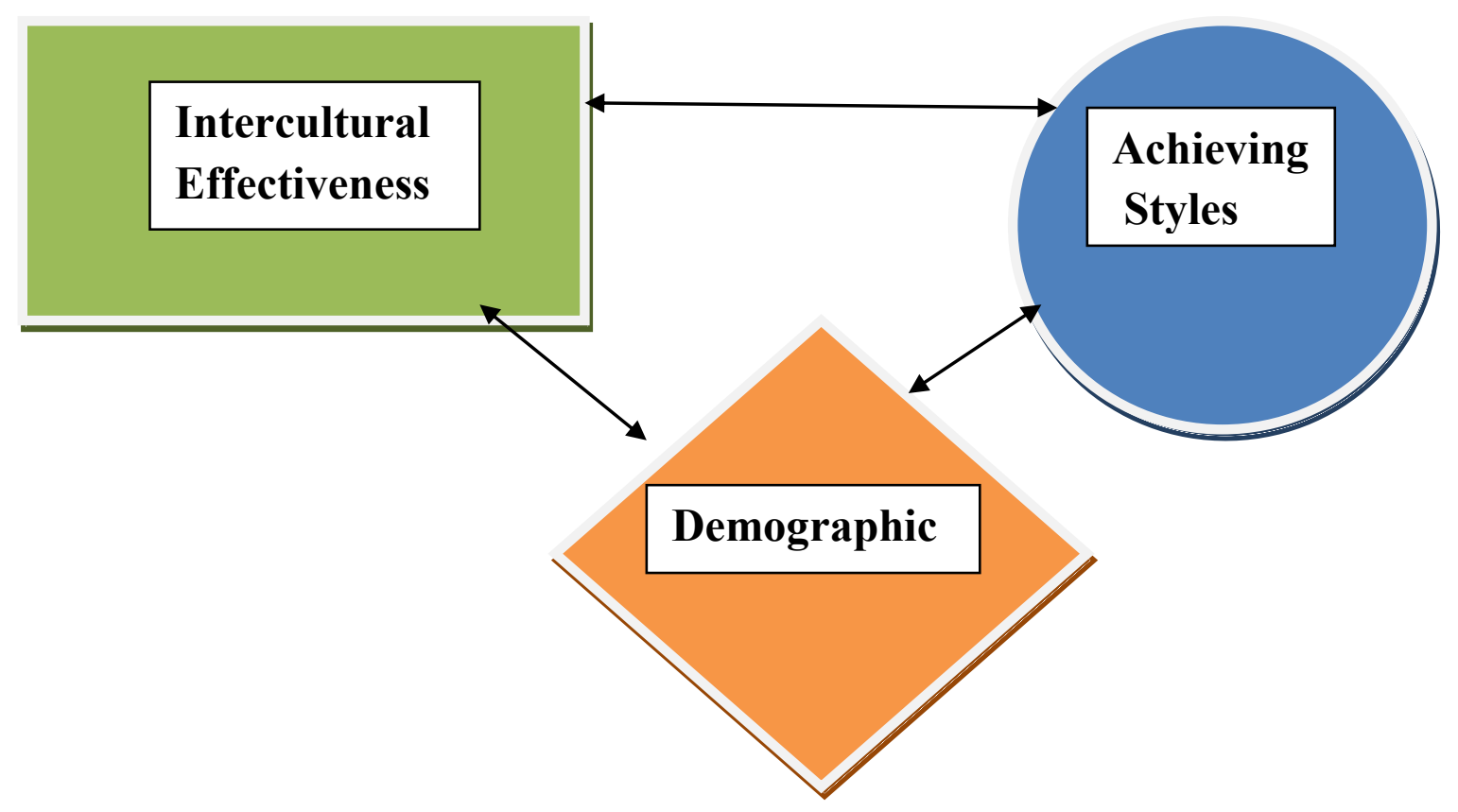


Figure 8. Connective Leadership Ideal: Access and Success

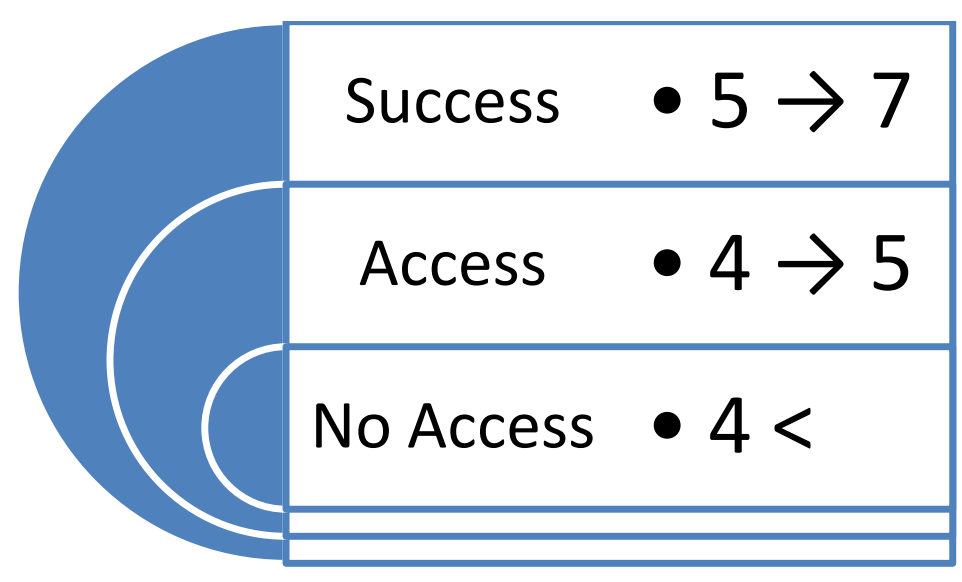


Figure 9. Results of Study in Venn Diagram Format
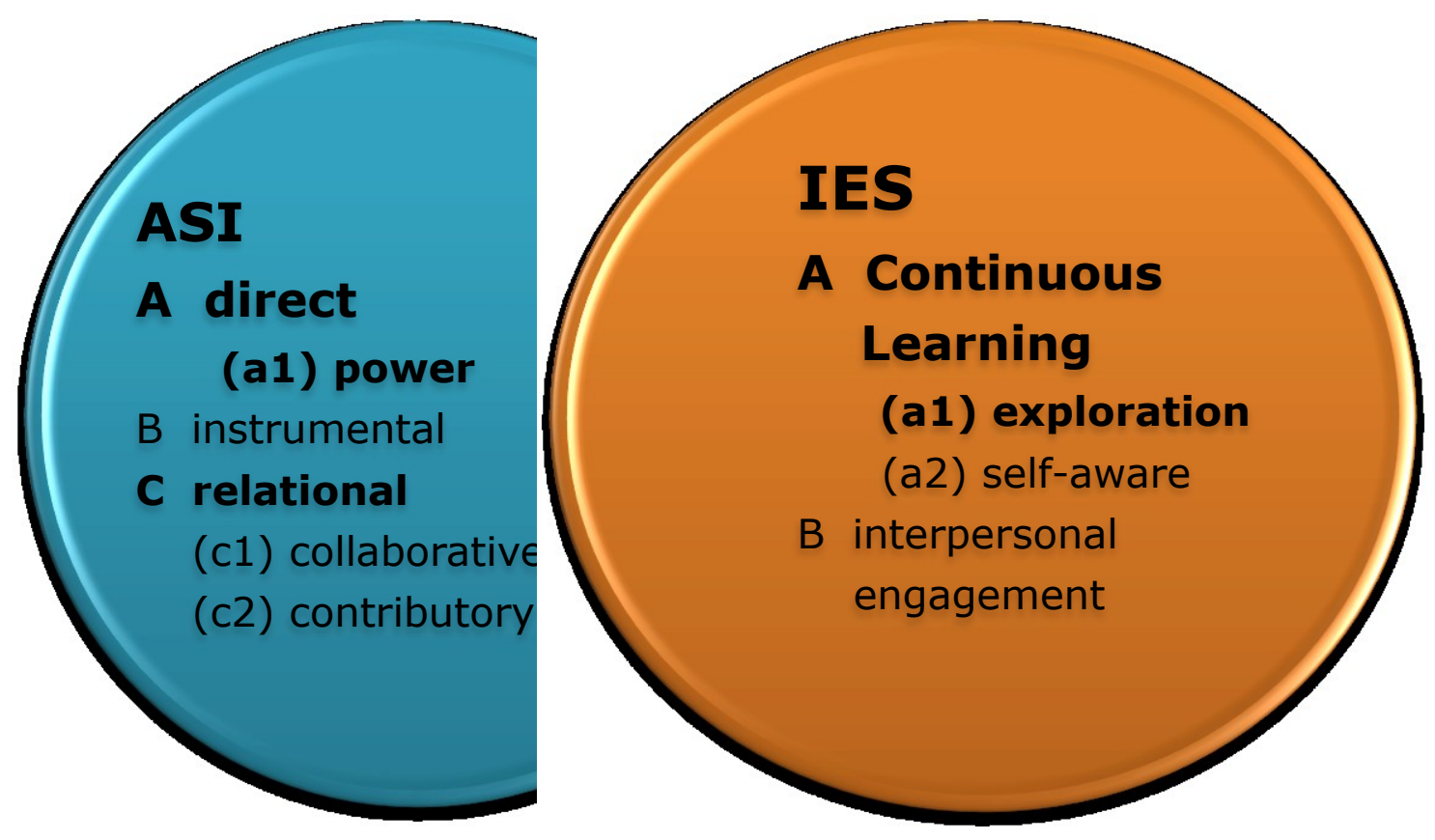
Figure 10. Recommended Intercultural and Leadership Professional Development Process

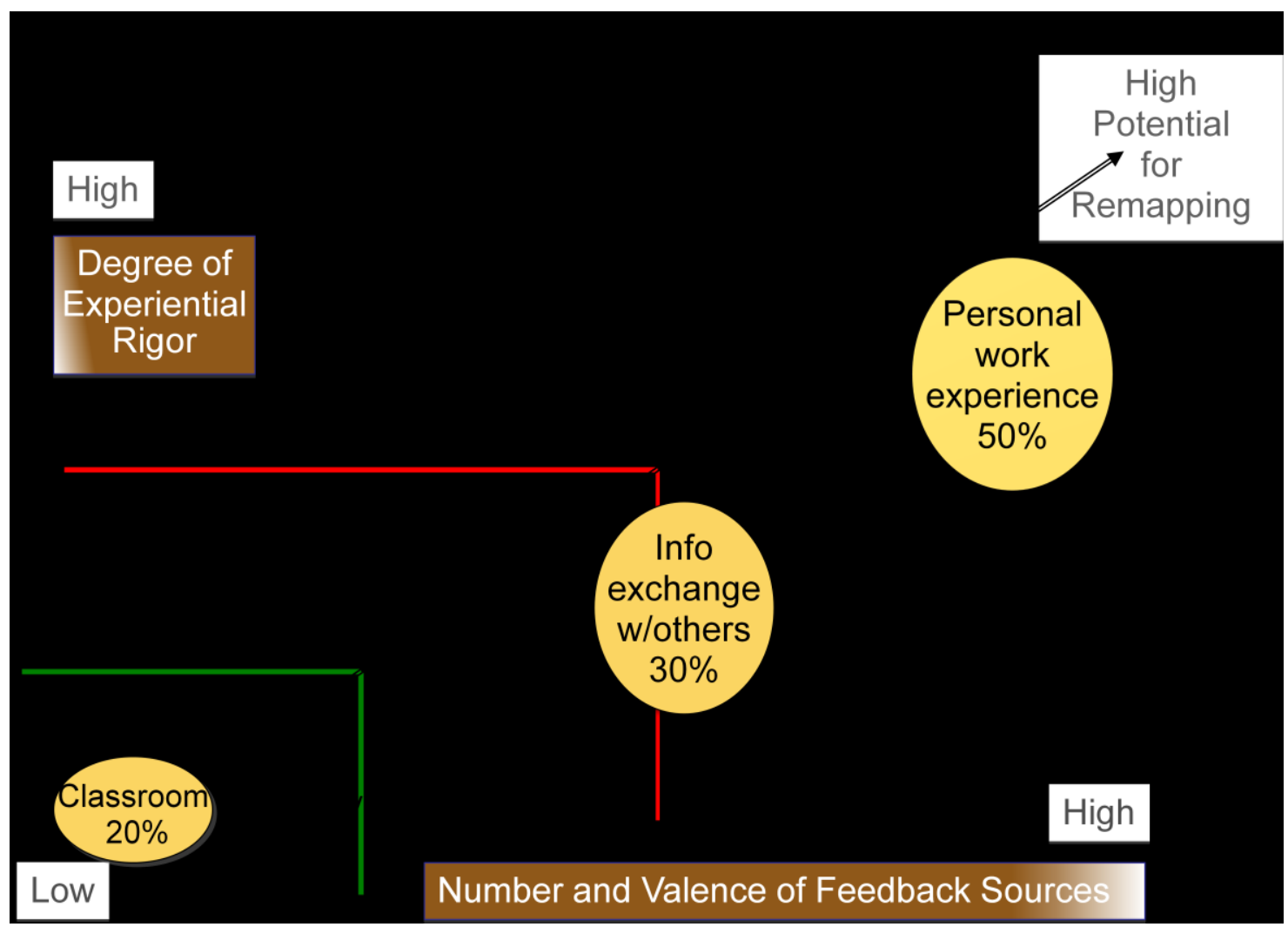

Osland, AACU Presentation, January 2010. Used with permission of the author. 


\section{Tables}

\section{Table 1. Fulbright Participant Demographics}

\begin{tabular}{|c|c|c|c|c|c|c|}
\hline Cohorts & $\begin{array}{l}\mathrm{FB}^{*} \\
\text { Cohort A }\end{array}$ & $\begin{array}{l}\% \text { of } \\
\text { Total }\end{array}$ & $\begin{array}{l}\mathrm{FB} * \\
\text { Cohort B }\end{array}$ & $\begin{array}{l}\% \text { of } \\
\text { Total }\end{array}$ & Total & $\begin{array}{l}\% \text { of } \\
\text { Total }\end{array}$ \\
\hline Dates & Aug. 16-20 & & Aug. 23-27 & & & \\
\hline Total Participants & 52 & .48 & 56 & .52 & 108 & 1.00 \\
\hline \multicolumn{7}{|c|}{ Number of Countries } \\
\hline They Represent & 28 & .26 & 35 & .32 & 41 & .42 \\
\hline Males & 24 & .22 & 24 & .22 & 48 & .44 \\
\hline Females & 28 & .26 & 35 & .32 & 63 & .58 \\
\hline MA & 34 & .31 & 46 & .43 & 70 & .65 \\
\hline $\mathrm{PhD}$ & 15 & .14 & 8 & .07 & 21 & .19 \\
\hline Research & 9 & .08 & 10 & .09 & 17 & .16 \\
\hline
\end{tabular}


INTERCULTURAL COMPETENCE AND LEADERSHIP STYLES

Table 2. Fulbright Participant Inventories Completed

\begin{tabular}{|c|c|c|c|c|c|c|}
\hline Cohorts & $\begin{array}{l}\text { FB* } \\
\text { Cohort A }\end{array}$ & $\begin{array}{l}\% \text { of } \\
\text { Total }\end{array}$ & $\begin{array}{l}\text { FB * } \\
\text { Cohort B }\end{array}$ & $\begin{array}{l}\% \text { of } \\
\text { Total }\end{array}$ & Total & $\begin{array}{l}\% \text { of } \\
\text { Total }\end{array}$ \\
\hline Dates & Aug. 16-20 & & Aug. 23-27 & & & \\
\hline Total Participants & 52 & .48 & 56 & .52 & 108 & 1.00 \\
\hline IES Completed & 43 & .46 & 50 & .53 & 93 & .86 \\
\hline$\%$ of Cohort & & .83 & & .89 & & \\
\hline ASI Completed & 50 & .46 & 56 & .52 & 106 & .98 \\
\hline$\%$ of Cohort & & .96 & & 1.00 & & \\
\hline No Inventories & 2 & .02 & NA & NA & 2 & .02 \\
\hline$\%$ of Cohort & & .04 & & NA & & \\
\hline
\end{tabular}


INTERCULTURAL COMPETENCE AND LEADERSHIP STYLES

Table 3. Academic Fields of Study Pursued by the Fulbright Students in This Study, Categorized into Six Areas

\begin{tabular}{|c|c|c|c|}
\hline Academic Field Category & Category Includes & $\mathrm{N}$ & $\%$ of $\mathrm{N}$ \\
\hline Social Sciences & $\begin{array}{l}\text { anthropology, business, economics, education, } \\
\text { government, history, humanities, international } \\
\text { relations, law, philosophy, political science, } \\
\text { psychology (developmental), sociology }\end{array}$ & 46 & 49 \\
\hline Arts & $\begin{array}{l}\text { art, art design, art history, dramatic arts, fine } \\
\text { arts, music }\end{array}$ & 13 & 13 \\
\hline Languages & foreign languages, linguistics & 11 & 10 \\
\hline Communication & communication, English literature, journalism & 9 & 9 \\
\hline Science & $\begin{array}{l}\text { applied mathematics, computer sciences, } \\
\text { engineering (chemical, civil, electrical, } \\
\text { industrial), geology, pharmacy, public health, } \\
\text { speech-pathology, psychology (clinical) }\end{array}$ & 9 & 9 \\
\hline No Field & no declared field of study & 5 & 5 \\
\hline
\end{tabular}


INTERCULTURAL COMPETENCE AND LEADERSHIP STYLES

Table 4. World Regions Where Fulbright Students in This Study Are From, Categorized into Five Regions

\begin{tabular}{|c|c|c|c|}
\hline World Region & Countries includes & $\mathrm{N}$ & $\%$ of $\mathrm{N}$ \\
\hline Europe & $\begin{array}{l}\text { Albania, Austria, Bulgaria, Finland, Germany, } \\
\text { Hungary, Poland, Romania, Russian } \\
\text { Federation, Spain, Sweden, Ukraine, United } \\
\text { Kingdom of Great Britain }\end{array}$ & 38 & 40 \\
\hline Middle East & $\begin{array}{l}\text { Afghanistan, Azerbaijan, Bangladesh, India, } \\
\text { Lebanon, Morocco, Pakistan, Tajikistan, } \\
\text { Turkey, Uzbekistan }\end{array}$ & 22 & 23 \\
\hline Asia (East) & $\begin{array}{l}\text { China, Taiwan, Indonesia, Korea, New } \\
\text { Zealand*, Philippines, Vietnam }\end{array}$ & 15 & 15 \\
\hline $\begin{array}{l}\text { The Americas (Central and } \\
\text { South America) }\end{array}$ & $\begin{array}{l}\text { Argentina, Chile, Columbia, Ecuador, } \\
\text { Grenada, Honduras, Mexico, Trinidad and } \\
\text { Tobago }\end{array}$ & 12 & 12 \\
\hline Africa (Sub-Saharan) & Benin, Madagascar, South Africa & 6 & 6 \\
\hline
\end{tabular}


INTERCULTURAL COMPETENCE AND LEADERSHIP STYLES

Table 5. Data Set, Research Questions, and Items on Surveys

\begin{tabular}{|c|c|c|}
\hline Data Set & Research Question & Item on Survey \\
\hline Intercultural & Primary research question: & IES Questions 1-52 and ASI \\
\hline competence and & Is there a relationship between & Questions 1-45 \\
\hline \multirow[t]{2}{*}{ leadership styles } & intercultural competence and & \\
\hline & leadership style? & \\
\hline Leadership styles and & II. Secondary research question: & ASI Questions $1-45$ and IES \\
\hline intercultural & (a) What correlations, if any, exist & Questions 1-52 \\
\hline \multirow[t]{2}{*}{ competence } & between leadership styles and & \\
\hline & intercultural competence factors? & \\
\hline Intercultural & II (b) What correlations, if any, & ASI Questions $1-45$ and IES \\
\hline competence and & exist between leadership styles and & Questions 1-52 \\
\hline leadership style & intercultural competence? & \\
\hline Leadership style and & II (c) Do patterns of relationship & ASI Questions $1-45$ and IES \\
\hline \multirow[t]{4}{*}{ demographic data } & emerge from analysis of different & Questions 1-52 Demographic \\
\hline & demographic variables? & fields \\
\hline & & ASI access and success score \\
\hline & & (see note 1 below) \\
\hline \multicolumn{3}{|c|}{ Note 1: ASI Access and Success Score } \\
\hline \multicolumn{3}{|c|}{ This is a new data set that will be computed by seeking ASI scores at 5 or above at each of the } \\
\hline \multicolumn{3}{|c|}{ three domains, indicating that the participant has access and acumen in each domain to flex their } \\
\hline
\end{tabular}


INTERCULTURAL COMPETENCE AND LEADERSHIP STYLES

\section{Table 6. Intercultural Effectiveness Scale (IES) Results Summary}

\begin{tabular}{lllll}
\hline IES Factors and Competencies & Minimum & Maximum & Mean & Std. Deviation \\
\hline A. Continuous Learning & 3.17 & 5.00 & 4.10 & 0.38 \\
1. self-awareness & 2.44 & 5.00 & 3.82 & 0.48 \\
2. exploration & 3.50 & 5.00 & 4.38 & 0.41 \\
B. Interpersonal Engagement & 2.38 & 5.00 & 3.84 & 0.51 \\
3. global mindset & 1.00 & 5.00 & 3.23 & 0.78 \\
4. relationship interest & 2.63 & 5.00 & 4.45 & 0.47 \\
C. Hardiness & 2.28 & 4.44 & 3.34 & 0.41 \\
5. positive regard & 1.89 & 4.44 & 3.34 & 0.52 \\
6. emotional resilience & 1.67 & 4.78 & 3.33 & 0.62 \\
IES Total & 2.93 & 4.48 & 3.76 & 0.30 \\
N = 93 & & & &
\end{tabular}


INTERCULTURAL COMPETENCE AND LEADERSHIP STYLES

Table 7. Achieving Styles Inventory (ASI) Results Summary

\begin{tabular}{|c|c|c|c|c|}
\hline ASI Dimensions and & & & & \\
\hline Styles & Minimum & Maximum & Mean & Std. Deviation \\
\hline \multicolumn{5}{|l|}{ Direct Leadership Set } \\
\hline 1. intrinsic & 0.87 & 7.00 & 5.39 & 0.87 \\
\hline 2. competitive & 1.13 & 7.00 & 4.38 & 1.13 \\
\hline 3. power & 1.20 & 7.00 & 4.83 & 1.29 \\
\hline \multicolumn{5}{|c|}{ Instrumental Leadership Set } \\
\hline 4. personal & 1.00 & 7.00 & 4. 61 & 1.37 \\
\hline 5. social & 1.24 & 6.80 & 4.17 & 1.24 \\
\hline 6. entrusting & 0.99 & 7.00 & 4.84 & 0.99 \\
\hline \multicolumn{5}{|c|}{ Relational Leadership Set } \\
\hline 7. collaborative & 1.00 & 7.00 & 4.62 & 1.36 \\
\hline 8. contributory & 1.09 & 7.00 & 4.85 & 1.10 \\
\hline 9. vicarious & 1.04 & 7.00 & 4.92 & 1.04 \\
\hline ASI Total & 0.74 & 6.30 & 4.74 & 0.74 \\
\hline
\end{tabular}


INTERCULTURAL COMPETENCE AND LEADERSHIP STYLES

Table 8. IES Factors/ASI Dimensions Correlation Coefficients in Pearson's $\rho ; \mathbf{N}=93$ for all measures

ASI Leadership Dimensions

IES Factors

Direct

Instrumental

Relational Total ASI

A. Continuous Learning

correlation coefficients $\rho$

.381

.306

.339

.433

sig. p

$.001 * * *$

$.001 * * *$

$.003 * *$

$.001 * * *$

B. Interpersonal Engagement

$\begin{array}{lllll}\text { correlation coefficients } \rho & .254 & .003 & .152 & .177 \\ \text { sig. } \mathrm{p} & .637 & .831 & .849 & .156\end{array}$

C. Hardiness

$\begin{array}{lllll}\text { correlation coefficients } \rho & -.022 & -.020 & .149 & .050\end{array}$

sig. $\mathrm{p}$

.637

.831

.849

.156

IES Total

$\begin{array}{lllll}\text { correlation coefficients } \rho & .299 & .123 & .305 & .312 \\ \text { sig. p } & .002 * * & .004 * * & .243 & .003 * *\end{array}$

All p scores are two-tailed; ** p .01; *** p .001 
INTERCULTURAL COMPETENCE AND LEADERSHIP STYLES

Table 9. Correlation Coefficients for IES Continuous Learning Factor and Competencies with ASI Direct Dimensions and Intrinsic and Power Leadership Styles

IES Factors and Competencies

Self-Aware $\quad$ Exploration $\quad$ Continuous Learning

ASI Dimensions and Leadership

Styles

\begin{tabular}{|c|c|c|c|}
\hline \multicolumn{4}{|l|}{ A. Direct } \\
\hline \multicolumn{4}{|l|}{ direct total } \\
\hline correlation coefficients $\rho$ & NS* & .369 & .381 \\
\hline sig. $\mathrm{p}$ & --- & $.001 * * *$ & $001 * * *$ \\
\hline \multicolumn{4}{|l|}{ Intrinsic } \\
\hline correlation coefficients $\rho$ & NS* & .349 & .326 \\
\hline sig. $\mathrm{p}$ & --- & $.001 * * *$ & $.002 * *$ \\
\hline \multicolumn{4}{|l|}{ Power } \\
\hline correlation coefficients $\rho$ & .315 & .402 & .417 \\
\hline sig. $p$ & $.002 * *$ & $.001 * * *$ & $.001 * * *$ \\
\hline \multicolumn{4}{|c|}{ All significance scores are 2 -tailed; $* \mathrm{NS}=$ not significant $\geq .290 ; * * \mathrm{p} .01 ; * * * \mathrm{p} .001$. The } \\
\hline
\end{tabular}


INTERCULTURAL COMPETENCE AND LEADERSHIP STYLES

Table 10. Correlation Coefficients for IES Continuous Learning Factor and Competencies with ASI Instrumental Dimension/Social Leadership Style

IES Factor and Competencies

Self-Aware $\quad$ Exploration $\quad$ Continuous Learning

ASI Leadership Style

B. Instrumental

Social

$\begin{array}{llll}\text { correlation coefficients } \rho & .306 & \text { NS* } & .292 \\ \text { sig. p } & .003^{* *} & --- & .005^{* *}\end{array}$

All significance scores are 2-tailed; $*$ NS $=$ Not Significant .290; ** p .01; *** p .001 
INTERCULTURAL COMPETENCE AND LEADERSHIP STYLES

Table 11. Correlation Coefficients for IES Continuous Learning Factor and Competencies with ASI Relational Dimension and Leadership Styles

IES Factor and Competencies

Self-Aware $\quad$ Exploration $\quad$ Continuous Learning

ASI Dimension and Leadership

Styles

C. Relational

Relational Total

$\begin{array}{llll}\text { correlation coefficients } \rho & \text { NS* } & .322 & .339\end{array}$

$\begin{array}{llll}\text { sig. } \mathrm{p} & -- & .021 & .003 * *\end{array}$

Collaborative

$\begin{array}{llll}\text { correlation coefficients } \rho & \text { NS* } & .293 & \text { NS* }\end{array}$

$\begin{array}{llll}\text { sig. } \mathrm{p} & --- & .001 * * *\end{array}$

Contributory

$\begin{array}{llll}\text { correlation coefficients } \rho & \text { NS* } & .334 & .346\end{array}$

$\begin{array}{llll}\text { sig. p } & -- & .001 * * * & .001 * * *\end{array}$

All significance scores are 2-tailed; $* \mathrm{NS}=$ Not Significant .290; ** p .01; *** p .001.

The vicarious leadership style is not displayed because the correlational scores were not significant in this context. 
INTERCULTURAL COMPETENCE AND LEADERSHIP STYLES

Table 12. Correlation Coefficients - IES Continuous Learning Factor and Competencies with ASI Total Scores

IES Factor and Competencies

Self - Aware $\quad$ Exploration $\quad$ Continuous Learning

ASI Leadership Total

D. ASI Total

$\begin{array}{llll}\text { correlation coefficients } \rho & .351 & .391 & .433 \\ \text { sig. p } & .012 & .002^{* *} & .001^{* * *}\end{array}$

All significance scores are 2-tailed; ** p .01; *** p .001 
INTERCULTURAL COMPETENCE AND LEADERSHIP STYLES

Table 13. IES Interpersonal Engagement Factor and Relationship Interest Competency Correlated to the ASI Power Leadership Style

IES Factors/Competencies

\begin{tabular}{|c|c|}
\hline Relationship & Interpersonal \\
\hline Interest & Engagement \\
\hline
\end{tabular}

ASI Leadership Style

Power

$\begin{array}{llll}\text { correlation coefficients } \rho & .394 & .311 & .389\end{array}$

$\begin{array}{llll}\text { sig. p } & .001^{* * *} & .003 * * & <001 * * *\end{array}$

All significance scores are 2-tailed; ** p .01; *** p .001 
Table 14. IES Total Scores Correlated to the ASI Relational Dimension Total, Collaborative, and Contributory Leadership Styles

IES Total

ASI Dimension and Leadership

Styles

A. Relational

Relational Total

correlation coefficients $\rho \quad .305$

sig. p $\quad .243$

Collaborative

correlation coefficients $\rho \quad .303$

sig. $\mathrm{p} \quad .003 * *$

Contributory

correlation coefficients $\rho \quad .323$

sig. p .002**

All significance scores are 2-tailed; ** p .01; *** p .001 
INTERCULTURAL COMPETENCE AND LEADERSHIP STYLES

Table 15. Kendall's $\tau$ Correlation Coefficients when the IES Continuous Learning and

\section{Exploration Factors are Correlated to the ASI Power Leadership Style}

IES Factor and Competency

Exploration Continuous Learning

ASI Leadership Style and ASI

Total

Power

correlation coefficients $\tau \quad .317 \quad .306$

$\begin{array}{lll}\text { sig. } \mathrm{p} & .001 * * * \quad .001 * * *\end{array}$

D ASI Total

correlation coefficients $\tau \quad .317$

$\begin{array}{lll}\text { sig. } \mathrm{p} & .001 * * & .003^{* *}\end{array}$

All significance scores are 2-tailed; ** p .01; *** p .001 


\section{References}

Allport, G. W. (1954). The nature of prejudice. Cambridge, MA: Addison-Wesley.

Allport, G. W., \& Kramer, B. M. (1946). Some roots of prejudice. The Journal of General Psychology, 22, 9-39.

Altbach, P., \& Knight, J. (2007). The internationalization of higher education: Motivations and realities. Journal of Studies in International Education, 11(3-4), 290-305. doi: 10.1177/1028315307303542

American Council on Education. (2002). Investing in people: Developing all of America's talent on campus and in the workplace. Retrieved from http://www.acenet.edu/bookstore/pdf/investing_in_people.pdf

American Management Association. (2011). Developing successful global leaders:

The second annual study of challenges and opportunities. Retrieved from http://www.amanet.org/pdf/developing-successful-global-leaders.pdf

Andrade, M. S. (2006). International student persistence: integration or cultural integrity. Journal of College Student Retention, Research, Theory \& Practice, 8(1), 57-81. Antonakis, J., Avolio, B. J., \& Sivasubramaniam, N. (January 01, 2003). Context and leadership: an examination of the nine-factor full-range leadership theory using the Multifactor Leadership Questionnaire. The Leadership Quarterly, 14(3), 261295.

Antonakis, A., Cianciolo, A., \& Sternberg, R. (2004). The nature of leadership. Thousand Oaks, CA: SAGE. 
Antonio, A. L., Chang, M. J., Hakuta, K., Kenny, D. A., Levin, S., \& Milem, J. F. (August 01, 2004). Research Report: Effects of Racial Diversity on Complex Thinking in College Students. Psychological Science, 15(8), 507-510.

Arasaratnam, L. A. (July 01, 2006). Further Testing of a New Model of Intercultural Communication Competence. Communication Research Reports, 23(2), 93-99. Association of American Colleges and Universities. (1995). The drama of diversity and democracy: Higher education and American commitments. Retrieved from http://www.aacu.org/publications/pdfs/DramaofDiversity.pdf Association of American Colleges and Universities. (2008). Our students' best work: A framework for accountability worthy of our mission. Retrieved from http://www.aacu.org/publications/pdfs/StudentsBestReport.pdf

The Association to Advance Collegiate Schools of Business. (2011). Globalization of management education: Changing international structures, adaptive strategies, and the impact on institutions. Bradford, England: Emerald Group Publishing.

Astin, H., Antonio, A. L., Cress, C. M., \& Astin, A. A. (1998). Race and ethnicity in the American professorate, 1995-96. Los Angeles, CA: UCLA Higher Education Research Institute.

Babbie, E. R. (1999). The basics of social research. Belmont, CA: Wadsworth Thomson Learning.

Babbie, E. R. (2002). The basics of social research. Belmont, CA: Wadsworth Thomson Learning. 
INTERCULTURAL COMPETENCE AND LEADERSHIP STYLES

Barnlund, D. C. (1962). Consistency of emergent leadership in groups with changing tasks and members. Speech Monographs, 29, 45-52. doi:

$10.1080 / 03637756209375335$

Bass, B.M. (1985). Leadership and performance beyond expectations. New York, NY: Free Press

Bass, B.M. (1997). Does the Transactional-Transformational Leadership Paradigm Transcend Organizational and National Boundaries? American Psychologists, 52(2), (1997), 130-139.

Bass, B. M., Stogdill, R. M., \& Stogdill, R. M. (1990). Bass \& Stogdill's handbook of leadership: Theory, research, and managerial applications. New York, NY: Free Press.

Beardsley, K., Stewart, G., \& Wilmes, M. (1987). Achieving styles of students and student affairs professionals. Journal of College Student Personnel, 28(5), $412-419$.

Belenky, D.M. \& Nokes, T.J., (2009). Examining the Role of Manipulatives and Metacognition on Engagement, Learning, and Transfer. Journal of Problem Solving, 2(2), 102-129.

Bennett, J. M. (1985). Intercultural communication training in cultural self-awareness for study abroad (international education) (Doctoral dissertation). Available from ProQuest Dissertations and Theses database. (UMI No. 8606210) 
Bennett, J. M. (2008a). On becoming a global soul. In Savicki, V. (Ed.), Developing intercultural competence and transformation: Theory, research, and application in international education (pp. 13-31). Sterling, VA: Stylus.

Bennett, J. M. (2008b). Transformative training: Designing programs for cultural learning. In M. A. Moodian (Ed.), Contemporary leadership and intercultural competence: Understanding and utilizing cultural diversity to build successful organizations (pp. 95-110). Thousand Oaks, CA: SAGE.

Bennett, J. M., \& Bennett, M. J. (1994). Multiculturalism and international education: Domestic and international differences. In G. Althen (Ed.), Learning across cultures (pp. 145-172). Washington, DC: NAFSA.

Bennett, J. M., \& Bennett, M. J. (2004). Developing intercultural sensitivity: An integrative approach to global and domestic diversity. In D. Landis (Ed.), Handbook of intercultural training (pp. 153-165). Thousand Oaks, CA: SAGE.

Bennett, M. J. (1993). Towards ethnorelativism: A developmental model of intercultural sensitivity. In R. M. Paige (Ed.), Education for the intercultural experience (pp. 21-71). Yarmouth, ME: Intercultural Press.

Bennett, M. J. (2001). Paradigmatic assumptions of intercultural communication (intercultural development inventory manual). Portland, OR: The Intercultural Communications Institute. 
Bennett, J. M., \& Castiglioni, I. (2004). Embodied ethnocentrism and the feeling of culture: A key to training for intercultural competence. In D. Landis (Ed.), Handbook of intercultural training (pp. 249-265). Thousand Oaks, CA: SAGE.

Bennis, W. G. (December 01, 1959). Leadership Theory and Administrative Behavior: The Problem of Authority. Administrative Science Quarterly, 4(3), 259-301.

Berry, H. \& Chisholm, L. (1999). Service-learning in higher education around the world: An initial look. New York, NY: International Partnership for Service Learning and Leadership.

Bhandari, R., \& Blumenthal, P. (2011). International students and global mobility in higher education: National trends and new directions. New York: Palgrave Macmillan.

Bhaskar-Shrinivas, P., Harrison, D. A., Shaffer, M. A., \& Luk, D. M. (2005). Inputbased and time-based models of international adjustment: Meta-analytic evidence and theoretical extensions. Academy of Management Journal, $48(2), 257$.

Bird, A., \& Osland, J. S. (2004). Global competencies: An introduction. In H. W. Lane, M. L. Maznevski, M. E. Mendenhall, \& J. McNett (Eds.), The Blackwell handbook of global management. (pp. 57-79). Hoboken, NJ: Wiley-Blackwell. 
Black, H. T., \& Duhon, D. L. (2006). Assessing the impact of business study abroad programs on cultural awareness and personal development. Journal of Education for Business, 81(3), 140-144.

Black, J.S., Mendenhall, M., \& Oddou, G. (1991) Toward a comprehensive model of international adjustment: An integration of multiple theoretical perspectives. Academy of Management Review. 16(2), 291-317.

Bleszynska, K. M. (2008). Constructing intercultural education. Intercultural Education, 19(6), 537-545.

Bolen, M. C. (2007). A guide to outcomes assessment in education abroad. Carlisle, PA: The Forum on Education Abroad.

Boyacigiller, N., Beechler, S., Taylor, S., \& Levy, O. (2004). The crucial yet elusive global mindset. In H. W. Lane, M. L. Maznevski, M. E. Mendenhall, \& J. McNett (Eds.), The Blackwell handbook of global management. (pp. 81-93). Hoboken, NJ: Wiley-Blackwell.

Boyatzis, R. E. (1982). The competent manager: A model for effective performance. New York, NY: Wiley.

Braskamp, L., Trautvetter, L., \& Ward, K. (2006). Putting students first: creating a climate of support and challenge. Journal of College and Character, 6(8), 1-5.

Braskamp, L. (2009a). Internationalization in higher education: Four issues to consider. Journal of College and Character, 10(6), 1-7. 
INTERCULTURAL COMPETENCE AND LEADERSHIP STYLES

Braskamp, L. (2009b). Internationalizing a campus: A framework for assessing its progress. Journal of College and Character, 10(7), 1-8.

Braskamp, L. (2010). Being effective interventionist to foster student global citizenship. Journal of College and Character, 11(1). doi: 10.2202/1940-1639.1014

Brewer, M. B. (1999). The psychology of prejudice: Ingroup love and outgroup hate? Journal of Social Issues, 55, 429-444. doi: 10.1111/0022-4537.00126

Brown, L., \& Holloway, I. (January 01, 2008). The initial stage of the international sojourn: excitement or culture shock?. British Journal of Guidance \& Counselling, 36(1), 33-49.

Brown, D. J., Scott, K. A., \& Lewis, H. (2004). Information Processing and Leadership. In A. Antonakis, A. Cianciolo, \& R. Sternberg (Eds.), The nature of leadership (pp. 125-147). Thousand Oaks, CA: SAGE.

Brown, D. M. (2007). Transformational leadership behaviors and achieving styles of fraternity and sorority leaders. Ohio University). ProQuest Dissertations and Theses, Retrieved from http://search.proquest.com/docview/304831361?accountid=13265

Bryman, A. (1992). Charisma and leadership in organizations. London, UK: Sage Publications.

Burns, J. M. G. (1978). Leadership. New York: Harper \& Row. 
INTERCULTURAL COMPETENCE AND LEADERSHIP STYLES

C-SPAN \& Washington Journal. (2011, November 14). State Department role in international education [interview]. Retrieved from http://www.cspanvideo.org/program/RoleinInte

Cameron, K. S. \& Quinn, R. E. (2011). Diagnosing and changing organizational culture: Based on the competing values framework. San Francisco, CA: Jossey-Bass.

Charest, G. (1996). Study of achieving styles of Massachusetts middle and high school principles to determine which styles they are using to implement mandates of the Massachusetts Education Reform Act. Unpublished manuscript. University of Massachusetts, Amherst.

Chhokar, J., Brodbeck, F., \& House, R.J. (Eds.). (2007). Culture and leadership across the world: The GLOBE book of in-depth studies of 25 societies. Mahwah, NJ: Lawrence Erlbaum.

Chickering, A. W. (2010). Our purposes: Personal reflections on character development and social responsibility in high education. Liberal Education, 96(3), 54-59. Retrieved from http://portlandstate.worldcat.org/title/our-purposes-personalreflections-on-character-development-and-social-responsibility-in-highereducation/oclc/672136450\&referer=brief_results

Chomsky, N. (1984). Language knowledge: Its components and origins.

Communications, 40, 7-24. 
Clark, B. C. (1987). The academic profession: National, disciplinary, and institutional settings. Berkeley: University of California Press.

Cornwell, G. H., \& Stoddard, E. W. (1999). Globalizing knowledge: Connecting international and intercultural studies. Washington, DC: Association of American Colleges and Universities.

Cornwell, G. H., \& Stoddard, E. W. (2006). Freedom, diversity, and global citizenship. Liberal Education, 92(2), 23-26.

Cress, C.M., Collier, P.J., \& Reitenaurer, V.L., (2005). Learning through serving : a student guidebook for service-learning across the disciplines. Sterling, VA: Stylus Publishing

Creswell, J. W. (1994). Research design: Qualitative \& quantitative approaches. Thousand Oaks, CA: SAGE.

Deardorff, D. K. (2004a). The identification and assessment of intercultural competence as a student outcome of internationalization at institutions of higher education in the United States (Doctoral dissertation). Available from ProQuest Dissertations and Theses database. (UMI No. 3128751)

Deardorff, D. K. (2004b). “In search of intercultural competence.” International Educator, 8(2), 13-15.

Deardorff, D. K. (2009). The SAGE handbook of intercultural competence. Thousand Oaks, CA: SAGE. 
De Hoogh, A. H. B., Den Hartog, D. N., \& Koopman, P. L. (2005). Linking the big fivefactors of personality to charismatic and transactional leadership; perceived dynamic work environment as a moderator. Journal of Organizational Behavior, 26, 839-865. doi: 10.1002/job.344

DeJaeghere, J., \& Zhang, Y. (January 01, 2008). Development of intercultural competence among US American teachers: professional development factors that enhance competence. Intercultural Education, 19, 3, 255-268. http://portlandstate.worldcat.org/oclc/357043626

Den Hartog, D. N., \& Dickson, M. W. (2004). Leadership and culture. In A. Antonakis, A. Cianciolo, \& R. Sternberg (Eds.), The nature of leadership. (pp. 249-279). Thousand Oaks, CA: SAGE.

Di Vita, G. (2006). Towards a culturally inclusive pedagogy in UK higher education: a business and management perspective. A dissertation, Oxford, UK : Oxford Brookes University.

Dinges, N. G., \& Baldwin, K. D. (1996). Intercultural competence: A research perspective. In D. Landis, \& R. S. Bhagat (Eds.), Handbook of intercultural training. Thousand Oaks, CA: SAGE.

Dolby, N., \& Rahman, A. (2008). Research in International Education. Review of Educational Research, 78(3): 676-726

Durrant, M., \& Dorius, C. (2007). Study abroad survey instruments: A comparison of survey types and experiences. Journal of Studies in International Education, 
INTERCULTURAL COMPETENCE AND LEADERSHIP STYLES

11(1), 33-53. Retrieved from http://portlandstate.worldcat.org/title/study-abroadsurvey-instruments-a-comparison-of-survey-types-andexperiences/oclc/440291948\&referer=brief_results

Economist Intelligence Unit. (2010). Up or out: Next moves for the modern expatriate. A report from the Economist Intelligence Unit, a division of The Economist. Retrieved from http://www.deplacementpros.com/file/92316

Edwards, R., Crosling, G., Petrovic-Lazarovic, S., \& O'Neill, P. (January 01, 2003). Internationalisation of Business Education: Meaning and implementation. Higher Education Research and Development, 22(2), 183-192.

Eland, A., Greenblatt, S., \& Smithee, M. (2009). U.S. Culture Series. Washington, DC: NAFSA: Association of International Educators.

Ensari, N., \& Murphy, S.E. (2003). Cross-cultural variations in leadership perceptions and attribution of charisma to the leader. Organizational Behavior and Human Decision Processes, 92(1-2), 52-66. doi: 10.1016/S0749-5978(03)00066-9

Field, A. (2009). Discovering statistics using SPSS (3rd ed.). Los Angeles, CA: SAGE. Fiedler, F. E. (1971). Leadership. Morristown, N.J: General Learning Press.

Fischer, K. (2007). Flat world lessons for real-world students. Chronicle of Higher Education, 54(10), A35.

Fobbs, J. (1988). Achieving styles of female community college presidents. Unpublished manuscript, Ohio State University, Columbus, OH. 
Franek, Robert. (2000). The best 331 colleges (2001 ed.). Framingham, MA: The Princeton Review.

Fulbright Program. (2011a). About Fulbright. Retrieved August 1, 2011, from http://foreign.fulbrightonline.org/about.html Fulbright Program. (2011b). State alumni, your global community, pamphlet by the Fulbright Program, Washington, DC.

Fulbright Program. (2011c). Legacy of leadership, the Nobel Prize winners, pamphlet by the Fulbright Program, Washington, DC.

, M. (2001). Assessing campus diversity initiatives: A guide for campus practitioners. Washington, DC: Association of American Colleges and Universities.

Gardner, J. W. (1990). On leadership. New York, NY: Free Press.

General Motors Corporation. (2001). Brief of General Motors Corporation as amicus curiae in support of appellants in Grutter vs. Bollinger (No. 01-1447). Retrieved from http://www.umich.edu/ urel/admissions/legal/gru_amicus/gru_gm.html Gertsen, M. (1990). Intercultural competence and expatriates. Copenhagen, Denmark: Copenhagen School of Economics and Business Administration, Institute of International Economics and Management.

Graen, G. \& Uhl-Bien, M. (1995). Relationship-based approach to leadership: Development of leader-member exchange (LMX) theory of leadership over 25 
INTERCULTURAL COMPETENCE AND LEADERSHIP STYLES

years: Applying a multi-level multi-domain perspective. Leadership Quarterly, $6,219-247$.

Gray, K.S., Murdock, G.K., \& Stebbins, C.D., (2002). Assessing Study Abroad's Effect on an International Mission. Change, 34(3): 44-51

Grayson, J. P., (2008). The experiences and outcomes of domestic and international students at four Canadian universities. Higher Education Research \& Development, 27(3), 215-230

Green, M. F. (2003). Mapping internationalization on U.S. campuses: 2003 ed. Washington, DC: American Council on Education.

Green, M. F. (2008). Mapping internationalization on U.S. campuses: 2008 ed. Washington, DC: American Council on Education.

Grunig, J. E. (July 01, 1971). Communication and the Economic Decision-Making Processes of Colombian Peasants. Economic Development and Cultural Change, 19(4), 580-597.

Gurin, P. (2003). Expert report of Patricia Gurin; Gratz, et al. v. Bollinger, et al., No. 9775321 (E.D. Mich.) and Grutter, et al. v. Bollinger, et al., No. 97-75928 (E.D. Mich.). Retrieved from http://www.umich.edu/ urel/admissions/legal/expert/ref.html

Gurin, P., Dey, E. L., Hurtado, S., \& Gurin, G. (2002). Diversity and higher education: Theory and impact on educational outcomes. Harvard Education Review, 70(3), $330-336$. 
INTERCULTURAL COMPETENCE AND LEADERSHIP STYLES

Haigh, M. (2002). Internationalisation of the curriculum: Designing inclusive education for a small world. Journal of Geography in Higher Education, 26(1), 49-66.

Hall, E. T. (1959). The silent language. Garden City, N.Y: Doubleday.

Hall, E. T. (1966). The hidden dimension. Garden City, NY: Anchor Books.

Hall, E. T. (1976). Beyond culture. Garden City, NY: Anchor Press.

Hambleton, R. K., \& Swaminathan, H. (1985). Item response theory: Principles and applications. Boston: Kluwer-Nijhoff.

Hambleton, R. K., Swaminathan, H., \& Rogers, H. J. (1991). Fundamentals of item response theory. Newbury Park, CA: SAGE.

Hammer, M. R., \& Bennett, M. J. (2001a). The intercultural development inventory [instrument]. Portland, OR: Intercultural Communication Institute.

Hart, P.D. (2008). How should colleges assess and improve student learning; Employer's view on the accountability challenge. A survey of employers conducted on behalf of: The American Association of Colleges and Universities. Peter D. Hart Associates, Washington, D.C http://www.aacu.org/press_room/press_releases/2008/survey.cfm.

Hayden, M., \& Thompson, J.J., (2008). International education: principles and practice. London, UK: Taylor \& Francis

Hayward, F. M. (2000). Internationalization of U.S. higher education. Retrieved from American Council on Education website: http://www.acenet.edu/bookstore/pdf/2000-intl-report.pdf 
Hechanova, R., Beehr, T., \& Christiansen, N. (December 01, 2003). Antecedents and consequences of employees' adjustment to overseas assignment: a meta-analytic review. Human Resources Abstracts, 38(4), 213-236

Hernandez, D. (2004). Principal leadership and student achievement: An examination of the impact of principals' achievement styles. Unpublished manuscript, Claremont Graduate University, Claremont, CA.

Hofstede, G. H. (1980). Culture's consequences: International differences in workrelated values. Beverly Hills, CA : Sage Publications.

Hofstede, G. H. (1984). Culture's consequences: Comparing values, behaviors, institutions, and organizations across nations. Thousand Oaks, CA: Sage Publications.

Hofstede, G. H. (1985). Cultural differences in teaching and learning. International Journal of Intercultural Relations, 10(3), 301-320.

Hofstede, G. H. (1991). Cultures and organizations: Software of the mind: Intercultural cooperation and its importance for survival. London, England: Harper Collins.

Hofstede, G. H. (2001). Culture's consequences: Comparing values, behaviors, institutions, and organizations across nations. Thousand Oaks, CA: Sage Publications. 
House, R. J. (1977). A 1976 theory of charismatic leadership. In Hunt, J. G., \& Larson, L. L. (1977). Leadership: The cutting edge. Carbondale, Ill.: Southern Illinois University Press.

Hovland, K., \& Association of American Colleges and Universities. (2006). Shared futures: Global learning and liberal education. Washington, DC: Association of American Colleges and Universities.

Hovland, K. (September 01, 2009). Global Learning: What Is It? Who Is Responsible for It?. Peer Review, 11(4), 4-7

Huba, M. E. \& Freed, J. E. (2000). Learning-centered assessment on college campuses: Shifting the focus from teaching to learning. Needham, MA: Allyn \& Bacon.

Ibrahim, N. \& Penfield, S. (2005). Dynamic diversity: new dimensions in mixed composition classes. ELT Journal, 59(3): 217-225

Institute of International Education. (2010). Open doors 2010 fast facts. Retrieved from http://www.iie.org/en/Research-and-Publications/ /media/Files/Corporate/OpenDoors/Fast-Facts/Fast\%20Facts\%202010.ashx

Jenkins, N. H. (2009). The new Mediterranean diet cookbook: a delicious alternative for lifelong health. New York, NY: Bantam Books.

Karp, M. M. (2011). How non-academic supports work: Four mechanisms for improving student outcomes (CCRC Brief No. 54). New York, NY: Teachers College, Columbia University. 
Keeley, T. (2012, July). Psychological traits affecting both cultural adaptation and foreign language acquisition. Paper presented at the 21st Congress of the International Association for Cross-Cultural Psychology, Stellenbosch, South Africa. Abstract retrieved from http://www.iaccp2012southafrica.co.za/getpage.php?title=home

Kenny, D. A. \& Zaccaro, S. J. (1983). An estimate of variance due to traits in leadership. Journal of Applied Psychology, 68, 678-685. doi: 10.1037/0021-9010.68.4.678

Kezar, A., \& Eckel, P. (2000). The effect of institutional culture on change strategies in higher education: Universal principles or culturally responsive concepts? (Research Report No. ED446719). Retrieved from Education Resources Information Center database: http://www.eric.ed.gov/ERICWebPortal/recordDetail?accno=ED446719

King, P. M., \& Baxter Magolda, M. (2005). A Developmental Model of Intercultural Maturity. Journal of College Student Development, 46, 571-592.

Kluckhohn, C. K. M., \& Kluckhohn, F. R. (1947). American culture: generalized orientations and class patterns. In L. Bryson (Ed.), Conflicts or power in modern culture. New York, NY: Harper Bros.

Kluckhohn, F. R., \& Strodtbeck, F. L. (1961). Variations in value orientations. Evanston, Ill: Row, Peterson.

Kolb, D. (1984). Experiential learning: Experience as the source of learning and development. Englewood Cliffs, NJ: Prentice Hall. 
INTERCULTURAL COMPETENCE AND LEADERSHIP STYLES

Komives, S. (1992). Getting things done: A gender comparison of resident assistant and hall directors' achieving styles. Journal of College and Student Housing, 22(2), $30-38$.

Kozai Group. (2004). Global competencies inventory, St. Louis, MO: Kozai Group.

Kozai Group. (2009). Intercultural effectiveness scale, St. Louis, MO: Kozai Group.

Kozai Group. (2010). Global competencies inventory qualifying seminar handbook.

Portland, OR: Intercultural Communication Institute.

Lagarde, C. (2012, May). Global Connections and Global Citizens-an address to the Kennedy School of Government. Speech delivered at Harvard University, Cambridge, MA. Retrieved from http://www.imf.org/external/np/speeches/2012/052312.htm

Lange, D. K. (1993). Achieving styles of managerial and non-managerial employees: Implications for the management of diversity. University of Pretoria (South Africa)). ProQuest Dissertations and Theses, , 1. Retrieved from http://search.proquest.com/docview/304101676?accountid=13265

Leavitt, H., \& Lipman-Blumen, J. (1980). A case for the relational manager. Organizational Dynamics 9, 27-41.

Lee, S.-T. (January 01, 2001). SPECIAL REPORTS - International Education: 20 Years after Implementation of a Training Program. Neurosurgery, 48( 6,) 1348-1351 
INTERCULTURAL COMPETENCE AND LEADERSHIP STYLES

Lewin. R. (2009). The handbook of practice and research in study abroad: Higher education and the quest for global citizenship. Washington, DC: AAC\&U and Routledge.

Lipman-Blumen, J. (1972). How ideology shapes women's lives. Scientific American, $226(1), 34-42$.

Lipman-Blumen, J. (1992). Connective leadership: Female leadership styles in the 21st century workplace. Sociological Perspectives, 35(1), 183-203.

Lipman-Blumen, J. (1996). The Connective Edge: Leading in an interdependent world. San Francisco, CA: SAGE.

Lipman-Blumen, J. (1998). Connective leadership: What business needs to learn from academe. Change, 30(1), 49-53.

Lipman-Blumen, J. (2006). Individual and organizational achieving styles: A conceptual handbook for researchers and human resource professionals. Pasadena, CA: The Achieving Styles Institute.

Lipman-Blumen, J. (2011, October). A connective leadership strategy for global and enduring peace: A work in progress. Presented at the International Leadership Association 12th Annual Meeting, London, England.

Lipman-Blumen, J., Handley-Isaksen, A., \& Leavitt, H. (1983). Achieving styles in men and women: A model, an instrument, and some findings. In J. Spence (Ed.), Achievement and achievement motives: Psychological and sociological approaches (pp. 151-204). San Francisco, CA: Freeman. 
Lipman-Blumen, J., \& Leavitt, H. (1976). Vicarious and direct achievement patterns in adulthood. Counseling Psychologist, 6(1), 26-32.

Lord, R. G., de Vader, C. L., \& Alliger, G. M. (1986). A meta-analysis of the relation between personality traits and leadership perceptions: An application of validity generalization procedures. Journal of Applied Psychology, 71(3), 402-410. Retrieved from http://portlandstate.worldcat.org/title/a-meta-analysis-of-therelation-between-personality-traits-and-leadership-perceptions-an-application-ofvalidity-generalization-procedures/oclc/4643237015\&referer=brief_results

Lord, R. G., Foti, R. J., \& De, V. C. L. (December 01, 1984). A Test of Leadership Categorization Theory: Internal Structure, Information Processing, and Leadership Perceptions. Organizational Behavior \& Human Performance, 34(3), 343-378

Lou, K. H. \& Bosley, G. W. (2008). Dynamics of cultural contexts: Meta-level intervention in the study abroad experience. In V. Savicki (Ed.), Developing intercultural competence and transformation: Theory, research, and application in international education (pp. 276-296). Sterling, VA: Stylus.

Lucena, J. C. (2006). Globalization and organizational change: Engineers' experiences and their implications for engineering education. European Journal of Engineering Education, 31(3), 321-338. http://portlandstate.worldcat.org/title/globalization-and-organizational-change- 
INTERCULTURAL COMPETENCE AND LEADERSHIP STYLES

engineers-experiences-and-their-implications-for-engineeringeducation/oclc/361303904\&referer=brief_results

Mann, R. D. (1959). A review of the relationships between personality and performance in small groups. Psychological Bulletin, 56, 241-270. doi: 10.1037/h0044587

Marcy, M. B. (2002). Diversity, demographics and dollars: Challenges for higher education. Working paper No. 3 in Project on the Future of Higher Education series. Retrieved from http://www.cgee.org.br/atividades/redirKori/331

Maslow, A. (1968). Toward a psychology of being. New York, NY: Van Norstrand Rheinhold.

Maslow, A. \& Frager, R. (1970). Motivation and personality (2nd ed.). New York, NY: Harper \& Row.

Horner, M. S. (1968). Sex differences in achievement motivation and performance in competitive and non-competitive situations. University of Michigan). ProQuest Dissertations and Theses, , 246 p. Retrieved from http://search.proquest.com/docview/302311521?accountid=13265

McClelland, D. C. (1975). The effects of power training on community action agencies. The Journal of Applied Behavioral Science, 11(1), 92-115.

McClelland, D. C., Atkinson, J. W., Clark, R. A., \& Lowell, E. L. (1953). The achievement motive. New York, NY: Appleton-Century-Crofts.

McClure, J. W. (2007). International graduates' cross-cultural adjustment: Experiences, coping strategies, and suggested programmatic responses. Teaching in Higher 
INTERCULTURAL COMPETENCE AND LEADERSHIP STYLES

Education, 12, 199-217. Retrieved from

http://portlandstate.worldcat.org/title/international-graduates-cross-cultural-

adjustment-experiences-coping-strategies-and-suggested-programmaticresponses/oclc/425244211\&referer=brief_results

McNamara, D., \& Harris, R. J. (1997). Overseas students in higher education: Issues in teaching and learning. London, UK: Routledge.

McTighe, C., Garcia, M., Hudgins, C., Nettles, W., Sedlacek, W., \& Smith, D. (1999).

To form a more perfect union: Campus diversity initiatives. Washington, DC:

Association of American Colleges and Universities.

McTighe-Musil, C. (2006). Assessing global learning: Matching good intentions with

good practice. Washington, DC: Association of American Colleges and

Universities.

McWhirter, P. T. \& McWhirter, J. J. (2010). Historical antecedents: counseling psychology and the Fulbright Program. The Counseling Psychologist, 38(1), 32 49. doi: $10.1177 / 0011000009349914$

Meacham, J. \& Graff, J. G. (2006). Learning goals in mission statements: Implications for educational leadership. Liberal Education, 92(1), 6-13.

, R. (1962). The study of culture at a distance. Chicago, IL, U.P.

Mead, M. (1970). Sex and temperament in three primitive societies. New York: Morrow.

Meade, R.D. (1967). An experimental study of leadership in India. The Journal of social psychology, 72(1): 35-43 
Mendenhall, M. E., Kuhlmann, T. M., \& Stahl, G. K. (2001). Developing global business leaders: Policies, processes, and innovations. Westport, CT: Quorum Books.

Mendenhall, M. E., Kuhlmann, T. M., \& Stahl, G. K., \& Osland, J.S. (2002). Employee development and expatriate assignments: A review of the expatriate adjustment theory literature. In Gannon, M. J., \& Newman, K. L., The Blackwell handbook of cross-cultural management. Oxford, UK: Blackwell Publisher: 155-183.

Mendenhall, M., \& Oddou, G. (1985). The dimensions of expatriate acculturation: A review. Academy of Management Review, 10(1), 39-47.

Mendenhall, M., Stevens, M. J., Bird, A., \& Oddou, G. (2008). Specification of the content domain and reliability and validity of the intercultural effectiveness scale. St. Louis, MO: The Kozai Group.

Mendenhall, M., Stevens, M. J., Bird, A., \& Oddou, G. (2010). Specification of the content domain and reliability and validity of the global competencies inventory. St. Louis, MO: The Kozai Group.

Mendenhall, M., Stevens, M. J., Bird, A., \& Oddou, G. (2011). Specification of the content domain and reliability and validity of the global competencies inventory. St. Louis, MO: The Kozai Group Mezirow, J. (2000). Learning as transformation: Critical perspectives on a theory in progress. San Francisco, CA: Jossey-Bass. 
Milem, J. F., Chang, M. J., \& Antonio, A. L. (2005). Making diversity work on campus: A research-based perspective. Washington, DC: Association of American Colleges and Universities.

Moreno, J. F., Smith, D. G., Clayton-Pedersen, A. R., Parker, \& Hiroyuki-Teraguchi, D. (2006). The revolving door for under-represented minority faculty in higher education: An analysis from the campus diversity initiative. Washington, DC: Association of American Colleges and Universities.

Morey, A., \& Kitano, M. (1997). Multicultural course transformation in higher education: A broader truth. Boston, MA: Allyn and Bacon.

Mouw, R., \& Tippett, C. (Producers). (2011, August 18). Restoring political civility: An evangelical view. On Being. Retrieved from http://being.publicradio.org/programs/2011/ccp-mouw

Munoz, S. C. (1994). Achieving and leadership styles of mexican-american business and professional women. California State University, Long Beach). ProQuest Dissertations and Theses, , 71 p. Retrieved from http://search.proquest.com/docview/304176335?accountid=13265

Myburgh, C. P. H., Niehaus, L., \& Poggenpoel, M. (September 01, 2002). International learners' experiences and coping mechanisms within a culturally diverse context. Education, 123(1), 107-129 
INTERCULTURAL COMPETENCE AND LEADERSHIP STYLES

NAFSA: An Association of International Educators. (2009) NAFSA's principles for U.S. study abroad. Retrieved on September 26, 2011, from http://www.nafsa.org/about/default.aspx?id=2475

National Center for Postsecondary Improvement. (2002). Beyond reckoning: Research priorities for redirecting American higher education. Retrieved from http://www.stanford.edu/group/ncpi/unspecified/from_the_director.html

Noddings, N., \& Boston Research Center for the 21st Century. (2005). Educating citizens for global awareness. New York, NY: Teachers College Press.

Noronha, J. (2003). Building bridges: Internationalization and cultural diversity. International Educator, 12(1), 52.

Oberg, K. (1960). Culture shock: Adjustment to new cultural environments. Practical Anthropology, 7, 177-182.

Olson, C., Evans, R., \& Shoenberg, R. (2007). At home in the world: Bridging the gap between internationalization and multicultural education. Washington, DC: American Council on Education.

Onwuegbuzie, A. J. (2002). Why can't we get along? Towards a framework for unifying research paradigms. Education, 122, 518-530.

Osland, J. S. (2011, January). Creating global ready graduates. Presentation at Association of American Colleges \& Universities annual meeting, San Francisco, CA. 
Osland, J. S., Bird, A., Mendenhall, M., \& Osland, A. (2006). Developing global leadership capabilities and global mindset. In G. K. Stahl \& I. Bjorkman (Eds.), Handbook of research in international human resource management (pp. 197222). Cheltenham, England: E. Elgar.

Overland, W. (1996). College presidents' achieving styles and gender role perceptions (Doctoral dissertation). Available from ProQuest Dissertations and Theses database. (UMI No 9726237)

Paige, R. M., Fry, G. W., Stallman, E. M., Josic, J., \& Jon, J. E. (2009). Study abroad for global engagement: The long-term impact of mobility experiences. Intercultural Education, 20, 29-44.

Paige, R. M., Jacobs-Cassuto, M., Yershova, Y. A., \& DeJaeghere, J. (2003). Assessing intercultural sensitivity: A psychometric analysis of the Hammer and Bennett intercultural development inventory. International Journal of Intercultural Relations, 27(4), 467-486.

Paige, R. M., \& University of Minnesota. (2006). Maximizing study abroad: A students' guide to strategies for language and culture learning and use. Minneapolis: Center for Advanced Research on Language Acquisition, University of Minnesota.

Paige, R. M., Lange, D. L., Yershova, Y. A., \& Center for Advanced Research on Language Acquisition. (1999). Culture as the core: Integrating culture into the language curriculum. Minneapolis: University of Minnesota. 
INTERCULTURAL COMPETENCE AND LEADERSHIP STYLES

Pappamihiel, N. E., \& Walser, T. M. (2009). English language learners and complexity theory: Why current accountability systems do not measure up. Educational Forum, 73, 133-140.

SPSS Statistics Software (Student Version 18) [Computer software]. Thousand Oak, CA: SAGE.

Perry, W. G., Jr. (1970). Forms of intellectual and ethical development in the college years: A scheme. Austin, TX: Holt, Rinehart, and Winston.

Pettigrew, T. F. (2008). Future directions for intergroup contact theory and research. International Journal of Intercultural Relations, 32, 187-199.

Pettigrew, T. F., \& Tropp, L. R. (2006). A meta-analytic test of intergroup contact theory. Journal of Personality and Social Psychology, 90, 751-783.

Pettigrew, T. \& Tropp, L. R. (2008). Does intergroup contact reduce prejudice? Recent meta-analytic findings. In S. Oskamp (Ed.), Reducing prejudice and discrimination (pp. 93-114). Mahwah, NJ: Lawrence Erlbaum.

Pettigrew, T. F., \& Tropp, L. R. (2011). When groups meet: The dynamics of intergroup contact. New York, NY: Psychology Press.

Piaget, J. (1950). The psychology of intelligence. London, England: Routledge \& Paul.

Preece, J., Olssen, M., Codd, J., \& O’Neill, A. M. (2005). Review of education policy: Globalization, citizenship and democracy. International Review of Education, 51, 246-247. Retrieved from http://portlandstate.worldcat.org/title/review-ofeducation-policy-globalization-citizenship-anddemocracy/oclc/480153411\&referer=brief_results 
INTERCULTURAL COMPETENCE AND LEADERSHIP STYLES

Preskill, H. \& Russ-Eft, D. (2005). Building Evaluation Capacity. Thousand Oaks, CA: SAGE.

Pusch, M. D. \& Merrill, M. (2008). Reflection, reciprocity, responsibility, and committed relativism. In V. Savicki (Ed.), Developing intercultural competence and transformation: Theory, research, and application in international education, (pp. 297-321). Sterling, VA: Stylus.

Quinn, R.E. \& Rohrbaugh, J. (1983). A spatial model of effectiveness criteria: Towards a competing values approach to organizational analysis. Management Science, 29, 363-377. doi: 10.1287/mnsc.29.3.363

Reibling, C. (1989). Styles of achievement: The influence of developmental factors and academic experience. Unpublished manuscript, College of William and Mary, Williamsburg, VA.

Rhodes, T. L., (2010). Assessing outcomes and improving achievement: Tips and tools for using rubrics. Washington, DC: Association of American Colleges and Universities.

Rubenstein, F. D. (1971). A behavioral study of pollution: The role of perceived instrumentality in an externality situation (Doctoral dissertation). Available from ProQuest Dissertations \& Theses database. (UMI No. 7123553)

Rubin, K. (2003). Keeping the door open. International Educator, 12(2), 6-11.

Sandell, E. J. (June 01, 2007). Impact of International Education Experiences on Undergraduate Students. Delta Kappa Gamma Bulletin, 73(4), 12-39. 
Savicki, V. (2008). Developing intercultural competence and transformation: Theory, research, and application in international education. Sterling, VA: Stylus.

Scandura, T. A., \& Lankau, M. J. (1996). Developing diverse leaders: A leader-member exchange approach. The Leadership Quarterly, 7, 243-263.

Schoorman, D. (2000). What Really Do We Mean by “internationalization?” Contemporary Education, 71(4), 5. Retrieved from http://portlandstate.worldcat.org/title/what-really-do-we-mean-byinternationalization/oclc/93710638\&referer=brief_results

Schuerholz-Lehr, S. (2007). Teaching for global literacy in higher education: How prepared are the educators? Journal of Studies in International Education, 11, 180-204. Retrieved from http://portlandstate.worldcat.org/title/teaching-forglobal-literacy-in-higher-education-how-prepared-are-theeducators/oclc/440403231\&referer=brief_results

Shaffer, M. A., Harrison, D. A., \& Gilley, K. M. (September 01, 1999). Dimensions, Determinants, and Differences in the Expatriate Adjustment Process. Journal of International Business Studies, 30(3), 557-581.

Shamir, B., \& Howell, J. M. (January 01, 1999). Organizational and Contextual Influences on the Emergence and Effectiveness of Charismatic Leadership. Leadership Quarterly,10(2), 257-284.

Smith, R. M. (1992). Crossing pedagogical oceans: International teaching assistants in U.S. undergraduate education (Research Report No. ED358812).Washington, 
DC: George Washington University. Retrieved from Education Resources Information Center database: http://www.eric.ed.gov/ERICWebPortal/contentdelivery/servlet/ERICServlet?acc no $=\mathrm{ED} 358812$

Snow, N. E. (1992). Fulbright scholars as cultural mediators: An exploratory study. (Doctoral dissertation). Available from ProQuest Dissertations and Theses database. (UMI No. 9312019)

Stewart, C. (2010, February). Intercultural Effectiveness Survey: Administration \& Coaching. A presentation to the Society for Intercultural Education Training and Research, Tokyo, Japan.

Stewart, G. M. (1983). Achieving styles as a gauge for co-worker productivity in college student co-curricular environments. The American University). ProQuest Dissertations and Theses, , 119 p. Retrieved from http://search.proquest.com/docview/303109796?accountid=13265

Steinberg, M. (2007). The place of outcomes assessment in higher education today and the implications for education abroad. In M. C. Bolen (Ed.), A guide to outcomes assessment in education abroad. Carlisle, PA: The Forum on Education Abroad.

Stogdill, R. M. (1948). Personal factors associated with leadership: A survey of the literature. Journal of Psychology: Interdisciplinary and Applied, 25, 35-71. 
INTERCULTURAL COMPETENCE AND LEADERSHIP STYLES

Stokamer, S. T. (2011). Pedagogical catalysts of civic competence: The development of a critical epistemological model for community-based learning. Portland State University). ProQuest Dissertations and Theses, Retrieved from http://search.proquest.com/docview/889930492?accountid=13265

Stokely, L. (1986). Faculty fit: The relationship of academic culture and achieving styles to faculty satisfaction. Unpublished manuscript, Claremont Graduate University, Claremont, CA.

Stoddard, E.W., \& Cornwell, G. H. (2003). Peripheral visions: Towards a Geoethics of Citizenship. Liberal Education 89(3), 44-51. Retrieved from http://www.aacu.org/liberaleducation/le-su03/le-su3fperspective.cfm

Suckow, M. A. (1988). Differences in achieving styles among female college students from the United States and India. The Claremont Graduate University). ProQuest Dissertations and Theses, , 163 p. Retrieved from http://search.proquest.com/docview/303543221 accountid=13265

Sumner, W. G. (1907). Folkways: A study of the sociologic, importance of usages, manners, customs, mores, and morals. Boston, MA: Ginn.

Surbeck, B. (1997). Achieving style differences among university faculty (Doctoral dissertation). Available from ProQuest Dissertations and Theses database. (UMI No. 9732383)

Tanaka, G. K. (2003). The intercultural campus: Transcending culture \& power in American higher education. New York, NY: P. Lang. 
INTERCULTURAL COMPETENCE AND LEADERSHIP STYLES

Taylor, D. B. (1998). Change and the United States American Fulbright scholar (Doctoral dissertation). Available from ProQuest Dissertations and Theses database. (UMI No. 9826766)

Thomas, D. C. (1998). The expatriate experience: A critical review and synthesis. Advances in International Comparative Management, 12, 237-273.

Thompkins, T. C. (1989). Differences in achieving styles among Finns and Americans. Unpublished paper, The Claremont Graduate University, Claremont, CA Thompson, H. B., \& Thompson, G. H. (1996). Confronting diversity issues in the classroom with strategies to improve satisfaction and retention of international students. Journal of Education for Business, 72(1), 53--5.

Tinto, V. (2006). Student success and the construction of inclusive educational communities, recruitment and retention in higher education. Washington, DC: American Association of State Colleges and Universities. Retrieved from http://survey.csuprojects.org/uploads/HO/RQ/HORQxb19ritxiGXPo8yi7g/Tintore-Inclusive-Educational-Communities.pdf

Tokorozawa, Y. (1996). The effects of the Fulbright graduate study program: Its personal and social meanings in post-war Japan. University of California, Los Angeles). ProQuest Dissertations and Theses, , 134 p. Retrieved from http://search.proquest.com/docview/304281498?accountid=13265 
Triandis, H. C., Leung, K., Villareal, M. J., \& Clack, F. I. (December 01, 1985).

Allocentric versus idiocentric tendencies: Convergent and discriminant validation. Journal of Research in Personality, 19(4), 395-415.

Trooboff, S., VandeBerg, M., \& Rayman, J. (2007). Employer attitudes toward study abroad. Frontiers: the Interdisciplinary Journal of Study Abroad, 15, 17-33.

Tuleja E.A. (2008). Aspects of intercultural awareness through an MBA study abroad program: Going "backstage". Business Communication Quarterly, v71 n3 (2008 $0901), 314-337$

Tyler, K. M., Wade, B. A., \& Walton, T. R. (2006). Cultural considerations in teachers' perceptions of student classroom behavior and achievement. Teaching and Teacher Education, 22, 998-1005. Retrieved from http://portlandstate.worldcat.org/title/cultural-considerations-in-teachersperceptions-of-student-classroom-behavior-andachievement/oclc/109461985\&referer=brief_results

Ukpokodu, O. N. (2011). How a sustainable campus-wide diversity curriculum fosters academic success. Multicultural Education, 17, 2, 27-36. Retrieved from http://portlandstate.worldcat.org/title/how-a-sustainable-campus-wide-diversitycurriculum-fosters-academic-success/oclc/652116310\&referer=brief_results

Vande, B. M. (January 01, 2007). Intervening in the Learning of U.S. Students Abroad. Journal of Studies in International Education, 11(3-4), 392-399. 
Vander Horst, N. (1994). Achieving Styles in Eastern Europe: A case study of Bulgaria. An unpublished paper presented in the Symposium on Multi-Cultural and Gender Differences, at the annual meeting of the Western Psychological Association, Kona, Hawaii, April 30, 1994.

Van de Vijver, J. R., \& Leung, K. (2009). Theories of intercultural competence. In D. K. Deardorff (Ed.), The Sage handbook of intercultural competence (pp. 404-418) Thousand Oaks, CA: SAGE.

Van de Vijver, J. R., \& Tanzer, N. K. (2004). Bias and equivalence in cross-cultural assessment: an overview. European Review of Applied Psychology, 54, 2, 119 135.

Wangler, V. E. (2009). Connective leadership, behavioral complexity, and managerial effectiveness. The Claremont Graduate University). ProQuest Dissertations and Theses, , n/a. Retrieved from http://search.proquest.com/docview/304863784?accountid=13265

Whalley, T. R., Langley, L., Villarreal, L., British Columbia., \& Centre for Curriculum, Transfer and Technology. (1997). Best practice guidelines for internationalizing the curriculum. Victoria, B.C: The Ministry.

Wiersma, W. (2000). Research methods in education: An introduction. Boston, MA: Allyn and Bacon. 
INTERCULTURAL COMPETENCE AND LEADERSHIP STYLES

Williams, D. A., Berger, J. B., \& McClendon, S. A. (2005). Toward a model of inclusive excellence and change in postsecondary institutions. Washington, DC: American Association of Colleges and Universities.

Witte, A., Sequeira, I., \& Fonteyne, C. (2003). Internationalizing the assessment criteria to build cross-cultural competency: American and Chinese educational encounters. Journal of Teaching in International Business, 14, 4, 61-78. (Research Report No. EJ843249). Retrieved from Education Resources Information Center database: http://www.eric.ed.gov/ERICWebPortal/search/detailmini.jsp?_nfpb=true\&_\&ERICExtS earch_SearchValue_0=EJ843249\&ERICExtSearch_SearchType_0=no\&accno=EJ84324 9

Wlodkowski, R., \& Ginsberg, M. (1995). Diversity \& motivation: culturally responsive teaching. San Francisco, CA: Jossey-Bass.

Wu, G. J. (2006). Exploring outdoor leaders' cross-cultural experiences in the wilderness education setting (Doctoral dissertation). Available from ProQuest Dissertations and Theses Database. (UMI No. 3274252)

Yamashita, M. (2009). Japanese international graduate students in U.S. higher education classrooms: An investigation of their pedagogical and epistemological challenges and supports. (Doctoral dissertation). Available from ProQuest Dissertations and Theses database. (UMI No. 3358491)

Zaccaro, S. J., Foti, R. J., Kenny, D. A. (1991). Self-monitoring and trait-based variance in leadership: An investigation of leader flexibility across multiple group 
INTERCULTURAL COMPETENCE AND LEADERSHIP STYLES

situations. Journal of Applied Psychology, 76, 308-315. doi: 10.1037/00219010.76 .2 .308

Zaccaro, S. J., \& Klimoski, R. J. (2001). The nature of organizational leadership: Understanding the performance imperatives confronting today's leaders. San Francisco, CA: Jossey-Bass.

Zaleznik, A. (1989). The managerial mystique: Restoring leadership in business. New York, NY: Harper \& Row.

Zhou, Y., Jindal-Snape, D., Topping, K., \& Todman, J. (February 01, 2008). Theoretical Models of Culture Shock and Adaptation in International Students in Higher Education. Studies in Higher Education, 33(1), 63-75.

Zuniga, X., Williams, E. A., \& Berger, J. B. (2005). Action-oriented democratic outcomes: The impact of student involvement with campus diversity. Journal of College Student Development, 46, 660-678. Retrieved from http://portlandstate.worldcat.org/title/action-oriented-democratic-outcomes-theimpact-of-student-involvement-with-campusdiversity/oclc/356615786\&referer=brief_results 


\section{Appendix A}

The Intercultural Effectiveness Survey, 3 pages (including this one).

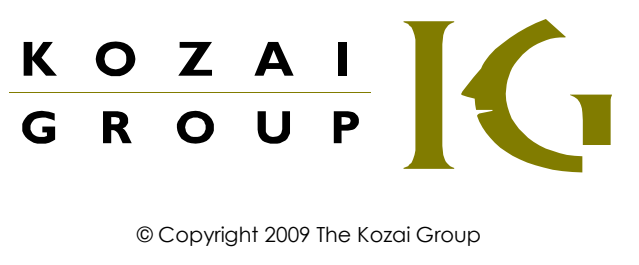

Version 2.1

www.kozaigroup.com

info@kozaigroup.com 


\begin{tabular}{|c|l|}
\hline \multicolumn{2}{|l|}{ Sample Statement: I believe children should listen to their parents. } \\
\hline 1 & I'm aware of my interpersonal style and can easily describe it to others. \\
\hline 2 & I know what I am good at. \\
\hline 3 & I am comfortable with myself. \\
\hline 4 & People who don't know themselves well are really doing themselves a \\
\hline 5 & $\begin{array}{l}\text { If someone asked me what my main weaknesses are, I could give them an } \\
\text { accurate answer right away. }\end{array}$ \\
\hline 6 & Thinking about my strengths and weaknesses is a good use of my time. \\
\hline 7 & I can clearly articulate my personal values to others. \\
\hline 8 & Usually I can tell what impact my behavior has on others. \\
\hline 9 & I enjoy reflecting on my past experiences to see what I can learn from them. \\
\hline 10 & I like to have contact with people from different cultures. \\
\hline 11 & $\begin{array}{l}\text { When I make an important decision, I look for information from as many } \\
\text { different sources as possible. }\end{array}$ \\
\hline 12 & I have grown over time. \\
\hline 13 & I take advantage of opportunities to do new things. \\
\hline 14 & I treat all situations as an opportunity to learn something. \\
\hline 15 & I have developed significant new skills over time. \\
\hline 16 & I seek experiences that will change my perspective. \\
\hline 17 & I can make mid-course corrections. \\
\hline 18 & I learn from mistakes. \\
\hline 19 & I am able to start over after setbacks. \\
\hline 20 & My friends would say I know a lot about world geography. \\
\hline 21 & I regularly read the travel section of the newspaper or news web sites. \\
\hline 22 & I can often be found reading about world geography. \\
\hline 23 & Every now and then I watch television programs about other countries and \\
\hline 24 & I regularly listen to the BBC or similar world news sources. \\
\hline 25 & As a student, I took many courses on foreign countries and cultures. \\
\hline 26 & $\begin{array}{l}\text { I routinely read the international section of the newspaper or news web } \\
\text { sites. }\end{array}$ \\
\hline
\end{tabular}




\begin{tabular}{|l|l|}
\hline 27 & The idea of learning a foreign language is more exciting to me than it is \\
\hline 28 & I tend to avoid conversations with people who are not fluent in my \\
\hline 29 & It doesn't bother me to start up a conversation with someone I don't \\
\hline 30 & Meeting people from other cultures is stressful. \\
\hline 31 & Given a choice, I would rather vacation at home than go abroad. \\
\hline 32 & Meeting people from other cultures is stimulating. \\
\hline 33 & It is hard to find things to talk about with people from other cultures. \\
\hline 34 & I enjoy making friends with people from other cultures. \\
\hline 35 & People these days have pretty low moral standards. \\
\hline 36 & $\begin{array}{l}\text { The only thing people can talk about these days, it seems, is movies, TV, } \\
\text { and foolishness like that. }\end{array}$ \\
\hline 37 & People get ahead by using "pull" and not because of what they know. \\
\hline 38 & Once you start doing favors for people, they'll just walk all over you. \\
\hline 39 & People are too self-centered. \\
\hline 40 & People are always dissatisfied and hunting for something new. \\
\hline 41 & You've probably got to hurt someone if you're going to make \\
\hline 42 & In my experience, people are pretty stubborn and unreasonable. \\
\hline 43 & Average people are not very well satisfied with themselves. \\
\hline 44 & It takes me a long time to get over a particularly stressful experience. \\
\hline 45 & I have never been good at coping with negative emotions. \\
\hline 46 & I find that little things often bother me. \\
\hline 47 & It's hard for me to get over my failures. \\
\hline 48 & It doesn't take me long to get over setbacks. \\
\hline 49 & I cope well with most things that come my way. \\
\hline 50 & Sometimes there is so much pressure I feel like I will burst. \\
\hline 51 & People who know me would say I remain calm in stressful situations. \\
\hline 52 & It usually takes me awhile to get over my mistakes. \\
\hline
\end{tabular}




\section{Appendix B}

The Achieving Styles Inventory Items, 2 pages (including this one).

\section{ff DONNEETIVE LAAERBHAP INSTTUTE}

ACHIEVING STYLES INVENTORY ITEMS

\section{DIRECT ITEMS}

Instrinsic:

1 For me, the most gratifying thing is to have solved a tough problem.

8 More than anything else, I like to take on a challenging task

16 For me, the most exciting thing is working on a tough problem.

32 I go out of my way to work on challenging tasks.

41 For me, the greatest satisfaction comes from breaking through to the solution of a new problem.

Competitive:

3 For me, winning is the most important thing.

9 Winning in competition is the most thrilling thing I can imagine.

14 The more competitive the situation, the better I like it.

22 I am not happy if I don't come out on top of a competitive situation.

37 I select competitive situations because I do better when I compete.

Power:

7 I want to be the leader.

10 I seek out leadership positions.

19 I seek positions of authority.

28 I want to take charge when working with others.

38 Being the person in charge is exciting to me.

\section{INSTRUMENTAL ITEMS}

Entrusting:

4 When I want to achieve something, I look for assistance.

17 I seek guidance when I have a task to accomplish.

23 I look for support from others when undertaking a new task.

29 I look for reassurance from others when making decisions.

42 When I encounter a difficult problem I go for help. 
Social:

2 I get to know important people in order to succeed.

18 I develop some relationships with others to get what I need to succeed.

24 I establish some relationships for the benefits they bring.

33 I use my relationships with others to get things done.

40 I establish a relationship with one person to get to know others.

Personal:

5 I work hard to achieve so people with think well of me.

11 I strive to achieve so that I will be well liked.

25 I try to be successful at what I do so that I will be respected.

30 I strive to achieve in order to gain recognition.

39 I work to accomplish my goals to gain the admiration of others.

\section{RELATIONAL ITEMS}

Vicarious:

6 I achieve my goals through contributing to the success of others.

12 I feel the successes or failures of those close to me as if they were my own.

31 When a loved one succeeds, I also have a sense of accomplishment.

34 For me, the greatest accomplishment is when people I love achieve their goals.

42 The accomplishments of others give me a feeling of accomplishment as well.

Contributory:

19 I achieve by guiding others toward their goals.

20 I have a sense of failure when those I care about do poorly.

26 My way of achieving is by coaching others to their own success.

35 I succeed by taking an active part in helping others with their success.

43 My way of achieving is by helping others to learn how to get what they want.

Collaborative:

12 Faced with a task, I prefer a team approach to an individual one.

15 Real team effort is the best way for me to get a job done.

24 For me, group effort is the most effective means of accomplishment.

36 Working with others brings out my best efforts.

45 My best achievements come from working with others. 


\section{Appendix C}

Intercultural Effectiveness Scale Results, 2 pages (including this one).

\section{Intercultural Effectiveness Scale Group Scores Fulbright Group A - Summer 2010}

\begin{tabular}{|c|c|c|c|c|c|c|}
\hline & \multicolumn{6}{|c|}{ Demonstrated Level of Effectiveness } \\
\hline & \multicolumn{2}{|c|}{ Low } & \multicolumn{2}{|c|}{ Moderate } & \multicolumn{2}{|c|}{ High } \\
\hline & 1 & 2 & 3 & 4 & 5 & 6 \\
\hline Continuous Learning & 5 & 4 & 8 & 5 & 13 & 8 \\
\hline Self-Awareness & 7 & 6 & 5 & 10 & 6 & 9 \\
\hline Exploration & 9 & 4 & & 9 & 9 & 12 \\
\hline $\begin{array}{l}\text { Interpersonal } \\
\text { Engagement }\end{array}$ & 2 & 7 & 4 & 8 & 14 & 8 \\
\hline Global Mindset & 7 & 2 & 7 & 4 & 12 & 11 \\
\hline Relationship Interest & 2 & 3 & 2 & 11 & 4 & 21 \\
\hline Hardiness & 8 & 6 & 7 & 8 & 6 & 8 \\
\hline Positive Regard & 9 & 7 & 1 & 5 & 15 & 6 \\
\hline Emotional Resilience & 10 & 8 & 9 & 6 & 4 & 6 \\
\hline Overall IES Score & 3 & 4 & 6 & 7 & 11 & 12 \\
\hline
\end{tabular}




\section{Intercultural Effectiveness Scale Group Scores}

\section{Fulbright Group B - Summer 2010}

\begin{tabular}{|c|c|c|c|c|c|c|}
\hline & \multicolumn{6}{|c|}{ Demonstrated Level of Effectiveness } \\
\hline & \multicolumn{2}{|c|}{ Low } & \multicolumn{2}{|c|}{ Moderate } & \multicolumn{2}{|c|}{ High } \\
\hline & 1 & 2 & 3 & 4 & 5 & 6 \\
\hline Continuous Learning & 7 & 7 & 5 & 3 & 8 & 6 \\
\hline Self-Awareness & 10 & 3 & 9 & 5 & 4 & 5 \\
\hline Exploration & 7 & 7 & 5 & 4 & 6 & 7 \\
\hline Interpersonal Engagement & 2 & 5 & 6 & 15 & 7 & 1 \\
\hline Global Mindset & 6 & 5 & 6 & 8 & 10 & 1 \\
\hline Relationship Interest & 2 & 5 & & 5 & 17 & 7 \\
\hline Hardiness & 2 & 4 & 8 & 11 & 5 & 6 \\
\hline Positive Regard & 3 & 3 & 5 & 6 & 11 & 8 \\
\hline Emotional Resilience & 8 & 5 & 9 & 4 & 4 & 6 \\
\hline Overall IES Score & 1 & 8 & 3 & 3 & 15 & 6 \\
\hline
\end{tabular}




\section{Appendix D}

Leadership: Achieving Styles Inventory Results, 2 pages (including this one).

Fulbright Cohort A - ASI Composite
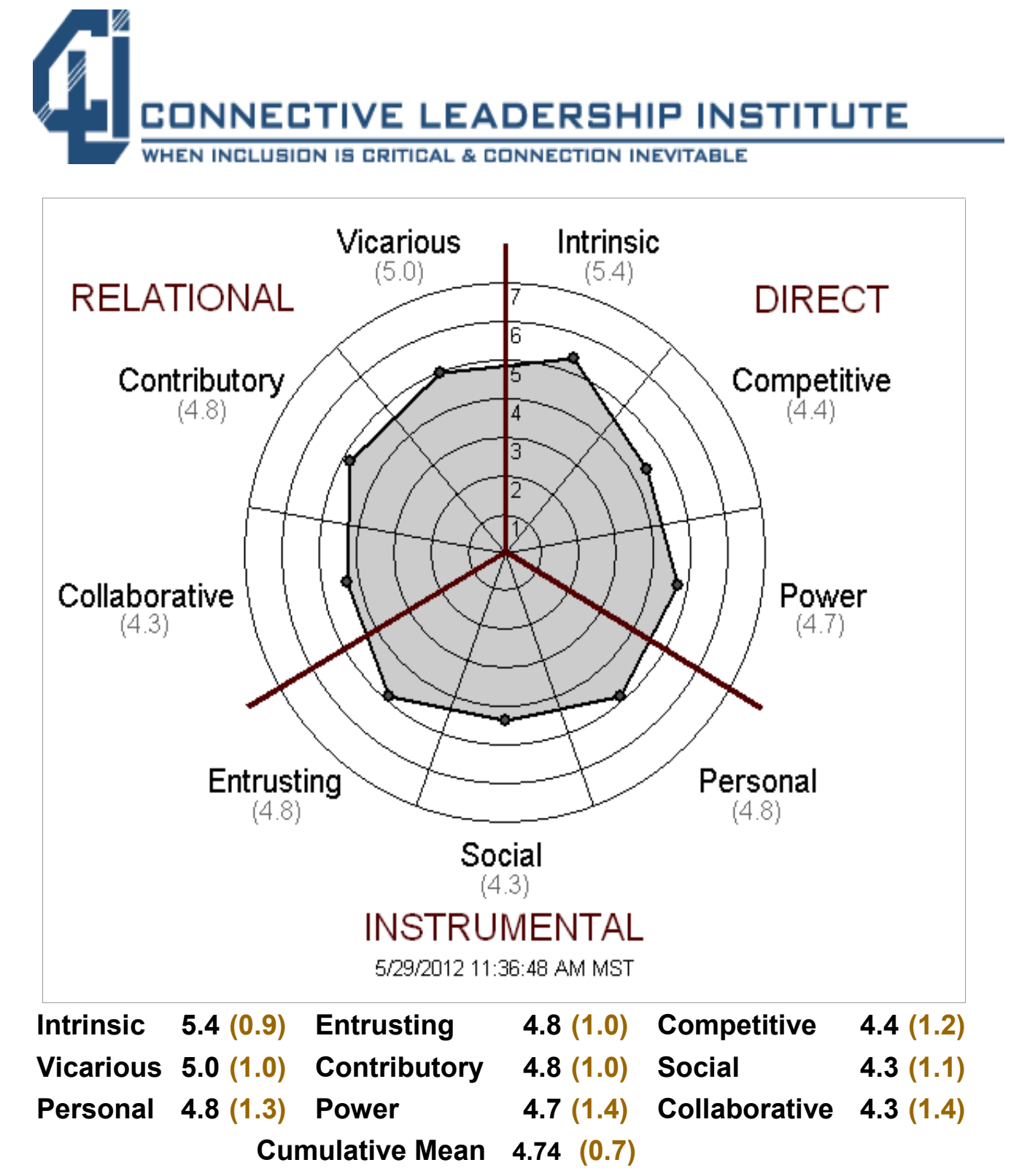


\section{Fulbright Cohort B - ASI Composite}
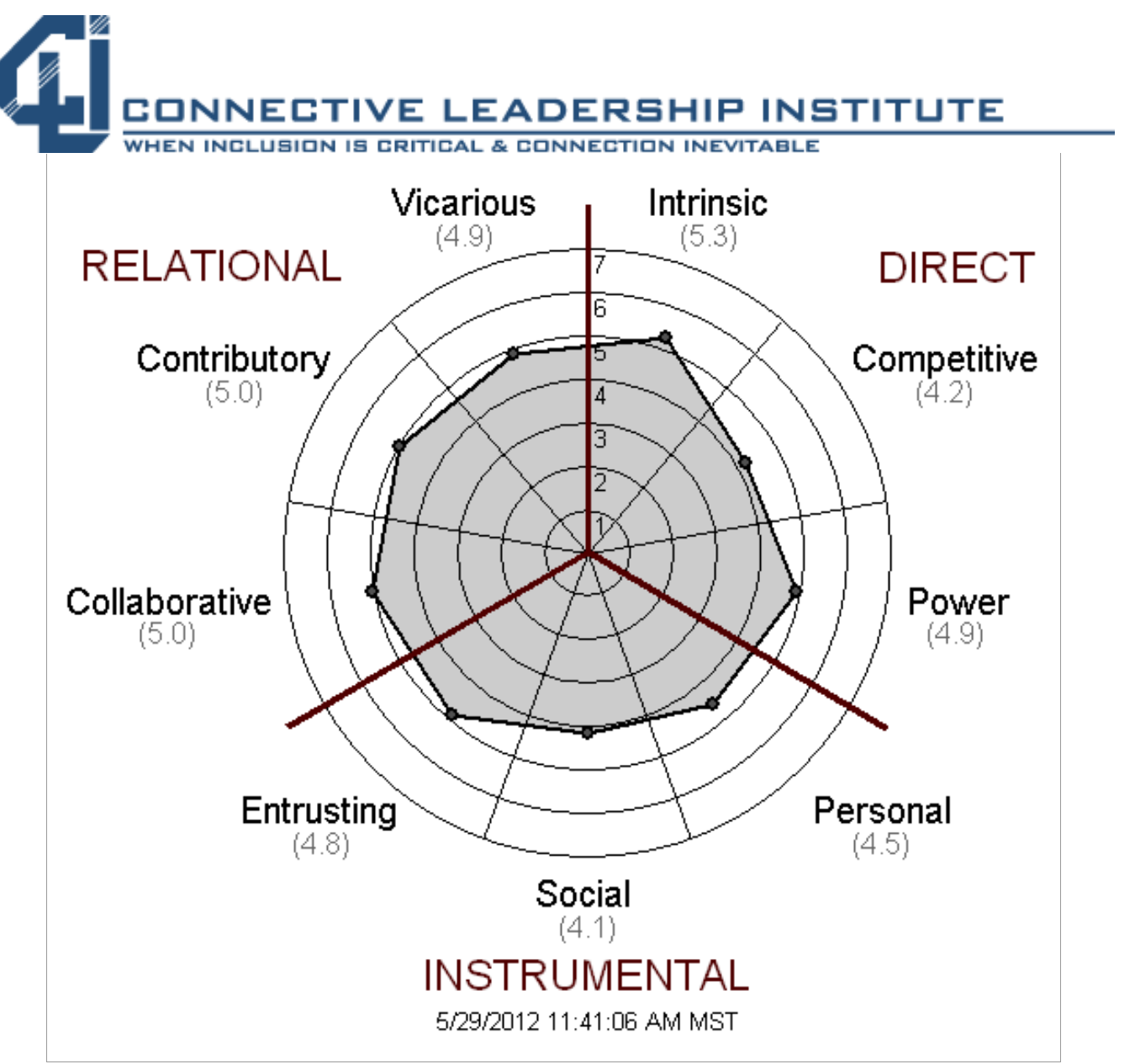
Intrinsic
$5.3(0.9) \quad$ Power
4.9 (1.2) Personal
$4.5(1.4)$
Collaborative
$5.0(1.3) \quad$ Vicarious
$4.9(1.1)$
Competitive
$4.2(1.1)$
Contributory
$5.0(1.2) \quad$ Entrusting
$4.8(1.0) \quad$ Social
$4.1(1.3)$

Cumulative Mean $4.75(0.8)$ 


\section{Appendix E}

Pearson's Rho $\rho$ Results, 4 pages

Key to abbreviations in statistical tables in Appendices $E$ and $F$

\begin{tabular}{|l|l|}
\hline Abbreviations & Full Titles \\
\hline ASI Terms & \\
\hline INT & Intrinsic \\
\hline COMP & Competitive \\
\hline PWR & Power \\
\hline PER & Personal \\
\hline SOC & Social \\
\hline ENT & Entrusting \\
\hline COLL & Collaborative \\
\hline CONT & Contributory \\
\hline VIC & Vicarious \\
\hline DIR & DIRECT \\
\hline INSTR & INSTRUMENTAL \\
\hline REL & RELATIONAL \\
\hline TOTAL & TOTAL \\
\hline IES Terms & \\
\hline saware & Self Aware \\
\hline explorat & Exploration \\
\hline globmind & Global Mindset \\
\hline relation & Relationship Interest \\
\hline posregrd & Positive Regard \\
\hline resilien & Resilient \\
\hline contlrng & Continuous learning \\
\hline interpng & Interpersonal Engagement \\
\hline hardines & Hardiness \\
\hline totlies & Total IES \\
\hline Demographic Terms & \\
\hline SEX & \\
\hline Masters & \\
\hline PHD & \\
\hline
\end{tabular}


Pearson's Rho $\rho$ Correlation

\begin{tabular}{|c|c|c|c|c|c|c|c|c|c|}
\hline & INT & COMP & PWR & PER & soc & ENT & COLL & CONT & VIC \\
\hline INT & 1 & .527 & .606 & .407 & .318 & .029 & .259 & .364 & .240 \\
\hline COMP & .527 & 1 & 645 & .480 & .405 & 132 & .055 & .209 & .268 \\
\hline PWR & .606 & 645 & 1 & 452 & .392 & .275 & .368 & .456 & .373 \\
\hline PER & .407 & 480 & .452 & 1 & .602 & 137 & 130 & 187 & .269 \\
\hline SOC & .318 & .405 & .392 & .602 & 1 & .048 & 145 & .207 & .283 \\
\hline ENT & .029 & .132 & .275 & .137 & .048 & 1 & .444 & .344 & .374 \\
\hline COLL & .259 & .055 & .368 & 130 & 145 & .444 & 1 & 614 & .500 \\
\hline CONT & .364 & .209 & .456 & .187 & .207 & .344 & .614 & 1 & .625 \\
\hline VIC & .240 & .268 & .373 & .269 & .283 & .374 & .500 & .625 & 1 \\
\hline DIR & .795 & .858 & .902 & .524 & .439 & .188 & .270 & .404 & .352 \\
\hline INST & .373 & .490 & .523 & .855 & .802 & .471 & .303 & .324 & .414 \\
\hline REL & .338 & .196 & .468 & .223 & .242 & .462 & .861 & .870 & .810 \\
\hline TOTAL & .629 & .637 & .788 & .652 & .604 & .475 & .618 & .689 & .672 \\
\hline saware & .217 & .187 & .315 & .215 & .306 & .064 & .167 & .261 & .250 \\
\hline explorat & .349 & .196 & .402 & .184 & .183 & .154 & .293 & .334 & .181 \\
\hline globmind & .038 & .169 & .172 & -.056 & .046 & .102 & -.004 & .095 & .029 \\
\hline relation & .174 & .150 & .394 & -.021 & .019 & .223 & .245 & .248 & .159 \\
\hline posregrd & .065 & -.167 & .040 & -.113 & -.270 & .215 & .266 & .270 & .100 \\
\hline resilien & .013 & .015 & .053 & .072 & .177 & .161 & .139 & -.034 & -.172 \\
\hline contlrng & .326 & .224 & .417 & .235 & .292 & .124 & .265 & .346 & .256 \\
\hline interpng & .108 & .197 & .311 & -.052 & .044 & .024 & .109 & .186 & .095 \\
\hline hardines & .049 & -.090 & .063 & -.016 & -.035 & .014 & 261 & 139 & -.063 \\
\hline totlies & .179 & .166 & 389 & .063 & .133 & .074 & .303 & .323 & .134 \\
\hline SEX & .127 & -.113 & .122 & -.056 & -.100 & .156 & .082 & .003 & .135 \\
\hline Masters & .019 & .108 & 179 & -.077 & -.018 & .197 & .171 & 218 & .103 \\
\hline PHD & .057 & -.045 & -.047 & .032 & .111 & .167 & -.086 & -.009 & -.086 \\
\hline
\end{tabular}

\begin{tabular}{|l|l|l|l|}
\hline cutoffs: & 0.2 & 0.25 & 0.3 \\
\hline
\end{tabular} 


\section{Pearsos's Rho $\rho$ Correlation}

\begin{tabular}{|l|l|l|l|l|}
\hline & DIR & INST & REL & TOTAL \\
\hline INT & .795 & .373 & .338 & .629 \\
COMP & .858 & .490 & .196 & .637 \\
PWR & .902 & .523 & .468 & .788 \\
PER & .524 & .855 & .223 & .652 \\
SOC & .439 & .802 & .242 & .604 \\
ENT & .188 & .471 & .462 & .475 \\
COLL & .270 & .303 & .861 & .618 \\
CONT & .404 & .324 & .870 & .689 \\
VIC & .352 & .414 & .810 & .672 \\
\hline DIR & 1 & .550 & .396 & .809 \\
INST & .550 & 1 & .404 & .803 \\
REL & .396 & .404 & 1 & .773 \\
\hline TOTAL & .809 & .803 & .773 & 1 \\
\hline saware & .286 & .280 & .261 & .351 \\
explorat & .369 & .240 & .322 & .391 \\
globmind & .158 & -.045 & .044 & .070 \\
relation & .294 & .081 & .260 & .272 \\
posregrd & -.069 & -.105 & .257 & .046 \\
resilien & .026 & .061 & -.009 & .030 \\
\hline contlrng & .381 & .306 & .339 & .433 \\
interpng & .254 & .003 & .152 & .177 \\
hardines & -.022 & -.020 & .149 & .050 \\
totlies & .299 & .123 & .305 & .312 \\
\hline SEX & -.029 & -.017 & .086 & .023 \\
Masters & .119 & .026 & .195 & .147 \\
PHD & -.022 & .006 & -.073 & -.041 \\
\hline
\end{tabular}

\begin{tabular}{|l|l|l|l|}
\hline cutoffs: & 0.2 & 0.3 & 0.4 \\
\hline
\end{tabular}




\section{Correlations}

Pearson's Rho $\rho$ Sig. (2-tailed)

\begin{tabular}{|l|l|l|l|l|l|l|l|l|l|}
\hline & INT & COMP & PWR & PER & SOC & ENT & COLL & CONT & VIC \\
\hline INT & & .000 & .000 & .000 & .002 & .781 & .012 & .000 & .020 \\
COMP & .000 & & .000 & .000 & .000 & .206 & .599 & .045 & .009 \\
PWR & .000 & .000 & & .000 & .000 & .008 & .000 & .000 & .000 \\
PER & .000 & .000 & .000 & & .000 & .192 & .214 & .073 & .009 \\
SOC & .002 & .000 & .000 & .000 & & .649 & .166 & .047 & .006 \\
ENT & .781 & .206 & .008 & .192 & .649 & & .000 & .001 & .000 \\
COLL & .012 & .599 & .000 & .214 & .166 & .000 & & .000 & .000 \\
CONT & .000 & .045 & .000 & .073 & .047 & .001 & .000 & & .000 \\
VIC & .020 & .009 & .000 & .009 & .006 & .000 & .000 & .000 & \\
\hline TOTAL & .000 & .000 & .000 & .000 & .000 & .000 & .000 & .000 & .000 \\
DIR & .000 & .000 & .000 & .000 & .000 & .072 & .009 & .000 & .001 \\
INSTR & .000 & .000 & .000 & .000 & .000 & .000 & .003 & .002 & .000 \\
\hline REL & .001 & .059 & .000 & .032 & .019 & .000 & .000 & .000 & .000 \\
\hline saware & .038 & .074 & .002 & .040 & .003 & .542 & .111 & .012 & .016 \\
explorat & .001 & .062 & .000 & .079 & .081 & .143 & .005 & .001 & .084 \\
globmind & .723 & .108 & .101 & .599 & .661 & .332 & .972 & .367 & .783 \\
relation & .097 & .152 & .000 & .843 & .861 & .033 & .019 & .017 & .130 \\
posregrd & .537 & .112 & .706 & .285 & .009 & .040 & .010 & .009 & .342 \\
resilien & .904 & .888 & .613 & .494 & .091 & .124 & .186 & .750 & .102 \\
contlrng & .002 & .032 & .000 & .024 & .005 & .238 & .011 & .001 & .014 \\
interpng & .306 & .060 & .003 & .623 & .679 & .822 & .301 & .076 & .369 \\
hardines & .645 & .392 & .553 & .878 & .737 & .898 & .012 & .185 & .550 \\
totlies & .088 & .113 & .000 & .552 & .206 & .486 & .003 & .002 & .203 \\
\hline SEX & .226 & .280 & .246 & .594 & .342 & .136 & .432 & .976 & .197 \\
Masters & .854 & .302 & .085 & .463 & .861 & .059 & .102 & .036 & .326 \\
PHD & .584 & .666 & .651 & .759 & .288 & .110 & .411 & .929 & .411 \\
\hline & & & & & & & & & \\
& & & & & & & & & \\
\hline
\end{tabular}

\begin{tabular}{|l|l|l|l|}
\hline cutoffs: & 0.05 & 0.01 & 0.001 \\
\hline
\end{tabular}


Pearson's Rho $\rho$ Sig. (2-tailed)

\begin{tabular}{|l|l|l|l|l|}
\hline & TOTAL & DIR & INST & REL \\
\hline INT & .000 & .000 & .000 & .001 \\
COMP & .000 & .000 & .000 & .059 \\
PWR & .000 & .000 & .000 & .000 \\
PER & .000 & .000 & .000 & .032 \\
SOC & .000 & .000 & .000 & .019 \\
ENT & .000 & .072 & .000 & .000 \\
COLL & .000 & .009 & .003 & .000 \\
CONT & .000 & .000 & .002 & .000 \\
VIC & .000 & .001 & .000 & .000 \\
\hline TOTAL & & .000 & .000 & .000 \\
DIR & .000 & & .000 & .000 \\
INST & .000 & .000 & & .000 \\
\hline REL & .000 & .000 & .000 & \\
\hline saware & .001 & .006 & .007 & .012 \\
explorat & .000 & .000 & .021 & .002 \\
globmind & .508 & .133 & .668 & .679 \\
relation & .009 & .004 & .440 & .012 \\
posregrd & .662 & .516 & .317 & .013 \\
resilien & .774 & .803 & .566 & .932 \\
contlrng & .000 & .000 & .003 & .001 \\
interpng & .091 & .014 & .980 & .148 \\
hardines & .637 & .831 & .849 & .156 \\
totlies & .002 & .004 & .243 & .003 \\
\hline SEX & .823 & .784 & .870 & .411 \\
Masters & .158 & .255 & .808 & .061 \\
PHD & .694 & .833 & .952 & .485 \\
\hline
\end{tabular}

\begin{tabular}{|l|l|l|l|}
\hline cutoffs: & 0.2 & 0.3 & 0.4 \\
\hline
\end{tabular}




\section{Appendix F}

Kendall's Tau $\tau, 4$ pages

(See Key to Abbreviations on page 188)

Kendall's tau $\tau$ Correlations

\begin{tabular}{|l|l|l|l|l|l|l|l|l|l|}
\hline & INT & COMP & PWR & PER & SOC & ENT & COLL & CON & VIC \\
\hline INT & 1 & .403 & .478 & .285 & .220 & .069 & .169 & .256 & .183 \\
COMP & .403 & 1 & .465 & .371 & .288 & .086 & .043 & .127 & .168 \\
PWR & .478 & .465 & 1 & .342 & .280 & .169 & .222 & .313 & .269 \\
PER & .285 & .371 & .342 & 1 & .433 & .097 & .035 & .096 & .181 \\
SOC & .220 & .288 & .280 & .433 & 1 & -.002 & .052 & .095 & .205 \\
ENT & .069 & .086 & .169 & .097 & -.002 & 1 & .306 & .200 & .232 \\
COLL & .169 & .043 & .222 & .035 & .052 & .306 & 1 & .408 & .325 \\
CONT & .256 & .127 & .313 & .096 & .095 & .200 & .408 & 1 & .383 \\
VIC & .183 & .168 & .269 & .181 & .205 & .232 & .325 & .383 & 1 \\
\hline DIR & .638 & .678 & .739 & .375 & .314 & .125 & .165 & .264 & .249 \\
INST & .288 & .383 & .372 & .681 & .606 & .316 & .151 & .160 & .279 \\
REL & .245 & .117 & .314 & .110 & .133 & .285 & .667 & .662 & .591 \\
\hline TOTAL & .488 & .488 & .629 & .459 & .431 & .293 & .399 & .439 & .457 \\
\hline saware & .143 & .128 & .212 & .121 & .174 & .035 & .091 & .146 & .186 \\
explorat & .261 & .174 & .317 & .109 & .107 & .119 & .227 & .273 & .141 \\
globmind & .010 & .137 & .058 & .004 & .001 & -.110 & .022 & .080 & .032 \\
relation & .137 & .062 & .189 & -.010 & .016 & .076 & .077 & .044 & .060 \\
posregrd & -.054 & -.100 & .017 & -.101 & -.160 & .197 & .156 & .221 & .047 \\
resilien & -.027 & .007 & .023 & -.042 & .064 & -.120 & .109 & -.034 & -.115 \\
contlrng & .235 & .177 & .306 & .136 & .169 & .096 & .176 & .234 & .192 \\
interpng & .057 & .132 & .141 & -.002 & .005 & -.040 & .058 & .097 & .048 \\
hardines & -.037 & -.040 & .018 & -.075 & -.044 & -.015 & .168 & .119 & -.088 \\
totlies & .125 & .098 & .246 & .031 & .060 & .035 & .199 & .233 & .098 \\
\hline SEX & -.093 & -.099 & .092 & -.029 & -.083 & .114 & .091 & -.006 & .114 \\
Masters & .000 & .086 & .134 & -.052 & -.013 & .145 & .120 & .165 & .062 \\
PHD & .030 & -.049 & -.061 & .026 & .090 & -.150 & -.060 & -.013 & -.063 \\
\hline & & & & & & & & & \\
\hline
\end{tabular}

\begin{tabular}{|l|l|l|l|}
\hline cutoffs: & 0.2 & 0.3 & 0.4 \\
\hline
\end{tabular} 
Kendall's tau $\tau$ Correlations

\begin{tabular}{|l|l|l|l|l|}
\hline & DIR & INST & REL & TOTAL \\
\hline INT & .638 & .288 & .245 & .488 \\
COMP & .678 & .383 & .117 & .488 \\
PWR & .739 & .372 & .314 & .629 \\
PER & .375 & .681 & .110 & .459 \\
SOC & .314 & .606 & .133 & .431 \\
ENT & .125 & .316 & .285 & .293 \\
COLL & .165 & .151 & .667 & .399 \\
CON & .264 & .160 & .662 & .439 \\
VIC & .249 & .279 & .591 & .457 \\
\hline DIR & 1 & .412 & .260 & .648 \\
INST & .412 & 1 & .227 & .601 \\
REL & .260 & .227 & 1 & .531 \\
\hline TOTAL & .648 & .601 & .531 & 1 \\
\hline saware & .181 & .159 & .140 & .220 \\
explorat & .271 & .170 & .241 & .317 \\
globmind & .104 & -.044 & .045 & .054 \\
relation & .170 & .044 & .045 & .133 \\
posregrd & -.047 & -.069 & .179 & .010 \\
resilien & -.002 & -.010 & -.010 & .007 \\
contlrng & .267 & .197 & .215 & .321 \\
interpng & .160 & -.019 & .063 & .097 \\
hardines & -.026 & -.051 & .095 & .018 \\
totlies & .175 & .056 & .203 & .213 \\
\hline SEX & -.011 & -.018 & .081 & .022 \\
Masters & .099 & .007 & .117 & .090 \\
PHD & -.035 & .010 & -.041 & -.023 \\
\hline & & & & \\
\hline
\end{tabular}

\begin{tabular}{|l|l|l|l|}
\hline cutoffs: & 0.2 & 0.3 & 0.4 \\
\hline
\end{tabular}


Kendall's tau $\tau$ Sig. (2-tailed) Correlations

\begin{tabular}{|l|l|l|l|l|l|l|l|l|l|}
\hline & INT & COMP & PWR & PER & SOC & ENT & COLL & CONT & VIC \\
\hline INT &. & .000 & .000 & .000 & .003 & .357 & .022 & .001 & .014 \\
COMP & .000 &. & .000 & .000 & .000 & .247 & .555 & .087 & .023 \\
PWR & .000 & .000 &. & .000 & .000 & .022 & .002 & .000 & .000 \\
PER & .000 & .000 & .000 &. & .000 & .186 & .634 & .194 & .014 \\
SOC & .003 & .000 & .000 & .000 &. & .973 & .480 & .198 & .006 \\
ENT & .357 & .247 & .022 & .186 & .973 &. & .000 & .007 & .002 \\
COLL & .022 & .555 & .002 & .634 & .480 & .000 &. & .000 & .000 \\
CONT & .001 & .087 & .000 & .194 & .198 & .007 & .000 &. & .000 \\
VIC & .014 & .023 & .000 & .014 & .006 & .002 & .000 & .000 &. \\
\hline TOTAL & .000 & .000 & .000 & .000 & .000 & .000 & .000 & .000 & .000 \\
DIR & .000 & .000 & .000 & .000 & .000 & .087 & .023 & .000 & .001 \\
INST & .000 & .000 & .000 & .000 & .000 & .000 & .038 & .028 & .000 \\
\hline REL & .001 & .108 & .000 & .127 & .066 & .000 & .000 & .000 & .000 \\
\hline saware & .057 & .086 & .004 & .103 & .020 & .639 & .222 & .051 & .013 \\
explorat & .001 & .021 & .000 & .143 & .153 & .114 & .002 & .000 & .062 \\
globmind & .895 & .064 & .430 & .957 & .995 & .138 & .771 & .283 & .672 \\
relation & .073 & .411 & .012 & .897 & .835 & .316 & .305 & .558 & .429 \\
posregrd & .474 & .178 & .823 & .172 & .031 & .008 & .036 & .003 & .528 \\
resilien & .719 & .930 & .758 & .569 & .389 & .107 & .140 & .652 & .122 \\
contlrng & .001 & .015 & .000 & .059 & .019 & .187 & .015 & .001 & .008 \\
interpng & .434 & .069 & .052 & .978 & .949 & .579 & .425 & .182 & .507 \\
hardines & .616 & .586 & .808 & .302 & .547 & .834 & .022 & .105 & .232 \\
totlies & .087 & .178 & .001 & .668 & .406 & .629 & .006 & .001 & .179 \\
\hline SEX & .292 & .261 & .292 & .737 & .339 & .195 & .298 & .944 & .196 \\
Masters & .997 & .329 & .125 & .551 & .883 & .098 & .169 & .061 & .482 \\
PHD & .731 & .580 & .483 & .765 & .300 & .087 & .495 & .881 & .473 \\
\hline
\end{tabular}

\begin{tabular}{|l|l|l|l|}
\hline cutoffs: & 0.05 & 0.01 & 0.001 \\
\hline
\end{tabular} 
Kendall's tau $\tau$ Sig. (2-tailed) Correlations

\begin{tabular}{|l|l|l|l|l|}
\hline & TOTAL & DIR & INST & REL \\
\hline INT & .000 & .000 & .000 & .001 \\
COMP & .000 & .000 & .000 & .108 \\
PWR & .000 & .000 & .000 & .000 \\
PER & .000 & .000 & .000 & .127 \\
SOC & .000 & .000 & .000 & .066 \\
ENT & .000 & .087 & .000 & .000 \\
COLL & .000 & .023 & .038 & .000 \\
CONT & .000 & .000 & .028 & .000 \\
VIC & .000 & .001 & .000 & .000 \\
\hline TOTAL &. & .000 & .000 & .000 \\
DIR & .000 &. & .000 & .000 \\
INSTR & .000 & .000 &. & .002 \\
\hline REL & .000 & .000 & .002 &. \\
\hline saware & .003 & .014 & .031 & .057 \\
explorat & .000 & .000 & .022 & .001 \\
globmind & .464 & .155 & .545 & .543 \\
relation & .078 & .023 & .556 & .542 \\
posregrd & .889 & .518 & .345 & .015 \\
resilien & .922 & .978 & .887 & .887 \\
contlrng & .000 & .000 & .006 & .003 \\
interpng & .179 & .026 & .795 & .380 \\
hardines & .802 & .718 & .486 & .191 \\
totlies & .003 & .014 & .437 & .004 \\
\hline SEX & .803 & .901 & .839 & .350 \\
Masters & .302 & .254 & .935 & .177 \\
PHD & .796 & .683 & .909 & .633 \\
\hline & & & & \\
\hline
\end{tabular}

\begin{tabular}{|l|l|l|l|}
\hline cutoffs: & 0.2 & 0.3 & 0.4 \\
\hline
\end{tabular}

